\title{
Competency-based portfolio assessment
}

Citation for published version (APA):

Oudkerk Pool, A. (2020). Competency-based portfolio assessment: unraveling stakeholder perspectives and assessment practices. [Doctoral Thesis, Maastricht University]. Ipskamp Printing BV. https://doi.org/10.26481/dis.20201106ao

Document status and date:

Published: 01/01/2020

DOI:

10.26481/dis.20201106ao

Document Version:

Publisher's PDF, also known as Version of record

\section{Please check the document version of this publication:}

- A submitted manuscript is the version of the article upon submission and before peer-review. There can be important differences between the submitted version and the official published version of record.

People interested in the research are advised to contact the author for the final version of the publication, or visit the DOI to the publisher's website.

- The final author version and the galley proof are versions of the publication after peer review.

- The final published version features the final layout of the paper including the volume, issue and page numbers.

Link to publication

\footnotetext{
General rights rights.

- You may freely distribute the URL identifying the publication in the public portal. please follow below link for the End User Agreement:

www.umlib.nl/taverne-license

Take down policy

If you believe that this document breaches copyright please contact us at:

repository@maastrichtuniversity.nl

providing details and we will investigate your claim.
}

Copyright and moral rights for the publications made accessible in the public portal are retained by the authors and/or other copyright owners and it is a condition of accessing publications that users recognise and abide by the legal requirements associated with these

- Users may download and print one copy of any publication from the public portal for the purpose of private study or research.

- You may not further distribute the material or use it for any profit-making activity or commercial gain

If the publication is distributed under the terms of Article $25 \mathrm{fa}$ of the Dutch Copyright Act, indicated by the "Taverne" license above, 
Competency-based portfolio assessment

Unraveling stakeholder perspectives and assessment practices 
The research reported here was carried out at

\section{Maastricht University}

\section{Maastricht UMC+}

in the School of Health Professions Education

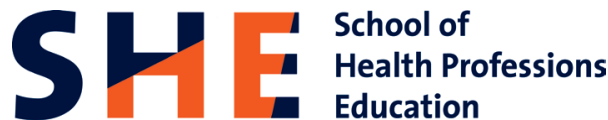

(C) Andrea Oudkerk Pool, 2020, Maastricht

ISBN: 978-94-028-1929-8

Layout: Ipskamp Pinting

Cover: Julia Krewinkel

Printed by: Ipskamp Printing

Printed with financial support from Maastricht University. 


\section{Competency-based portfolio}

\section{assessment}

UNRAVELING STAKEHOLDER PERSPECTIVES

AND ASSESSMENT PRACTICES

\section{PROEFSCHRIFT}

ter verkrijging van de graad van doctor

aan de Universiteit Maastricht,

op gezag van de Rector Magnificus,

Prof.dr. Rianne M. Letschert

volgens het besluit van het College

van Decanen, in het openbaar

te verdedigen op vrijdag 6 november

om 12.00 uur

door

Andrea Oudkerk Pool 


\section{TABLE OF CONTENTS}

\section{CHAPTER 01}

General Introduction

\section{CHAPTER 02}

Student perspectives on Competency-based Portfolios:

Do they reflect competence development in clinical settings?

\section{CHAPTER 03}

How Students Gain Confidence in their capabilities

and competence development During Clerkships:

An Audio Diary Study

\section{CHAPTER 04}

From aggregation to interpretation: How assessors judge complex data in a competency-based portfolio

CHAPTER 05

Variations in use of portfolio in assessment of trainee competence: The influence of assessor beliefs and implicit goals

CHAPTER 06

General Discussion

SUMMARY

SAMENVATTING

VALORIZATION

ABOUT THE AUTHOR

DANKWOORD 


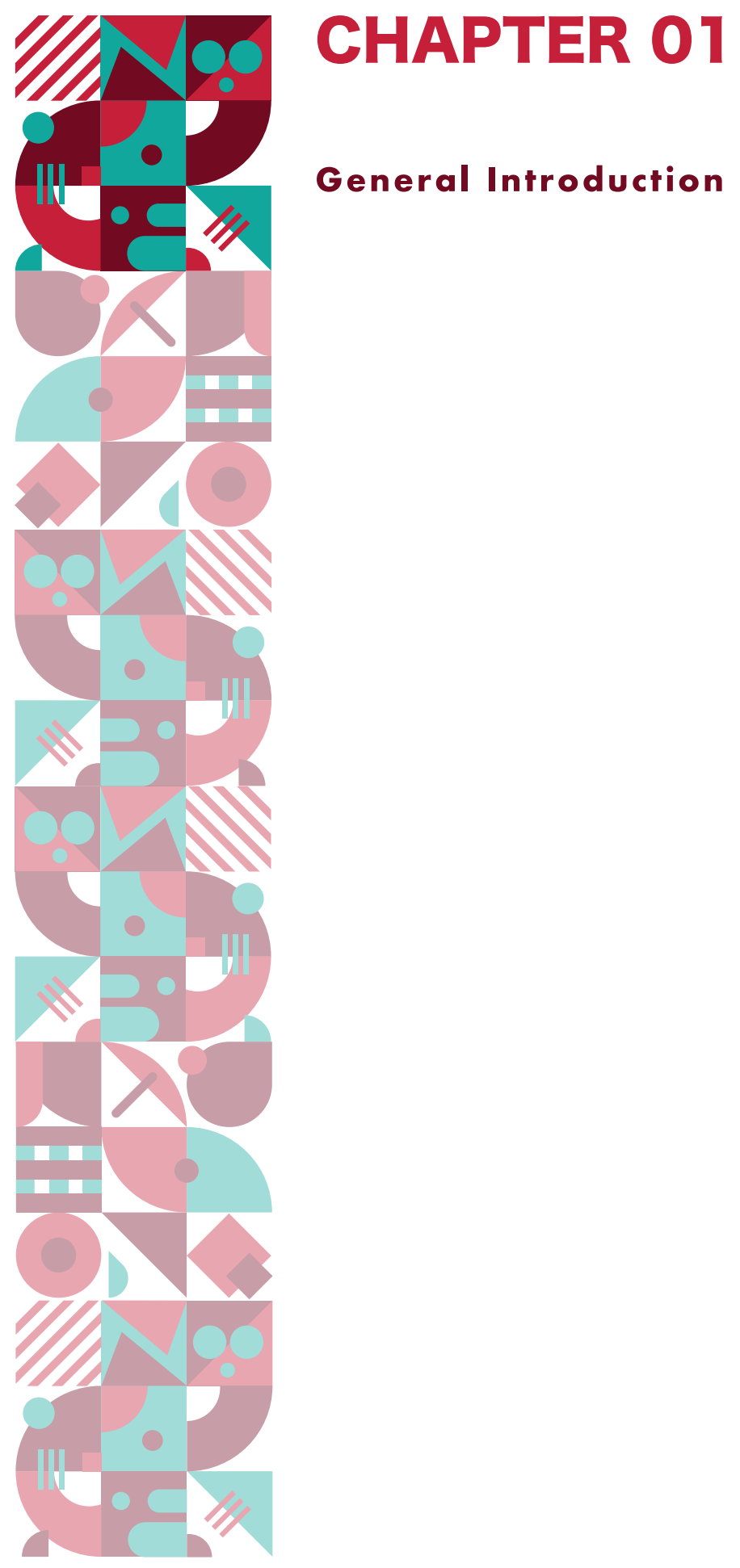


In competency-based medical education, portfolios are increasingly used as an instrument to assess students' competence and to make high-stakes pass-fail decisions. A portfolio contains performance data that provide evidence of a student's competence and competence development. Multiple assumptions concerning portfolio construction and the portfolio assessment process underlie the use of portfolio as an assessment instrument. For example, the use of portfolios for high-stakes decision-making assumes that evidence uploaded to the portfolio accurately reflects a student's achievement in various competency domains and that the portfolio contains sufficient information to ensure robustness and trustworthiness of high-stakes decisions. Evidence in the portfolio should enable creation of a coherent, accurate and complete story of a student's competency profile. Similarly, one would expect that those who interpret information in the portfolio integrate all relevant information and evidence and that decision-makers agree upon interpretations of, and decisions based on performance data in a student's portfolio. Evidence supporting the use of competency-based portfolios for high-stakes decision-making is developing -but still limited-raising questions about the degree to which portfolio-based decision-making is defensible and robust. When using the lens of assessment validity, there is an obvious need to collect more evidence to support the interpretations and use of portfolio-based performance data for high-stakes decision-making about a student's competence and competence development. A critical evaluation of the assumptions underlying portfolio as an assessment instrument is therefore necessary. The studies in this $\mathrm{PhD}$ focus on a number of assumptions and inferences that are made when using a comprehensive portfolio as the instrument for the assessment of competence. More specifically, we will focus on how various key stakeholders (students, portfolio assessors and daily supervisors) perceive and use the portfolio for purposes of competence assessment and decision-making, and how this is related to the quality of the information in the portfolio and interpretation of the performance data collected in the student portfolio.

This introductory chapter first introduces competency-based medical education (CBME) and describes the role of portfolios within CBME as well as presents key findings from the literature thus far. More specifically, we will elaborate on challenges that students, portfolio assessors, and daily supervisors may face when using the portfolio as an assessment instrument. Finally, this chapter presents our research questions as well as an outline of this thesis.

\section{Competency-based medical education}

Over the past few decades, the focus of assessment has shifted from mainly concentrating on knowledge and technical skills acquisition as assessment outcomes towards the assessment of professional competence (Frank et al., 2010). In the health sciences education literature different views exist on the meaning of competence. Based on their review of different competence definitions Fernandez and colleagues (2012) developed a comprehensive definition of competence, which stated that competence is to be seen as consisting of knowledge, skills and 
multiple components related to personal abilities and attributes that enable a professional to combine or select those components that will cause maintenance of performance standards.

As a result of the shift towards competency-based education and assessment, a number of national and international competency frameworks have been developed which aim to specify educational outcomes in terms of competencies or roles that are required of doctors (e.g. Canadian Medical Education Directives for Specialists (CanMEDS) (Frank \& Danoff, 2007), the Dundee Outcomes model (Harden, 1999) and the Accreditation Council for Graduate Medical Education (ACGME) (Swing, 2007). These competency frameworks not only provide guidance for the development and organization of curricula in medical education, but also for assessment design.

CBME requires a multifaceted assessment approach, serving dual purposes of assessment for and of learning (Lockeyer et al., 2017). In CBME, assessments should preferably take place in the authentic clinical setting, supporting the development of all relevant competencies. Ideally, it combines robust assessment of learning with high quality assessment for learning in which sturdy and rich feedback for developmental purposes is provided. The assessment tools and instruments used in CBME need to support both of these functions.

Competency-based assessment implies that traditional assessment tools with an exclusive focus on knowledge testing, or off-site testing of technical procedures, are no longer sufficient. Multiple workplace-based assessment (WBA) tools were developed in an attempt to assess the integration of knowledge, clinical skills and other relevant individual attributes or abilities in performance of professional tasks, e.g. the mini-Clinical Evaluation Exercise (Mini-CEX), Multi-source feedback (MSF), Objective Structured assessment of technical skills (OSATS) or Direct Observation of Procedural Skills (DOPS). In order to develop judgements about a student's development in various competency domains (or roles), assessment data have to be combined and aggregated in meaningful ways (van der Vleuten et al., 2012). The competencybased portfolio has been introduced as an instrument that can be used to manage and aggregate assessment data in ways that are meaningful for learning and development as well as for decision-making.

\section{Competence assessment: the competency-based portfolio and its key stakeholders}

Within CBME, a portfolio can be no longer seen as a log or 'dossier' in which students present an overview of completed learning tasks. Competency-based portfolios typically contain reports not only on work done, but also documented feedback received from peers and faculty, reflective writings on feedback and progress made, and goals and plans on how to further improve competence (Swing, 2007). Although many variations between portfolios exist, we can distinguish two main types, i.e. the reflective and the comprehensive portfolio (Driessen, 2017). The main goal of a reflective portfolio is to support students' reflection and therefore reflective 
writings and assessments are the most important part of the portfolio. Comprehensive portfolios are integrated into an assessment program and are much more diverse in content compared to reflective portfolios. The goal of comprehensive portfolios is twofold: to support the student's learning process and to assess the student's progress (Driessen, 2017). The competency-based portfolios addressed within this thesis can be considered comprehensive because they are part of the assessment program implemented in the Master in Medicine curriculum at Maastricht University (van der Vleuten et al., 2012), and they are being used to both assess and support students' learning process.

In medical education, comprehensive portfolios serve as a tool to assist students' self-directed learning (SDL) and great emphasis is placed on student initiative and responsibility regarding the assessment process. In workplace settings, for example, students are encouraged to ask feedback from teachers, patients and peers and to document feedback in their portfolio using WBA tools. Students are expected to organize their portfolio in such a way that it helps them to better understand (i.e. assess and make decisions about) their own development and subsequently plan their learning (van Tartwijk \& Driessen, 2009), as well as to present meaningful evidence about their competence development to decision-makers. Consequently, students are tasked to make decisions about which performance data they want to include in their portfolio. The way students engage in portfolio-based assessment processes may thus influence the usefulness of portfolio evidence for high-stakes decision-making.

In clinical workplace settings, students are often supported in their learning and competence development by daily supervisors who regularly evaluate and provide feedback on their level of performance, for example in formal feedback sessions. When evaluating students' competence development, supervisors can use multiple sources for their assessment such as personal experience with the student, verbal (formal or informal) feedback from colleagues and written feedback and performance evidence uploaded to the student's portfolio (Holmboe, 2015). Research findings show that an exclusive reliance on personal experiences or informal feedback (e.g. corridor chat) may result in biased and thus unfair or incredible assessment outcomes (Cleland, Knight, Rees, Tracey, \& Bond, 2008). As with students, daily supervisors' use of evidence in the portfolio, and the way they interpret performance data may thus affect assessment of a student's competence development and achievement.

With the rise of CBME, and related programmatic assessment approaches in particular, highstakes pass-fail progress decisions are increasingly made by independent assessors, for example members of clinical competency committees (CCCs) (Bok et al., 2013; Driessen, Van Tartwijk, Govaerts, Teunissen, \& van der Vleuten, 2012). Typically, these examiners do not know the students and their assessments are therefore based on the evidence collected in the student's portfolio only (van der Vleuten et al., 2012). Key questions then arise with respect to richness and meaningfulness of performance data, allowing for robust decision-making, as well as independent assessors' approaches to interpretation of evidence in the portfolio. 
As can be inferred from the use of portfolios in competency-based assessment programs (as described above), use of portfolios for high-stakes decision-making assumes:

- First, that students fill their portfolio with evidence that is of high relevance and quality, accurately reflecting their learning trajectory and progress in competency development.

- Second, that portfolio evidence provides students with meaningful and relevant information to make decisions about their own competence development, to gain confidence in their own capabilities and develop control over their own learning and competence development.

- Third, that independent portfolio assessors (decision-makers) are able to reliably assess students' competence development, to distinguish and evaluate the different competencies, and make fair and defensible decisions.

- And fourth, that the portfolio supports and reflects performance evaluations from daily supervisors (i.e. assessors who have been working with the student) and independent portfolio assessors in similar ways.

\section{Potential challenges for portfolio assessment}

\section{THE STUDENT PERSPECTIVE}

It is important to explore factors influencing students' perceptions of any assessment process as research findings show that these may determine the usefulness of the assessment process and the degree to which assessment achieves its goals (Bogo, Regehr, Power, \& Regehr, 2007).

Students have an important influence on the execution of the portfolio-based assessment, as they are responsible for collecting and documenting evidence in their portfolio. Research suggests that students may act strategically when asking for feedback. For example, they may be reluctant to ask for feedback after failures or poor task performance, or wait until someone is in a good mood before requesting feedback (Crommelinck \& Anseel, 2013). Also, the literature identifies various reasons for students not to ask for observation of task performance. For example, students may feel nervous and intimidated when observed (Holmboe et al., 2011). Moreover, students could experience tensions between valuing the learning opportunity of direct observation, and core values of efficiency, autonomy and independence in the working culturehampering feedback seeking behaviors (Bok et al., 2013). Also, students may feel that faculty are too busy or think that the presence of faculty affects their relationship with patients (LaDonna, Hatala, Lingard, Voyer, \& Watling, 2017). Asking for feedback takes time away from patient care. It is difficult to implement WBA in the complex and busy clinical workplace and faculty may struggle to schedule student observations (Bok et al., 2013; Holmboe et al., 2011). This means that valuable learning experiences could go unobserved and, as a consequence, meaningful feedback will not be documented in a portfolio. When using portfolio as an assessment instrument, however, it is assumed that students fill their portfolio with evidence that accurately 
reflects their learning trajectory and progress in competency development. Research findings thus suggest that the portfolio content may not always be in accordance with students' actual learning and may present an incomplete picture of a student's competence development.

Clearly, CBME's emphasis on learner initiative and responsibility in assessment processes requires students to be highly motivated to collect and document evidence that provides others (e.g. decision-makers) with an accurate and complete overview of their competence development. Students' feelings of ownership over this assessment process greatly influence their motivation to work on their portfolio. However, research suggests that students do not always experience ownership over their portfolio (Driessen, Van Tartwijk, Van Der Vleuten, \& Wass, 2007), and consequently are not very motivated to work on their portfolio (Arntfield, Parlett, Meston, Apramian, \& Lingard, 2016). This lack of motivation may negatively impact the quality of the evidence collected in the student's portfolio. Literature identifies multiple factors that affect students' feelings of ownership. First, it is critical to consider how the portfolio is assessed. The portfolio regularly serves as an instrument for reflection and assessment (Dannefer \& Henson, 2007). Research findings show that the summative character of the portfolio could cause students to be hesitant to share their weaknesses because they fear that this will be used against them when the portfolio is assessed (Buckley et al., 2009; van Tartwijk \& Driessen, 2009). On the other hand, if portfolios are not summatively assessed, students will spend less time constructing their portfolio and will take the portfolio less seriously because they feel as if they are not rewarded for their efforts (Dannefer \& Henson, 2007). Second, it has been shown that portfolio effectiveness is dependent on balancing provision of clear guidance and predefined structures for how to build the portfolio, and flexibility allowing for different approaches to reflection and description of unique experiences (van Tartwijk \& Driessen, 2009). Although these factors have been identified and educational programs are trying to find ways to manage these tensions, students' experienced lack of ownership is still an important problem for portfolio assessment (Driessen, 2017). It is therefore critical to identify factors that could contribute to a greater feeling of ownership among students, for portfolio content to become more meaningful.

\section{THE PORTFOLIO ASSESSOR PERSPECTIVE}

When using portfolios for high-stakes decision-making, portfolio assessors are assumed to be able to reliably assess a student's competence development and achievement in various competency domains, and to arrive at fair and defensible decisions. Although there has been research into how assessors interpret information generated by single assessment tools (Govaerts, Schuwirth, Van der Vleuten, \& Muijtjens, 2011; Govaerts, Van de Wiel, Schuwirth, Van der Vleuten, \& Muijtjens, 2013), limited research has been done on how assessors interpret complex and aggregated data collected in a student's portfolio and how they arrive at holistic judgments of a student's competence. Previous research suggests that multiple factors may influence assessors' data interpretation and decision-making. For example, multiple studies suggest that assessors' perception of what comprises a competent physician differs from what is currently 
formulated within the various competence frameworks (Duitsman et al., 2019; Ginsburg, Gold, Cavalcanti, Kurabi, \& McDonald-Blumer, 2011; Ginsburg, McIlroy, Oulanova, Eva, \& Regehr, 2010; Renting et al., 2016). Assessors may very well hold their own conceptualizations of professional competence, and use their own (idiosyncratic) standards and criteria in decisionmaking. This may pose a problem for portfolio assessment since in most cases the espoused or imposed predefined competence framework not only provides the structure for the portfolio but also steers and predetermines assessment data that are to be collected by the learner. Assessors/ decision-makers may thus experience difficulties searching for relevant evidence supporting their competence decisions, or select specific performance information in line with their own competence conceptualizations, neglecting other relevant performance data.

Research findings furthermore suggest that the way we present and incorporate competency frameworks in our assessment systems may not be in line with how people arrive at judgments about others. For example, assuming that assessors use the same cognitive processes when assessing students' competence as when making social judgments, it is argued that assessment based on different competencies does not correspond to how assessors form an impression of students' capabilities. Psychology research has demonstrated that when people make social judgments, they are inclined to categorize other people (Macrae \& Bodenhausen, 2000). There are multiple conceptualizations of how this categorization process works. Despite differences between these views, however, there is a general agreement that social judgments are the result of an entirely personal categorization process that happens spontaneously and without awareness. When encountering an unfamiliar person, people assign this new person to one of a few broad categories already present in their long-term memory. Consequently, information about a typical member of this category is applied to this new person. The categorization process causes a reduction of the cognitive resources needed to monitor and evaluate the behavior of the unfamiliar person. Similar research findings have been reported in the domain of medical education. Kolars, McDonald, Subhiyah and Edson (2003), for example, examined the accuracy of faculty evaluations of residents' medical knowledge and asked faculty members to evaluate residents' capacities on other competence areas as well. Not only did they find that the ability of faculty to evaluate residents' medical knowledge was rather limited, they also concluded that faculty ratings of residents' knowledge were highly correlated with their evaluations of residents' capacities in other competence areas. This result is an indication for faculty's inability to reliably distinguish between different competencies. Expecting assessors to deliberately judge students' capabilities on predefined competencies or categories may therefore interfere with human judgment formation. If assessors automatically form categorical judgments of a student, an assessment system requiring the assessors to judge students on predefined competence categories may introduce conversion errors. This potentially poses a problem for competence-based assessment which depends on assessors' ability to evaluate students' development on the individual competencies. 


\section{THE DAILY WORKPLACE SUPERVISOR PERSPECTIVE}

In workplace settings, daily supervisors frequently assess students in order to determine students' level of performance, to guide their learning and to ensure patient safety. They have access to various information sources for their assessment such as personal experience with the student, feedback from colleagues and evidence collected in the student portfolio (Holmboe et al., 2011). Requiring daily supervisors to judge students' competence implies that a portfolio provides them with information that is of interest and sufficient to make informed decisions about a student's competence development.

Supervisors' evaluation of students' clinical performance may incorporate components that are currently not accounted for in competence-based assessment. When asked to assess the level of students' clinical performance, faculty seem to use criteria that differ from the ones specified within the different competence frameworks. For example, Ginsburg et al. (2010) interviewed internal medicine supervisors and asked them to discuss problematic, average and outstanding residents they had supervised. They found that the supervisors' judgments were based on several aspects that took on various degrees of importance depending on the resident. Shortcomings of exceptional residents could be discounted while strong attributes of weaker residents were overlooked. Moreover, some constructs that were of importance in the considerations of the supervisors were not even competencies at all. For example, supervisors attached great importance to how the student affected the supervisor (also called impact on staff). It seems that these constructs served as evidence to support the supervisors' judgment. In subsequent research, supervisors' comments on residents' in-training evaluation reports (ITERs) were analyzed (Ginsburg et al., 2011). Results confirmed findings from previous research that faculty judgments are not solely based on factors related to currently used competency frameworks. Faculty's comments frequently contained elements that Ginsburg et al. (2011) labelled "noncompetencies" (e.g. attitude, personality or trustworthiness). Similar findings were reported by Rosenbluth, O'Brien, Asher and Cho (2014) who interviewed faculty members on what they perceived as specific traits present in outstanding residents. Most interviewees focused on traits like enthusiasm, passion, reliability and maturity. These aspects have overlap with some competencies, but are not specifically stated in the competence frameworks. It can be concluded that there is an ill fit between the content of the competence frameworks that shape the portfolios and the aspects of students' performance that clinical daily supervisors deem important. This discrepancy can be a threat to the quality of the portfolio assessment process because daily supervisors' personal assessment criteria may affect what kind of performance information they are looking for when developing an assessment about the students' competence. Discrepancies between supervisors' assessment criteria and portfolio content can thus hinder the supervisors when developing an assessment based on the information documented in the portfolio. But perhaps as important, supervisors' assessment of a student's competence development may consequently differ from assessments and decisions made by independent assessors (decision-making committees) who have to rely on performance data in the portfolio. 


\section{Research questions}

Based on the research findings as described in previous paragraphs, and questions raised about the assumptions underlying portfolio-based assessment of competence, we formulated the following research questions, in order to provide evidence to support the interpretation and use of portfolio-based performance data for decision-making:

- How well do students think their portfolio reflects their competence development and how do students select and document their performance in a portfolio?

- Which evidence do students use to gain confidence in their own capabilities and competence development during undergraduate clinical training?

- How do assessors judge students' competence when interpreting evidence from various sources and multiple performance data in a competency-based portfolio?

- How do daily supervisors and portfolio assessors interpret and enact their assessment task, and how do they use the portfolio to develop a judgment on student performance?

\section{Research context}

The research was set in the Master in Medicine (MiM) program of Maastricht University, the Netherlands. The MiM curriculum spans a 3-year period following the Bachelor in Medicine. It consists of clerkships, a research project, and electives. The curriculum has been designed according to the principles of competency-based education and assessment, using the CanMEDS framework as overarching assessment framework (Frank \& Danoff, 2007). Competency-based assessment is supported by a web-based portfolio system in which students collect and reflect on evidence of their learning and development in each of the competency domains. Every student is assigned a mentor who monitors the student's competency development by guiding the student in his or her self-assessments and reflections, and in setting learning goals. Mentor and student meet three to four times per year, during which the mentor discusses the competency development and portfolio with the student. At specific points in time the mentor must also assess the student's competency development and send an advisory judgment to the portfolio assessment committee (consisting of independent assessors / examiners) which is responsible for making a formal passfail decision.

\section{Thesis outline}

When examining the quality of the competency-based portfolio as an instrument to assess students' competence and monitor their progress, it is paramount to gain a better understanding of how students use and interpret the competency-based portfolio. Therefore Chapter 2 of this 
thesis addresses how students select and document performance data in their portfolio and describes how they perceive these data to be representative of their competence development. Through student interviews it was explored to which extent the students considered the performance evidence collected in their portfolio to be illustrative of their competence development. Consequently, Chapter 3 explores how students develop confidence in their own capabilities and gain control over their own performance during their undergraduate clinical training, using audio-diary data as student records of feedback and reflections on performance. Moving away from the student's perspective, Chapter 4 reports on a study that describes how portfolio assessors develop their judgment about a student's competence solely bases on the performance evidence documented in the student's portfolio. This study combines data gathered through a think-aloud procedure and semi-structured interviews. In Chapter 5 daily supervisors' and portfolio assessors' assessments are compared and contrasted in order to gain an understanding of how they develop a judgment on student performance and how they use the student's portfolio in their judgment and decision-making process. Chapter 6 discusses and synthesizes the results described in the previous chapters and reflects on study findings in the light of existing knowledge and frameworks. We furthermore describe potential implications for portfolio assessment within health care education. Additionally, we reflect upon strengths and limitations of the research described in this thesis and provide suggestions for further research.

Finally, we should point out that this thesis is based on journal articles. Overlap between chapters is therefore inevitable. 


\section{REFERENCES}

Arntfield, S., Parlett, B., Meston, C. N., Apramian, T., \& Lingard, L. (2015). A model of engagement in reflective writing-based portfolios: Interactions between points of vulnerability and acts of adaptability. Medical Teacher, 38(2),196-205.

Bogo, Marion, Regehr, Cheryl, Power, Roxanne, \& Regehr, Glenn. (2007). When values collide: Field instructors' experiences of providing feedback and evaluating competence. The Clinical Supervisior, 26(1-2), 99-117.

Bok, H. G., Teunissen, P. W., Favier, R. P., Rietbroek, N. J., Theyse, L. F., Brommer, H., ... Jaarsma, D. A. (2013). Programmatic assessment of competency-based workplace learning: when theory meets practice. BMC Medical Education, 13(1). https://doi.org/10.1186/1472-6920-13-123

Buckley, S., Coleman, J., Davison, I., Khan, K. S., Zamora, J., Malick, S., ... Sayers, J. (2009). The educational effects of portfolios on undergraduate student learning: A Best Evidence Medical Education (BEME) systematic review. BEME Guide No. 11. Medical Teacher, 31(4), 282-298. https:// doi.org/10.1080/01421590902889897

Cleland, J. A., Knight, L. V., Rees, C. E., Tracey, S., \& Bond, C. M. (2008). Is it me or is it them? Factors that influence the passing of underperforming students. Medical Education, 42(8), 800-809. https:// doi.org/10.1111/j.1365-2923.2008.03113.x

Crommelinck, M., \& Anseel, F. (2013). Understanding and encouraging feedback-seeking behaviour: a literature review. Medical Education, 47(3), 232-241. https://doi.org/10.1111/medu.12075

Dannefer, E. F., \& Henson, L. C., (2007). The portfolio approach to competency-based assessment at the Cleveland Clinic Lerner College of Medicine. Academic Medicine, 82(5), 493-502.

Driessen, E., Van Tartwijk, J., Van Der Vleuten, C., \& Wass, V. (2007). Portfolios in medical education: why do they meet with mixed success? A systematic review. Medical Education, 41(12), 1224-1233. https://doi.org/10.1111/j.1365-2923.2007.02944.x

Driessen, E. W. (2017). Do portfolios have a future? Advances in health sciences education, 22(1), 221-228.

Driessen, E. W, Van Tartwijk, J., Govaerts, M., Teunissen, P., \& van der Vleuten, C. P. M. (2012). The use of programmatic assessment in the clinical workplace: a Maastricht case report. Medical Teacher, 34(3), 226-231.

Duitsman, M. E., van Braak, M., Stommel, W., ten Kate-Booij, M., de Graaf, J., Fluit, C. R. M. G., \& Jaarsma, A. D. C. (2019). Using conversation analysis to explore feedback on resident performance. Advances in health sciences education, 1-18.

Epstein, R. M., \& Hundert, E. M. (2002). Defining and assessing professional competence. JAMA, 287(2), 226-235.

Fernandez, N., Dory, V., Ste-Marie, L., Chaput, M., Charlin, B., \& Boucher, A. (2012). Varying conceptions of competence: an analysis of how health sciences educators define competence. Medical Education, 46(4), 357-365.

Frank, J. R., \& Danoff, D. (2007). The CanMEDS initiative: implementing an outcomes-based framework of physician competencies. Med Teach, 29(7), 642-647. doi: 10.1080/01421590701746983

Frank, J. R., Mungroo, R., Ahmad, Y., Wang, M., De Rossi, S., \& Horsley, T.. (2010). toward a definition of competency-based education in medicine: a systematic review of published definitions. Med Teach, 32(8), 631-637.

Ginsburg, S., Gold, W., Cavalcanti, R. B., Kurabi, B., \& McDonald-Blumer, H. (2011). Competencies "plus": the nature of written comments on internal medicine residents' evaluation forms. Academic Medicine, 86(10), S30-S34. 
Ginsburg, S., McIlroy, J., Oulanova, O., Eva, K., \& Regehr, G. (2010). Toward authentic clinical evaluation: pitfalls in the pursuit of competency. Academic Medicine, 85(5), 780-786.

Govaerts, M. J. B., Schuwirth, L. W. T., Van der Vleuten, C. P. M., \& Muijtjens, A. M. M. (2011). Workplace-based assessment: effects of rater expertise. Advances in health sciences education, 16(2), 151-165.

Govaerts, M. J. B., Van de Wiel, M. W. J., Schuwirth, L. W. T., Van der Vleuten, C. P. M., \& Muijtjens, A. M. M. (2013). Workplace-based assessment: raters' performance theories and constructs. Advances in health sciences education, 18(3), 375-396.

Harden, J. R., Crosby, M. H., Davis, M., Friedman, R. M. (1999). AMEE Guide No. 14: Outcome-based education: Part 5-From competency to meta-competency: a model for the specification of learning outcomes. Medical Teacher, 21(6), 546-552.

Holmboe, E. S. (2015). Realizing the promise of competency-based medical education. Academic Medicine, 90(4), 411-413.

Holmboe, E. S., Ward, D. S., Reznick, R. K., Katsufrakis, P. J., Leslie, K. M., Patel, V. L., .. Nelson, E. A. (2011). Faculty development in assessment: the missing link in competency-based medical education. Academic Medicine, 86(4), 460-467.

LaDonna, K. A., Hatala, R., Lingard, L., Voyer, S., \& Watling, Ch. (2017). Staging a performance: learners' perceptions about direct observation during residency. Medical Education, 51(5), 498-510.

Lockyer, J., Carraccio, C., Chan, M. K., Hart, D., Smee, S., Touchie, C., ... Frank, J. R. (2017). Core principles of assessment in competency-based medical education. Medical Teacher, 39(6), 609-616. https://doi.org/10.1080/0142159x.2017.1315082

Macrae, C. N., \& Bodenhausen, G. V. (2000). Social Cognition: Thinking Categorically about Others. Annual Review of Psychology, 51(1), 93-120.

Renting, N., Dornan, T., Gans, R. O. B., Borleffs, J. C. C., Cohen-Schotanus, J., \& Jaarsma, A. D. C. (2016). What supervisors say in their feedback: construction of CanMEDS roles in workplace settings. Advances in health sciences education, 21(2), 375-387.

Swing, S. R. (2007). The ACGME outcome project: retrospective and prospective. Medical Teacher, 29(7), 648-654.

van der Vleuten, C. P. M., Schuwirth, L. W., Driessen, E. W., Dijkstra, J., Tigelaar, D., Baartman, L. K., \& van Tartwijk, J. (2012). A model for programmatic assessment fit for purpose. Medical Teacher, 34(3), 205-214. doi: 10.3109/0142159X.2012.652239

van Tartwijk, J., \& Driessen, E. W. (2009). Portfolios for assessment and learning: AMEE Guide no. 45. Medical Teacher, 31(9), 790-801. 


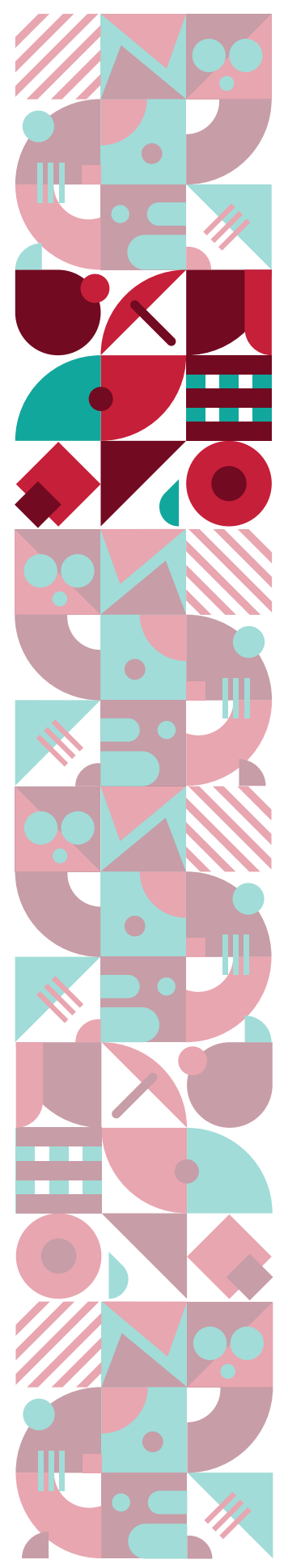

\section{CHAPTER 02}

Student perspectives on competency -based portfolios: does a portfolio reflect their competence development?

Andrea Oudkerk Pool, MSc

A.D. (Debbie) C. Jaarsma, DVM, PhD

Erik W. Driessen, PhD

Marian J. B. Govaerts, MD, PhD

Published in Perspectives on Medical Education, 9(3), 166-172. 


\section{ABSTRACT}

INTRODUCTION

Portfolio-based assessments require that learners' competence development is adequately reflected in portfolio documentation. This study explored how students select and document performance data in their portfolio and how they perceive these data to be representative for their competence development.

\section{METHODS}

Students uploaded performance data to a competency-based portfolio. During one clerkship period, twelve students also recorded an audio diary in which they reflected on experiences and feedback that they perceived to be indicants of their competence development. Afterwards, these students were interviewed to explore the extent to which the performance documentation in the portfolio corresponded with what they considered illustrative evidence of their development. The interviews were analyzed using thematic analysis.

\section{RESULTS}

Portfolios provide an accurate, but fragmented picture of students' development. Portfolio documentation was influenced by tensions between learning and assessment, students' beliefs about the goal of portfolios, students' performance evaluation strategies, the learning environment and portfolio structure.

\section{DISCUSSION}

This study confirms the importance of taking students' perceptions into account when implementing a competency-based portfolio. Students would benefit from coaching on how to select meaningful experiences and performance data for documentation in their portfolios. Flexibility in portfolio structure and requirements is essential to ensure optimal fit between students' experienced competence development and portfolio content. 


\section{INTRODUCTION}

Portfolios are used to foster students' development as well as to enable decision-making about competence achievement (Eva et al., 2016). Portfolio-based assessments therefore require that learners' competence development is adequately reflected in the portfolio content. Students have a prominent role in collecting and documenting portfolio content. A review of the portfolio literature found some evidence for the content validity of portfolios (van Tartwijk \& Driessen, 2009). A more recent study at the Cleveland Clinic Lerner College of Medicine demonstrated that, with monitoring from faculty, students are able to select evidence and document performance evaluations for summative decisions (Dannefer, Bierer \& Gladding, 2012). These studies did, however, not study portfolios used for competence assessment in clinical education.

In clinical settings, competency-based portfolios largely consist of workplace-based assessments (WBAs). Workplace-based assessments have, however, been implemented with mixed success (Miller \& Archer, 2010). In most competency-based education programs, it is the students' responsibility to collect WBAs that provide evidence of their competence development or mastery of entrustable professional activities. Collecting meaningful WBAs can be difficult for several reasons. For example, students may strategically ask for assessments in situations in which they are confident about task performance and avoid assessments in situations when they feel less confident (Crommelinck \& Anseel, 2013). Furthermore, in the clinical workplace time available for assessment is often limited. Engaging in WBA is often perceived to take time away from patient care. Faculty may therefore struggle to schedule WBAs and students may hesitate to ask for direct observations and evaluations of task performance if they feel that faculty are too busy (Madan, Conn, Dubo, Voore, \& Wiesenfeld, 2012; Watling, LaDonna, Lingard, Voyer, \& Hatala, 2016). Another issue, impacting student's willingness for initiating WBA, is that a student may feel nervous and intimidated when observed (Madan et al., 2012).

These issues with WBA can potentially affect the content of workplace-based portfolios, as some competencies and task-or content-specific performances are likely to be underrepresented, whereas other information might be overrepresented in the portfolio. This would imply that the portfolio content may not always accurately reflect a student's development and level of competence.

In competency-based assessment, it is essential that the portfolio content mirrors a student's competence development, to guide learning as well as to support high-stakes decision-making. Given students' agentic role in the composition of the portfolio it is essential to understand their perspective on the extent to which competency-based portfolios mirror their competence development. A better understanding of this is fundamental because Clinical Competency Committees (CCCs) mainly base their assessments on the content of competency-based portfolios (Driessen, van Tartwijk, Govaerts, Teunissen, \& van der Vleuten, 2012). In order to further our understanding, this study explored the following two research questions:

- how well do students think their portfolio reflects their competence development?; and

- how do students select and document their performance in a portfolio? 


\section{METHODS}

In this study, we triangulated data from students' audio diaries capturing day-to-day learning experiences, their competency-based portfolio content, and interviews with students.

\section{Setting}

The study was set in the final three years of the six year undergraduate Medicine program of Maastricht University, the Netherlands. The final three years of the curriculum consist of clinical clerkships, a research project, and electives. Clinical clerkships typically last between eight to twenty weeks depending on the discipline and the type of clerkship.

The curriculum is designed according to the principles of competency-based education and programmatic assessment, using the CanMEDS competencies as an overarching framework (Driessen et al., 2012).

The assessment programme is supported by a web-based portfolio system in which students collect and reflect on evidence of their learning and development in each of the competency domains (Van der Schaaf et al., 2017; Oudkerk Pool, Govaerts, Jaarsma \& Driessen, 2018).

At the start of their clerkship the student's competency-based portfolio only contains the student's learning plan. Over the course of the clerkship the portfolio is filled with student's selfassessments, WBAs (mini-Clinical Examinations (mini-CEX), Direct Observations of Procedural Skills (DOPS)), field notes, multi-source feedback, case-based discussions), progress test results and reflections on their learning process. Students are responsible for collecting WBAs in different settings from various assessors in order to ensure broad sampling. Depending on the clerkship, students gather between twenty-one and twenty-six WBAs in total. Each portfolio comprises narrative feedback and competency ratings (i.e., poor, average, and good) for the competency domains.

Mentors support students' learning. Students and mentors meet three to four times a year to discuss students' competence development and to formulate new learning plans.

Annually, a clinical competency committee makes a formal pass-fail decision about the student's competence development based on evidence in the portfolios and an advisory judgment from the mentor.

\section{Participants}

We sent students an invitation email explaining the goal and procedure of the study. Subsequently, the principal investigator (A.O.P.) visited the clerkship introduction days to invite students to participate. Twenty-one students within surgical, non-surgical and family medicine clerkships 
gave their informed consent and agreed to participate. Twelve students finished the study. Two students were in their final year and the others were fourth year students. Nine students decided to withdraw from the study because of the heavy workload associated with their clerkship. Their data was not included in the analysis, because it was stated in the students' informed consent that their data would be deleted if they decided to withdraw their participation. Students who completed the whole procedure received $€ 100$ in gift vouchers.

\section{Research procedure}

We collected data between November 2016 and May 2017. The research procedure consisted of three steps.

STEP 1: First, we wanted to have a better understanding of how students had experienced their development during the clerkship. Therefore, we asked students to record an audio diary twice a week during their clerkship using the audio recorder on their smartphone. The audio diary contained reflections on feedback and experiences that students perceived to be important and illustrative of their competence development. We used audio diaries because this enabled the students to regularly and instantly capture how they experienced their competence development process. The length of the recordings varied between 4 to 9 minutes each. Standardized questions about their learning experiences prompted students' reflections (Appendix 1). The students sent their audio files via email to A.O.P. The audio diaries were not part of the official portfolio procedure nor were they used in formal decision-making about students' competence achievement.

STEP 2: At the end of their clerkship the students granted the principal investigator access to their competency-based portfolio. A.O.P. compared the portfolio content with the content of the audio diary. Using content analysis, it was compared if the main learning experiences and feedback captured in the audio diary were also documented in the portfolio and vice versa. Also, A.O.P. asked students to select two audio diary fragments that described experiences that were most illustrative for their development. The results from the comparative content analysis and the selected fragments served as a starting point for the interviews conducted in step 3.

STEP 3: After the clerkship A.O.P. conducted semi-structured one-on-one interviews with the students. Interviews lasted about one hour. The aim of the interview was to gain an understanding of the extent to which students thought the portfolio reflected their competence development during the clerkship. The audio fragments were used to stimulate students to recall those experiences and feedback that they had considered most important for their development. Students were encouraged to compare their audio diaries with evidence uploaded to the portfolio 
and to elaborate to what extent the portfolio captured their development. Furthermore, questions focused on how students had used their portfolio to document their competence development and which portfolio elements would provide them and others insight into their learning process and competence achievement. The final interview guide can be found in Appendix 2. All interviews were in Dutch, audiotaped and transcribed verbatim.

\section{Analysis}

We analysed the interview data using thematic analysis (Braun \& Clarke, 2006). A.O.P and a research assistant (C.N.) coded the first two transcripts and developed an initial coding manual, on the basis of which another research assistant (A.B.) then coded the same transcripts again. Subsequently, A.O.P., and A.B. discussed the codes and themes and further refined the initial coding scheme. A.O.P., C.N. and A.B coded the remaining transcripts. After all transcripts were coded the research team (A.O.P., M.G., E.D., and D.J.) discussed key themes and conceptualizations reported by the students. Summaries of the discussions served as a basis for the further analysis of the transcripts by A.O.P and A.B. The research team met several times to further review and refine themes and define relations between themes in order to develop an understanding of how students compose their portfolio and their perceptions of how the portfolio reflects their competence development. ATLAS.ti software v1.0.17 for Mac (Scientific Software Development GmbH, Berlin, Germany) was used to facilitate the data analysis.

\section{Ethical approval}

The authors obtained ethical approval from the Ethical Review Board of the Netherlands Association for Medical Education (ERB-NVMO file number 745). Students' consent was obtained prior to participation. 


\section{RESULTS}

The dynamic nature of competence development, students' beliefs about the purpose of a portfolio, what information they considered valuable for assessors and students' strategies in feedback documentation influenced the representativeness of the portfolio. Also, the portfolio structure influenced the documentation of evidence. These aspects will be further explained in this section.

\section{Snapshots of competence development}

Although, students felt that performance evaluations documented in their portfolio were fairly representative, they also perceived these to form a rather fragmented picture of their actual development. The portfolios provided snapshots rather than a complete picture of the student's developmental trajectory. The portfolios mostly contained descriptions of single, unrelated events concerning medical procedures and patient contacts that were observed because it was difficult for students to repeatedly collect performance evaluations of the same skills. Only if the students managed to collect feedback on the same task multiple times during their clerkship, they felt the portfolio really reflected their competence development.

Students' decisions about what evidence to upload to their portfolio were often determined by educational requirements concerning the WBAs content and frequency.

"Portfolio is of course, [...] for me that is often just a lot of ticking off so it is very often a lot of things you have to ask [...] So in my portfolio I think it is more meeting the requirements or the criteria, while here in the audio diary I just thought more like okay, what have I actually seen and done today and which experiences changed me or changed my way of thinking." (Student 18)

Some experiences illustrative of their development were not part of WBA requirements or simply not observed and therefore not documented in their portfolios. In their audio-diaries students gave different examples of experiences that often were not documented: informal feedback, talks with peers, ethical dilemmas, mistakes, difficult situations, new experiences (e.g. first time taking a blood gas sample).

In addition, the content of the audio diaries and portfolios related mostly to the medical expert and communicator competency role and, to a lesser degree, to the collaborator and professional roles. The remaining roles (i.e. health advocate, scholar) were hardly mentioned. Students commented that these underrepresented competency roles are often not explicitly addressed during the clerkships. They also mentioned not knowing what to include about these competencies in their portfolio because they did not have a clear idea of the content of the, in their opinion, less well-defined competency roles. 


\section{Students' beliefs about the purpose of a portfolio}

Students had differing beliefs about the purpose of documenting information in their portfolios, which resulted in students including divergent experiences in their portfolios.

Some students predominantly considered a portfolio as a tool to demonstrate progress and competence development. Therefore, in their portfolio, these students were less inclined to document aspects that were in their opinion difficult to measure (e.g. self-confidence or assertiveness) or hard to show improvement in.

"It is something that is much less measurable and it is something that much less, well, that you can also concretely do much less about. And where you can show far less concrete improvements, because it is something that is in your head that you have to improve yourself [...] But, well, how are you going to show a rising learning curve in asking for feedback? And how are you going to show a stronger learning curve for being confident. These are things you cannot assess." (Student 3)

Other students perceived a portfolio to be more an instrument to document and demonstrate performance. Therefore, they were less inclined to document situations in which they had made a mistake, or moments when they had received critical feedback. Students feared that documenting these experiences in their portfolio would cause assessors to judge their performance as unsatisfactory. Also, documenting these perceived weaknesses might result in a lot of extra work because students have to follow-up on feedback, and provide evidence of improvement. Moreover, these students experienced their learning environment as competitive and were reluctant to ask for a WBA when they thought others had performed better. Students regretted these consequences of their mutual competition, though.

"In this clerkship, what I have noticed is that there is a lot pressure to get good assessments. And because other students have for instance received a very good assessment for something, you are going to think about it tactically, should I ask for something here, or should I not ask for something. And that's a pity." (Student 11)

\section{Students' perceptions of the relevance of portfolio content}

Students had various ideas about what information was relevant for their mentors and for portfolio assessors.

Students were less inclined to share experiences that, in their opinion, concerned something that was predominantly relevant to them personally or part of their personality, but less relevant to 
their role as a physician. For example, when a student received feedback on her posture and nonverbal communication she considered this to be something that was part of her personality she had to work on privately, not to be shared with her mentor.

"Yes they did tell me to sit up straight [...] that is something I often hear, also in other contexts so [...] that's something I have to work on on my own." (Student 4)

Students preferred to document experiences in their portfolio they thought would illustrate their unique, personal learning process. They did not document experiences when it concerned something that, in their opinion, all students had to go through, e.g. learning to combine work and private life. Although in their audio diaries students recognized that these experiences had influenced their competence development, they regarded these aspects as obvious and not worth mentioning in their portfolios.

\section{Students' performance evaluation strategies}

Students' documentation of WBA feedback in their portfolios was influenced by their perceptions of feedback credibility. For example, students felt that they could only ask for a WBA when they had sufficiently contributed to the care of a patient and the supervisor had had ample opportunity to observe them through multiple direct, because only then could the supervisor develop an accurate idea of the students' competence.

Also, students valued feedback on important steps in their development as explained by student 19:

"But I also ask for feedback especially when I have done something independently or I have done something new or I have done something differently or that I have been given feedback that I could not have thought of myself, that sort of thing." (Student 19)

Moreover, students preferred to ask for a WBA from someone who they knew would provide detailed and useful feedback and if such a person was not present during an important learning experience, this experience was not documented.

\section{Portfolio structure}

Students also described how the portfolio structure influenced how they documented their learning experiences.

Some experiences described in the students' audio diaries were difficult to capture in the 
portfolio. For example, conversations with faculty and peers had considerable impact on the student's development. However, their portfolio did not include pre-structured forms for documenting these informal conversations, making it hard to include this information in the portfolio.

Furthermore, students would like to have more possibilities to provide their own perspective or reflection on WBAs captured in their portfolio. WBA forms did not contain textboxes for students to provide more details about the context in which an event took place. In the students' opinion adding this possibility would help others to better interpret performance data in the portfolio.

"That as a student you then don't have any space in the portfolio to give your own opinion and to um to write what you think about that point of feedback and whether you agree with it [...] and if you are going to do anything about it and if so, what you are going to do about it and um. [...] So that the reviewer gets a bit better picture of how you yourself look at it." (Student 3) 


\section{DISCUSSION}

This study explored two questions: how well does the portfolio information represent the students' competence development?; and how do students select and document their performance in a portfolio? Students' beliefs, their perceptions of the relevance of portfolio content, performance evaluation strategies and the portfolio assessment system influenced how, why and when students upload evidence on performance and development to their portfolio. These aspects influenced the extent to which the portfolio information accurately represented students' performance and competence development. Overall, our findings suggest that a competencybased portfolio provides a fairly accurate, but fragmented picture of students' development in clinical settings.

Our findings seem to confirm previous research on tensions between assessment for and of learning, and integrating both assessment purposes in portfolio use (Bok et al., 2013). Students in our study who believed the portfolio's main goal was to demonstrate performance tended to avoid documentation of critical feedback that reflected weaknesses and specific learning needs, as they feared that this might impact decisions about progress and achievement. As a consequence, meaningful feedback for learning is likely to be missed when reviewing portfolio information in mentor meetings. Bok et al. [2013] also found that recording assessments in a portfolio was one of the reasons for students to perceive individual formative assessments as summative. This tension between learning and decision-making is problematic, as current educational approaches (e.g. competency based medical education and programmatic assessment) use portfolios or WBAs for dual purposes (Heeneman, Oudkerk Pool, Schuwirth, van der Vleuten \& Driessen, 2015; Frank et al., 2010; Holmboe et al., 2010). The central idea behind the dual purpose of assessment is that assessment can be used to drive learning (van der Vleuten, 1996). However, findings from our study seem to confirm that assessment can only drive learning when students feel safe to be vulnerable and disclose weaknesses they have to work on. Participants in our study indicated that they felt more safe to document critical feedback in their audio diary as these data were not shared with their mentors and decision makers. The students in our study and several other studies thus sketch a clear picture: we are still far away from such a safe environment (Bok et al., 2013; Eva et al., 2012). In their insightful synthesis of the assessment literature, Watling and Ginsburg (2019) propose ways to bridge the gap between the current assessment culture and learning environments that truly focus on the formative to ensure that learners are committed to continuous improvement. As summarized in one of their main conclusions

"We must embrace and routinely reinforce an improvement model of learning and of working, so that performing confidently is replaced by striving for improvement as a guiding professional value."[p. 83]. 
Findings from our study show that the non-medical expert CanMEDS roles were underrepresented in students' portfolios. Students predominantly focused on the medical expert and communicator role and were less inclined to document progress on the other roles, e.g. professional, health advocate. Students commented that these underrepresented competency roles are often not explicitly addressed during clerkships and that they did not know what to include about these competencies in their portfolio. Rietmeijer and Teunissen (2019) coined these underrepresented competencies as orphaned competencies. This underrepresentation of the non-medical expert roles is problematic, not only because both mentors and assessors need a complete and representative picture of the students competence development, but also because several key competencies seem to be marginalized in both students' and teachers' conceptualizations of professional competence.

Our findings show that portfolios, by their very nature, result in fragmented documentation of student learning and performance. This reflects the difficulties students may experience when trying to collect feedback during clerkships. Faculty's lack of time and students' reluctance to ask for feedback leads to feedback on isolated events rather than follow-up on feedback through repeated observation of clinical tasks. Some adaptations in our current WBA practice could support provision of more meaningful feedback. For example, incorporating dedicated time for observation and feedback into the daily clinical program seems essential for promoting the exchange and documentation of feedback (Bok et al., 2016). Moreover, videotaping consultations might enable supervisors to provide feedback when it fits their schedule (Lefroy, Watling, Teunissen, \& Brand, 2015). Also, it is critical to find the right amount of WBAs. Less mandatory WBAs could result in more meaningful and higher quality WBA content. Students indicated that the high number of required WBAs combined with the busy workplace caused them to ask for feedback when it was easy, instead of valuable for their development. Moonen-van Loon, Overeem, Donkers, van der Vleuten and Driessen (2013) demonstrated that combining different WBA tools in a portfolio can lead to a more feasible amount of required WBAs while still allowing for reliable decision-making about resident performance.

Our study underlines the importance of involving student perceptions when designing portfolios. Students in our study expressed the need to have more freedom in their portfolios to express their perspectives and add comments clarifying characteristics of the learning context and assessment setting. They felt that this additional information would help assessors to develop a better understanding of their competence development. Captions could be used for this purpose (Driessen, 2017). Captions are textboxes attached to each portfolio document describing what the document is, why this is valuable evidence, and for what development it provides evidence (Collins, 1991). Students' need for a more flexible portfolio resonates with the work of Van Tartwijk and Driessen (2009), who argue that students should be provided with clear guidance on how to develop their portfolio, but should also be given room for describing their unique experiences and composing an authentic product. Students value experiencing some freedom to 
adjust the content of their portfolio to their personal preferences. Some students indicated that it was easier to document learning experiences and reflections using the audio diary than having to write it down. Using audio may therefore be a good alternative to written text in a portfolio. Besides providing more flexibility in students' documentation of competence development, diaries may furthermore enhance learning and competence development through encouraging more frequent and timely reflection on recent performance feedback.

\section{Limitations}

Several limitations must be mentioned. The assignment of keeping an audio diary is different from the assignment to prove one's competence in a portfolio. Both assignments will generate different kinds of responses. We must therefore be cautious about judgments based on such a comparison. The interviews with the students were important to help interpret comparative data, though.

We conducted this research at Maastricht University where a specific competency-based portfolio is used. Portfolios differ considerably in content and design. We advise replication of this study in other settings where different types of portfolio are used.

Moreover, it is possible that our participant sample consisted of mainly very motivated and high achieving students. Nine students decided to withdraw their participation because of the demanding clerkships. However, the portfolio and audio diary of the participating students showed that our sample did include students who struggled with their competence development during their clerkship.

\section{Conclusion}

In clinical settings, a competency-based portfolio may provide a fairly accurate, yet fragmented picture of students' development. Non-medical expert roles tend to be underrepresented. This study confirms the importance of taking students' perceptions into account when implementing a competency-based portfolio. Students would benefit from guidance and coaching on how to combine assessment and learning, how to select meaningful evidence and how to document their development in their portfolios. Flexibility in portfolio structure and requirements is essential to ensure optimal fit between students' experienced competence development and portfolio documentation.

\section{Declaration of interest Funding/Support}

The authors declare no conflicts of interest. 


\section{REFERENCES}

Bok, H. G., Teunissen, P. W., Favier, R. P., Rietbroek, N. J., Theyse, L. F., Brommer, H., ... \& Jaarsma, D. A. (2013). Programmatic assessment of competency-based workplace learning: when theory meets practice. BMC medical education, 13(1), 123.

Bok, H. G., Jaarsma, D. A., Spruijt, A., Van Beukelen, P., Van Der Vleuten, C. P., \& Teunissen, P. W. (2016). Feedback-giving behaviour in performance evaluations during clinical clerkships. Medical Teacher, 38(1), 88-95.

Braun, V., \& Clarke, V. (2006). Using thematic analysis in psychology. Qualitative research in psychology, 3(2), 77-101.

Collins, A. (1991). Portfolios for Biology Teacher Assessment. Journal of Personnel Evaluation in Education, 5(2), 147-68.

Crommelinck, M., \& Anseel, F. (2013). Understanding and encouraging feedback-seeking behaviour: a literature review. Medical education, 47(3), 232-241.

Dannefer, E. F., Bierer, S. B., \& Gladding, S. P. (2012). Evidence within a portfolio-based assessment program: what do medical students select to document their performance?. Medical teacher, 34(3), 215-220.

Driessen, E. W., van Tartwijk, J., Govaerts, M., Teunissen, P., \& van der Vleuten, C. P. (2012). The use of programmatic assessment in the clinical workplace: a Maastricht case report. Medical Teacher, 34(3), 226-231.

Driessen, E. (2017). Do portfolios have a future?. Advances in Health Sciences Education, 22(1), 221- 228.

Eva, K. W., Armson, H., Holmboe, E., Lockyer, J., Loney, E., Mann, K., \& Sargeant, J. (2012). Factors influencing responsiveness to feedback: on the interplay between fear, confidence, and reasoning processes. Advances in health sciences education, 17(1), 15-26.

Eva, K. W., Bordage, G., Campbell, C., Galbraith, R., Ginsburg, S., Holmboe, E., \& Regehr, G. (2016). Towards a program of assessment for health professionals: from training into practice. Advances in Health Sciences Education, 21(4), 897-913.

Frank, J. R., Snell, L. S., ten Cate, O., Holmboe, E. S., Carraccio, C., Swing, S. R., ... \& Harden, R. M. (2010). Competency-based medical education: theory to practice. Medical teacher, 32(8), 638-645.

Heeneman, S., Oudkerk Pool, A., Schuwirth, L. W., van der Vleuten, C. P., \& Driessen, E. W. (2015). The impact of programmatic assessment on student learning: theory versus practice. Medical education, 49(5), 487-498.

Holmboe, E. S., Sherbino, J., Long, D. M., Swing, S. R., Frank, J. R., \& International CBME Collaborators. (2010). The role of assessment in competency-based medical education. Medical teacher, 32(8), 676-682.

Lefroy, J., Watling, C., Teunissen, P. W., \& Brand, P. (2015). Guidelines: the do's, don'ts and don't knows of feedback for clinical education. Perspectives on medical education, 4(6), 284-299.

Moonen-van Loon, J. M. W., Overeem, K., Donkers, H. H. L. M., Van der Vleuten, C. P. M., \& Driessen, E. W. (2013). Composite reliability of a workplace-based assessment toolbox for postgraduate medical education. Advances in Health Sciences Education, 18(5), 1087-1102.

Madan, R., Conn, D., Dubo, E., Voore, P., \& Wiesenfeld, L. (2012). The enablers and barriers to the use of direct observation of trainee clinical skills by supervising faculty in a psychiatry residency program. The Canadian Journal of Psychiatry, 57(4), 269-272.

Miller, A., \& Archer, J. (2010). Impact of workplace based assessment on doctors' education and performance: a systematic review. $B m j, 341, \mathrm{c} 5064$.

Oudkerk Pool, A., Govaerts, M. J., Jaarsma, D. A., \& Driessen, E. W. (2018). From aggregation to interpretation: how assessors judge complex data in a competency-based portfolio. Advances in Health Sciences Education, 23(2), 275-287. 
Rietmeijer, C. B., \& Teunissen, P. W. (2019). Good educators and orphans: the case of direct observation and feedback. Medicaleducation, 53(5), 421.

Van der Schaaf, M., Donkers, J., Slof, B., Moonen-van Loon, J., van Tartwijk, J., Driessen, E., ... \& Ten Cate, O. (2017). Improving workplace-based assessment and feedback by an E-portfolio enhanced with learning analytics. Educational Technology Research and Development, 65(2), 359-380.

Van Tartwijk, J., \& Driessen, E. W. (2009). Portfolios for assessment and learning: AMEE Guide no. 45. Medical teacher, 31(9), 790-801.

Van Der Vleuten, C. P. (1996). The assessment of professional competence: developments, research and practical implications. Advances in Health Sciences Education, 1(1), 41-67.

Watling, C., LaDonna, K. A., Lingard, L., Voyer, S., \& Hatala, R. (2016). 'Sometimes the work just needs to be done': socio-cultural influences on direct observation in medical training. Medical education, 50(10), 1054-1064.

Watling, C. J., \& Ginsburg, S. (2019). Assessment, feedback and the alchemy of learning. Medical education, 53(1), 76-85. 


\section{APPENDIX 1: AUDIO DIARY QUESTIONS}

- What did you learn during the past days? Do you have examples?

- Which experience made you discover how far along you are in you development? What did you discover about what you can and cannot do? Do you have examples?

- What feedback did you receive that was valuable? What feedback made you discover how far along you are in you development?

- Did you experience success during the past days? If yes, can you describe this experience?

- Did you have a difficult experience during the past days? If yes, can you describe this experience? 


\section{APPENDIX 2: INTERVIEW GUIDE}

\section{Audio diary}

1 A00 You selected two types of learning experiences from your audio diary that were the most valuable in your opinion. Why did you select these experiences? Could you explain the difference between these experiences?

1B00 Which learning experience you described in your audio diary was the most important for your learning process? Why this experience?

1B10 Did you document this experience in your portfolio? Was this a deliberate choice?

1B11 Do you think that the way in which this experience was documented in your portfolio provides valuable information about your development? Why?

1 COO Which feedback you have documented in your audio diary was the most valuable for your learning process? Why this feedback?

1 C10 Did you document this feedback in your portfolio? Was this a deliberate choice?

1C11 Do you think that the way in which this feedback was documented in your portfolio provides valuable information about your development? Why?

\section{Portfolio}

2A00 Could you select two types of learning experiences from your portfolio that were the most insightful in your opinion. Why did you select these experiences? Could you explain the difference between these experiences?

2B00 Do you think that the way in which these experiences are documented in your portfolio provide valuable information about your development? Why?

2B10 Did you mention these experiences in your audio diary? Why?

2C00 You also mention feedback/situations/learning experiences in your portfolio which you did not include in your audio diary. Could you elaborate on your reasons? 
$2 \mathrm{C} 10$ What is your opinion about this information?

2C20 To what extent is this information important for your mentor and portfolio assessors when assessing your development based on the performance documentation included in your portfolio?

2D00 Is there anything that you would not include in your portfolio? Why not?

2E00 What kind of performance documentation in the portfolio is not informative in your opinion?

\section{Current level of competence}

3A00 Could you describe your level of competence for all the different competency domains?

3B00 Did you feel competent during this clerkship?

\section{Porffolio and audio diary experiences}

4A00 What is your opinion about the audio diary? What are your experiences with recording the audio diary?

4B00 What is your opinion about the portfolio? What are your experiences with working on your portfolio?

4COO Did you work differently during this clerkship compared to how you worked during other clerkships? What is the difference? If yes, what are possible reasons for this difference in your opinion?

4D00 What was the biggest difference between keeping your audio diary and working on your portfolio? 


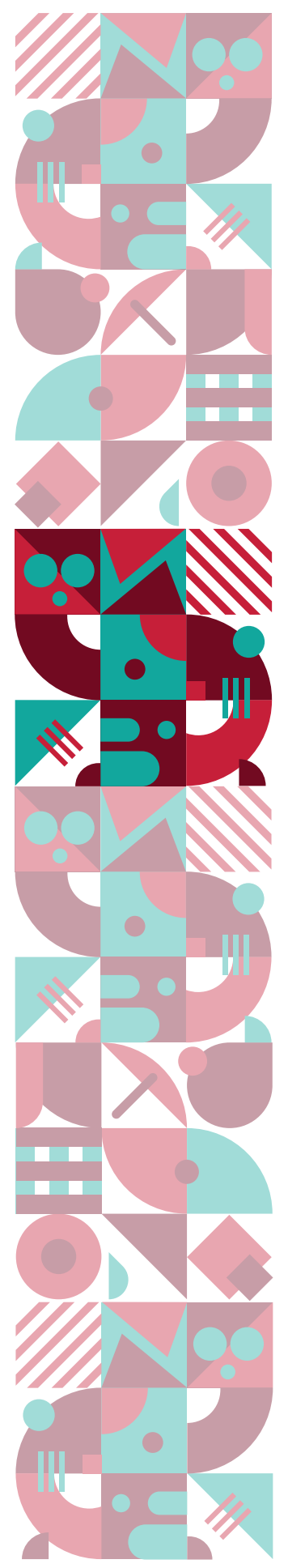

\section{CHAPTER 03}

How Students Gain Confidence in their capabilities and competence development During Clerkships: An Audio Diary Study

Andrea Oudkerk Pool, MSc,

Marian J. B. Govaerts, MD, PhD

Derk Bransen, MSc,

A. D. (Debbie) C. Jaarsma, DVM, PhD

Erik W. Driessen, PhD

Under Review 


\section{ABSTRACT}

PURPOSE

The aim of this study was to explore how students gain confidence in their own capabilities and competence development while learning in undergraduate clinical practice.

\section{METHOD}

Twice a week during one twelve-week clerkship, twelve students recorded an audio diary. In their audio diaries, the students answered questions that were designed to stimulate them to reflect on the feedback and experiences they perceived to be important for their competence development, adding to their sense of confidence in their capabilities. The diary transcripts were analyzed using template analysis.

\section{RESULTS}

The students described how they needed to feel related to their team members and be allowed to participate in order to develop control over their performance and gain confidence in their capabilities. Comparing their performance with the performance of their peers seemed to be a key strategy in developing a sense of competence. Moreover, the students recognized that being pro-active was a prerequisite for creating the conditions for a learning environment that supported their competence development and confidence in becoming a competent doctor.

\section{CONCLUSIONS}

This study describes how students' need for competence results from a continuous interaction with their learning environment. Faculty should strive for safe and trusting relationships with students in which students can discuss their personal goals and preferences. Raising awareness about aspects that influence students' need for competence and stimulating conversations about these issues between students and faculty can ultimately promote students' intrinsic motivation to self-direct their learning and pro-actively engage in and document meaningful learning experiences in the clinical setting. Future research should focus on how students' autonomy and pro-active behavior can be established early on in their clerkships. 


\section{INTRODUCTION}

Various studies stress the importance of intrinsic motivation for students' successful learning (Kusurkar \& Croiset, 2015; Renting et al., 2016; Williams \& Deci, 1998; Williams, Saizow, \& Ryan, 1999). Intrinsic motivation originates from the inherent satisfaction a person experiences when performing an action, rather than from rewards or reinforcements that are the result of these actions (Deci \& Ryan, 2002). Intrinsic motivation is associated with better learning outcomes, academic success and increased student well-being (Deci \& Ryan, 2002; Ryan \& Deci, 2000). However, medical students' motivation to perform is often driven by external pressures such as assessment requirements, or the need to obtain rewards (Kusurkar \& Croiset, 2015). It therefore remains a challenge to arrange learning environments in such a way that they foster students' intrinsic motivation to use performance assessment and feedback as opportunities for growth and development.

According to the self-determination theory (SDT) three basic psychological needs must be fulfilled in order to become and remain intrinsically motivated (Deci \& Ryan, 2008). First, the need for relatedness refers to the desire to belong to a group and be valued by members of this group. Second, the need for autonomy concerns the urge to control our lives and have a sense of free will when doing something. Third, the need for competence applies to the feeling of having confidence in our own capabilities and being able to controlour task performance (Ryan \& Deci, 2000; Watling, LaDonna, Lingard, Voyer, \& Hatala, 2016). This need drives learners to search for challenges that fit their level of competence in order to continuously develop their skills and capabilities. The need for competence, as defined within the theory of SDT, is closely related to the concept of self-efficacy. Self-efficacy results from the self-evaluation of one's ability to successfully perform a specific behavior or action (Bandura, 1977). If a student experiences high self-efficacy concerning a certain behavior or action it is very likely that he or she will perform this action.

The application of SDT principles could result in students becoming intrinsically motivated to self-direct their learning and self-assess their performance (Sklansky, Frohna, \& Schumacher, 2017). Both are considered imperative to competency-based medical education (CBME) (Lobst et al., 2010). Fulfilling the needs defined within SDT is essential during clinical training as students have to learn in a dynamic and unpredictable environment, and what and how they learn will, to a large extent, depend on their own initiative and type of motivation.

Previous research demonstrated that students' success in the clinical workplace largely depends on how the environment motivates students by supporting them to participate in clinical care (Dornan, 2006). This participation stimulates students' feelings of relatedness as well as triggers their need for autonomy in clinical functioning (Littlewood et al., 2005). Examples of increased autonomy, such as admitting new patients, are associated with students' increased learning effects (Lang, Mooney, O’Connor, Bordley, \& Lurie, 2009).

Although there has been research on the need for autonomy and relatedness in clinical 
training, it is relatively unknown how students navigate the clinical learning environment to fulfill their need for competence and how they develop confidence and self-efficacy during undergraduate clinical practice (Orsini, Binnie, \& Wilson, 2016; Watling et al., 2016). Gaining a better understanding of how students fulfill their need for competence in clinical training may help teachers and trainers to optimize student support and guidance of competence development as well as design and implementation of competence-based assessment systems that are wellaligned with students' actual learning experiences and learning needs. Fulfilling students' need for competence can boost their intrinsic motivation, resulting in better learning outcomes and improved students' well-being. This is especially important given the high rate of medical students experiencing psychological distress and the negative impact it has on their academic achievement, motivation and well-being (Dyrbye, Thomas, \& Shanafelt, 2005; Henning et al., 2011; Lyndon et al., 2017). Therefore, the aim of this study was to explore how students gain confidence in their own capabilities and competence development during undergraduate clinical training.

\section{METHODS}

\section{Setting}

The study was set in the 6-year undergraduate medicine program at Maastricht University, the Netherlands. The last three years of the curriculum consist of clerkships, a research project, and electives. Clerkships typically last between eight to twenty weeks depending on the discipline and the type of rotation. During rotations, students spend time in the wards, outpatient clinics and the emergency department. For the duration of the clerkship, students have a personal supervisor from the hospital department, who is responsible for supervision and assessment.

The curriculum was designed according to the principles of competency-based education and assessment, using the CanMEDS framework as overarching assessment framework (Crommelinck \& Anseel, 2013; Oudkerk Pool et al., 2017).

\section{Design and data collection}

Twice a week during one twelve-week clerkship, students recorded an audio diary via the audio recorder on their smartphone. In their audio diaries, the students answered questions that were designed to stimulate them to reflect on feedback and experiences that they perceived to be important in terms of their competence development and that added to their sense of confidence and self-efficacy. An overview of these questions can be found in Appendix 1. We chose audio 
diaries because they allow students to capture significant experiences almost immediately after they occur, reducing memory loss. The students sent their audio files via email to A.O.P. If the students did not send a recording for more than three workdays they were sent a reminder via email and text message. Audio recordings were transcribed verbatim. Data were collected between November 2016 and May 2017.

This study was part of a larger research project, which aimed to contribute to gaining an understanding of how students experience portfolio-based assessment of competence. We explored how students select and document performance documentation in their portfolio and how they perceive these data to be representative for their competence development. The results of this study are described elsewhere.

\section{Participants}

An invitation email explaining the goal and procedure of the study was sent to students within surgical, non-surgical and family medicine clerkships. Subsequently, the principal investigator (A.O.P.) visited the clerkship introduction days to provide students with information about the study and to invite them to participate. Twenty-one students agreed to participate and twelve students finished the study. Nine students withdrew their participation because they found it difficult to find time to record their diaries alongside their demanding clerkships. Their data were not included in the study and deleted. Students who completed the whole procedure received a total of $€ 100$ in gift vouchers.

\section{Analysis}

We analyzed the audio diary transcripts using template analysis. Template analysis is a type of theory-based thematic analysis in which a succession of coding templates, consisting of hierarchically structured themes, are applied to the data (King, 2004). We started with a small set of predefined codes based on relevant literature that had shaped this study's research question. These codes related to important SDT and self-efficacy concepts. Independent analysis of the first four audio diaries by A.O.P. and D.B. using the predefined codes led to the development of an initial template. This template was discussed within the research team (A.O.P, E.W.D, M.G., D.J. and D.B.). The template that resulted from this discussion was then used by D.B. and A.O.P to analyze audio diaries five to eight. This led to a final template that was again discussed within the research team. This final template was confirmed by analysis and coding of diaries nine to twelve. Students' conceptualizations of their need for competence, the sources they used to develop their need for competence and the prerequisite factors influencing their need for 
competence were identified as emerging themes. All audio diaries were reread by A.O.P. and D.B. to make sure no relevant information was missed. After discussing the complete dataset, the analysis was advanced from themes to an interpretation of the relationship between the themes, to develop a theory about how students' need for competence is influenced by the sources they use as evidence to develop a sense of confidence and self-efficacy, and contextual factors that may help or hinder development of feeling competent.

\section{RESULTS}

The extent to which students developed a sense of competence strongly depended on whether they felt related to their environment and were allowed to participate in clinical practice. This was most likely to occur in a safe learning environment. Also, students recognized that being pro-active was essential in enhancing feelings of relatedness and creating the opportunities to participate. Moreover, students explained how the interaction with peers influenced their feeling of being in control and confident. These aspects will be further explained in this section.

\section{Safe clinical learning environment: relatedness and participation}

In order to gain control and confidence, students had to frequently practice their skills with increasingly less support from faculty. This required a safe working environment in which students felt they were allowed to ask questions and make mistakes. Such an environment offered students the possibility to practice skills and select learning experiences in line with actual learning needs. This resulted in experiencing high levels of self-efficacy (e.g. having confidence in being able to successfully perform the desired behavior).

From the audio diaries it became clear that it was crucial that students felt at home in their environment. Some students indicated that it took them several weeks to get used to their role as a clerk because they missed someone explaining the rules and what was expected from them. These students were less often involved in valuable learning experiences because other members of the heath care team did not ask them to participate or because they were not sure if they were allowed to participate. Or as one student described: "I don't really have a function but I am not ignored". Because students were less involved in clinical practice they had less opportunity to practice and improve their skills. As a consequence they had more difficulty developing confidence and control over their performance compared with those students who felt connected with their team members.

On the other hand, students who did experience relatedness were often asked by faculty to 
actively participate in relevant tasks. Students valued supervisors who tried to engage them, provided detailed feedback and asked questions. If a supervisor actively engaged a student, they thought this was a sign of the supervisors' confidence in their capabilities. Simply being allowed to participate and perform a task already resulted in students feeling more adequate, regardless of the outcome. Students regarded this as a vote of confidence in their capabilities from their supervisors. These students also felt comfortable asking questions and were more likely to stand up for themselves.

"I am not afraid to ask the doctors more questions, I am also much less shy. I have also noticed that I am feeling more and more at home. Or, yes, that I have the impression that people are getting to know me better and know who I am" (Student 11)

Students recognized that they needed to experience freedom in deciding when and how to participate in order to boost their self-efficacy. Students who were allowed to choose new and challenging learning opportunities, for example participating at the emergency department, indicated that these new experiences motivated them because they could practice challenging skills and techniques that improved their performance.

"I have noticed that I am becoming more confident that I can do some things, also in the OR that I understand what the surgeon is doing etcetera and that I know um what I should do while he is busy at the table. But, no, you are not given much freedom at the moment so it is still difficult to work out where exactly I am in my development" (Student 6)

Second, students indicated that they needed some freedom to perform activities independently or with limited supervision as their ultimate goal was to be able to perform independently. They needed freedom to practice in order to self-assess to what extent they were able to independently perform a certain task, parts of a procedure, or a complete procedure. Successfully and independently completing a task greatly improved students' sense of competence, as described by student 19 .

"During the laparoscopy I was once allowed to, um, to maneuver the camera and hold it throughout the whole operation [.... that went very well, so it was a bit of a sort of victory, a reassurance of yes I can do this well" (Student 19)

\section{Engaged students: being pro-active}

The control and confidence students experienced did not only depend on their environment. Students recognized that their own behavior played an important role in creating the conditions 
for a learning environment that supported their need for competence. Therefore, all students put a lot of effort into being pro-active.

Students reported that they needed to be assertive and show initiative in order to be allowed to observe or participate. They also noticed that faculty valued students who were pro-active. Often, being allowed to actively participate resulted in a snowball effect in which the student increasingly had the opportunity to practice various skills. Therefore, being assertive and asking faculty to let them take an active role was one of students' most important goals, as described by student 6 .

"Yesterday I was really very proactive, helping everywhere in the OR, um, offering to see patients myself if the doctor was busy. And I got very good feedback for that. Also from the anesthetists, I was allowed to help them too because the surgeon had already left so, yes, I usually stay to help in the OR. And I know they appreciate that, but now that I am doing that more often they are letting me do more and more" (Student 6)

Students recognized that receiving feedback is vital for improving their performance. Many students struggled to actively ask faculty for feedback. Students did not manage to make appointments with faculty about when they would provide feedback or they were reluctant to ask for feedback. Students' success in asking for feedback was directly related to their confidence, regardless of the content of the feedback they received. Failed attempts to ask for feedback on the other hand resulted in students feeling unconfident.

"Yes of course there are things that can be improved, but if they don't tell me what, then I can't do anything about it. So, yes, that is something I have learned in the past days [...] So it is really purely specifically asking for feedback for the competence. Um, yes, I do actually think it is very important that I realized that because I really had the feeling that I wasn't getting anywhere" (Student 18)

\section{Social comparison: Interaction with peers}

Students' sense of competence strongly depended on comparing their performance with that of their peers. This information could either boost their confidence in their performance or make them doubt their capabilities.

Students often compared their own performance with that of other members in their team. They showed different styles of social comparison. Some students expressed their desire to continuously improve their performance. These students compared their own performance with that of more senior fellow students, or faculty members. However, the danger of this comparison was that 
students set unrealistic goals for themselves, potentially harming their confidence, as described by student 3 .

"that I can sometimes get really stressed that I can't retain knowledge, that I forget a lot of things and that I am not good enough [....] I still think that after 2.5 years I really won't be as far as the other final year students I see around me" (Student 3)

In order to make sure that their performance was not substandard they compared their performance with that of fellow students to check if they were not doing worse than their peers. Some students then started to feel unconfident about their performance when comparing their peers' level of participation in patient care. If their fellow students were allowed more opportunities to participate or received more positive feedback, this negatively influenced the students' confidence.

"I have noticed that in one way or another I get asked less questions or am less often put on the spot compared with other students who are currently doing rotations in XXX, sometimes I think it it's me but maybe I have other doctors or I don't notice the questions?" (Student 12)

\section{DISCUSSION}

Our study was designed to explore how students gain confidence in their own capabilities and competence development during undergraduate clinical training. Our findings show that the confidence and self-efficacy students experienced is the result of students' constant interactions with their learning environment.

First, students derive information about their competence from the extent to which they are allowed to participate and perform autonomously. Experiencing low levels of autonomy negatively influences students' feeling of being competent. This resonates with earlier findings in postgraduate medicine which show that residents' lack of experienced autonomy diminished their sense of competence (Biondi et al., 2015). The study by Biondi and colleagues (2015) also showed a discrepancy between the level of autonomy in patient care that faculty think they provide and residents think they receive. Faculty was hesitant to provide autonomy to insecure and passive residents who did not appear motivated. Similarly, the students in our study described their motivation and confidence as the result of the level of autonomy given to them by their supervisors as well as the fact that being pro-active enhanced supervisors' willingness to assign meaningful tasks or involve students in patient care. Therefore, it could be that the students in our study who experienced a lack of autonomy also appeared less confident and motivated to their supervisors compared with those students who did experience autonomy. As a result, these 
students are possibly provided with fewer opportunities to autonomously practice their skills, further enhancing feelings of in competence or lack of confidence in their own capabilities. As a consequence of these reciprocal student-supervisor relationships, the more confident students will develop confidence and control faster than the more insecure students, increasing the difference between these student groups.

Moreover, our results showed that the social comparison behavior of students influenced their confidence. The social comparison students displayed in our study resonates with earlier research showing that students' comparison with peers and faculty can greatly influence their motivation and level of distress (Raat, Schönrock-Adema, van Hell, Kuks, \& CohenSchotanus, 2015; Raat, Kuks, \& Cohen-Schotanus, 2010). Students who aspire to become a member of future health care teams will compare their performance with more skilled others to estimate their current position and look for opportunities to master the challenges of active engagement. In order to be successful and stay intrinsically motivated, students may need guidance in formulating realistic learning goals and strategies to achieve these goals. Without proper guidance, students who compare with more skilled others may set unrealistic expectations, become frustrated and experience a decline in self-efficacy and confidence. Students who experience high levels of self-efficacy and feel in control and confident usually make fewer comparisons, compare less with peers perceived as performing worse, and interpret the comparisons they make less negatively (Raat, 2015).

Our findings indicate that students rely on much more than formal feedback when developing confidence and control over their performance. This is in accordance with the proposition of Van der Leeuw, Teunissen and Van der Vleuten (2017) that a lot of relevant performance information that can be used to guide further competence development stems from social learning processes in the complex workplace. These authors argue that the current application of the feedback concept predominantly focuses on the use of formal feedback which limits the use of information that emerges more naturally and implicitly from social learning processes and interactions in the clinical setting. Therefore, they propose a redefinition of feedback as performance-relevant information (PRI). PRI concerns all the information that the learners consider relevant. Making students aware of these types of performance relevant feedback and asking them to critically reflect upon all feedback (formal and informal) may result in richer underpinnings of students' self-assessments and reveal additional starting points for learning and enhancement of competence development.

The challenges of students who try to gain confidence and control in a new learning environment involve much more than learning specialty-specific competencies. Students are unsure about their role and responsibilities in a new setting and therefore find it hard to adapt to their new role and responsibilities (O’Brien, Cooke, \& Irby, 2007). Also, clerkship directors often underestimate students' struggles with self-confidence, management of implicit or explicit expectations, or being part of the health care team (O'Brien et al., 2007). Therefore, findings from this and other 
studies indicate that we should pay more attention to promoting students' self-directed learning early on in their clerkships, by explicitly addressing and discussing the challenges that students are facing when transitioning to clinical learning environments. Moreover, students must be made aware of their own comparison behavior, and they have to be supported in developing comparison strategies that promote - rather than decrease- their motivation. Likewise, faculty must be made aware of students' tendency to compare and the possible positive and negative effects of these comparisons. Having conversations with students about their comparisons might reveal underlying assumptions and beliefs, which are worth encouraging or challenging. In addition, having discussions about mutual expectations and how to achieve mutually agreed upon learning goals may stimulate students to proactively engage in relevant learning activities and performance assessments, enhancing student learning and feelings of being (or becoming) competent.

These suggestions are in line with key principles underlying the "educational alliance" proposed by Telio, Ajjawi and Regehr (2015). These authors describe a framework of feedback as a negotiation in the environment of a supportive educational relationship. Establishing these reciprocal kinds of relationships between learners and supervisors is beneficial to students' wellbeing, learning and way of working (Voyer, Cuncic, Butler, MacNeil, Watling \& Hatala, 2016).

This study has several limitations. Firstly, a large number of students decided to withdraw their participation because the added workload of keeping an audio diary was too heavy. Diary studies place great demands on participants and therefore high levels of participant attrition is a known limitation of these studies (Miner, Glomb, \& Hulin, 2005). However, the data analyses confirmed that the remaining audio diaries did provide sufficient information to answer the research question.

Moreover, because of the high level of participant attrition, it is possible that our participant sample consisted of mainly very motivated and high achieving students. Nonetheless, the audio diaries of the participating students showed that our sample did include students who struggled during their clerkship.

Also, students were provided with diary questions to help them record relevant information. Although these questions encourage recall of significant events, they also shape this recall to some extent (Poppleton, Briner, \& Kiefer, 2008).

\section{CONCLUSION}

This study explored how students gain confidence in their own capabilities and competence development during undergraduate clinical training. Students described how their need for relatedness and desire to participate were prerequisites for gaining confidence in their capabilities and development of self-efficacy. Moreover, students recognized that being pro-active was essential in order to create the conditions for a learning environment that supported their need for competence. Also, they explained how the comparison of their performance with the 
performance of peers could impact their feelings of self-efficacy. Raising awareness about aspects that influence students' need for competence and stimulating conversations about these issues between students and faculty can ultimately promote students' motivation to engage in meaningful learning activities and assessment for learning.

\section{ETHICAL APPROVAL}

The authors obtained ethical approval from the Ethical Review Board of the Netherlands Association for Medical Education (ERB-NVMO file number 745). 


\section{REFERENCES}

Bandura, A. (1977). Self-efficacy: Toward a unifying theory of behavioral change. Psychological Review, 84, 191-215.

Biondi, E. A, Varade, W. S., Garfunkel, L. C., Lynn, J. F., Craig, M. S., Cellini, M. M., .. Baldwin, C. D. (2015). Discordance between resident and faculty perceptions of resident autonomy: can selfdetermination theory help interpret differences and guide strategies for bridging the divide? Academic Medicine, 90(4), 462-471.

Crommelinck, M., \& Anseel, F. (2013). Understanding and encouraging feedback-seeking behaviour: a literature review. Medical Education, 47(3), 232-241.

Deci, E. L., \& Ryan, R. M. (2002). Overview of self-determination theory: An organismic dialectical perspective. Handbook of self-determination research, 3-33. Rochester, America: The University of Rochester Press.

Deci, E. L., \& Ryan, R. M. (2008). Self-determination theory: A macrotheory of human motivation, development, and health. Canadian psychology/Psychologie canadienne, 49(3), 182.

Dornan, T. (2006). Experience based learning: learning clinical medicine in workplaces: Maastricht university.

Dyrbye, L. N., Thomas, M. R., \& Shanafelt, T. D. (2005). Medical Student Distress: Causes, Consequences, and Proposed Solutions. Mayo Clinical Proceedings, 80(12), 1613-1622. https://doi. org $/ 10.4065 / 80.12 .1613$

Henning, M. A., Krägeloh, C. U., Hawken, S. J., Doherty, I., Zhao, Y., \& Shulruf, B. (2011). Motivation to learn, quality of life and estimated academic achievement: medical students studying in New Zealand. Medical Science Educator, 21(2), 142-150.

Lobst, W. F., Sherbino, J., ten Cate, O., Richardson, D. L., Dath, D., Swing, S. R., . . Frank, J. R. (2010). Competency-based medical education in postgraduate medical education. Medical teacher, 32(8), 651-656.

King, N., Cassell, C., \& Symon, G. (2004). Using templates in the thematic analysis of text. Essential guide to qualitative methods in organizational research, 2, 256-70.

Kusurkar, R. A., \& Croiset, G. (2015). Autonomy support for autonomous motivation in medical education. Medical education online, 20(1), 27951.

Lang, V. J., Mooney, C. J., O’Connor, A. B., Bordley, D. R., \& Lurie, S. J. (2009). Association between hand-off patients and subject exam performance in medicine clerkship students. Journal of general internal medicine, 24(9), 1018-1022.

Littlewood, S., Ypinazar, V., Margolis, S. A., Scherpbier, A., Spencer, J., \& Dornan, T. (2005). Early practical experience and the social responsiveness of clinical education: systematic review. Bmj, 331(7513), 387-391.

Lyndon, M. P., Henning, M. A., Alyami, H., Krishna, S., Zeng, I., Yu, T., \& Hill, A. G. (2017). Burnout, quality of life, motivation, and academic achievement among medical students: A person-oriented approach. Perspectives on medical education, 6(2), 108-114.

Miner, A., Glomb, T., \& Hulin, C.. (2005). Experience sampling mood and its correlates at work. Journal of Occupational and Organizational Psychology, 78(2), 171-193.

O'Brien, B., Cooke, M., \& Irby, D. M. (2007). Perceptions and attributions of third-year student struggles in clerkships: do students and clerkship directors agree? Academic Medicine, 82(10), 970-978.

Orsini, C., Binnie, V. I., \& Wilson, S. L. (2016). Determinants and outcomes of motivation in health professions education: a systematic review based on self-determination theory. Journal of educational evaluation for health professions, 13, 19, 
Oudkerk Pool, A., Govaerts, M. J. B., Jaarsma, A. D. C., \& Driessen, E. W. (2017). From aggregation to interpretation: how assessors judge complex data in a competency-based portfolio. Advances in health sciences education, 23(2), 275-287. doi: 10.1007/s10459-017-9793-y

Poppleton, S., Briner, R. B., \& Kiefer, T. (2008). The roles of context and everyday experience in understanding work-non-work relationships: A qualitative diary study of white-and blue-collar workers. Journal of Occupational and Organizational Psychology, 81(3), 481-502.

Raat, A. N. J. (2015). Peer influence in clinical workplace learning: A study of medical students' use of social comparison in clinical practice. [Groningen]: University of Groningen.

Raat, A. N. J., Schönrock-Adema, J., van Hell, E. A., Kuks, J. B. M., \& Cohen-Schotanus, J. (2015). Student distress in clinical workplace learning: differences in social comparison behaviours. Advances in health sciences education, 20(1), 101-111.

Raat, A. N. J., Kuks, J., \& Cohen-Schotanus, J. (2010). Learning in clinical practice: Stimulating and discouraging response to social comparison. Medical Teacher, 32(11), 899-904.

Renting, N., Dornan, T., Gans, R. O. B., Borleffs, J. C. C., Cohen-Schotanus, J., \& Jaarsma, A. D. C. (2016). What supervisors say in their feedback: construction of CanMEDS roles in workplace settings. Advances in health sciences education, 21(2), 375-387.

Ryan, R. M., \& Deci, E. L. (2000). Self-determination theory and the facilitation of intrinsic motivation, social development, and well-being. American psychologist, 55(1), 68.

Sklansky, D. J., Frohna, J. G., \& Schumacher, D. J. (2017). Learner-driven synthesis of assessment data: engaging and motivating residents in their milestone-based assessments. Medical Science Educator, 27(2), 417-421.

Telio, S., Ajjawi, R., \& Regehr, G. (2015). The "educational alliance" as a framework for reconceptualizing feedback in medical education. Academic Medicine, 90(5), 609-614.

Van der Leeuw, R. M., Teunissen, P. W., \& van der Vleuten, C. P. (2018). Broadening the scope of feedback to promote its relevance to workplace learning. Academic Medicine, 93(4), 556-559.

Voyer, S., Cuncic, C. Butler, D. L., MacNeil, K., Watling, C., \& Hatala, R. (2016). Investigating conditions for meaningful feedback in the context of an evidence-based feedback programme. Medical education, 50(9), 943-954.

Watling, C., LaDonna, K. A., Lingard, L., Voyer, S., \& Hatala, R. (2016). 'Sometimes the work just needs to be done': socio-cultural influences on direct observation in medical training. Medical Education, 50(10), 1054-1064.

Williams, G. C., \& Deci, E. L. (1998). The importance of supporting autonomy in medical education. Annals of internal medicine, 129(4), 303-308.

Williams, G. C., Saizow, R. B., \& Ryan, R. M. (1999). The importance of self-determination theory for medical education. Academic Medicine. 74, 992-995. 


\section{APPENDIX 1: AUDIO DIARY QUESTIONS}

- What did you learn during the past days? Do you have examples?

- Which experience made you discover how far along you are in your development? What did you discover about what you can and cannot do? Do you have examples?

- What feedback did you receive that was important/valuable? What feedback made you discover where you are in your development?

- Did you experience success during the past days? If yes, can you describe this experience?

- Did you have a difficult experience during the past days? If yes, can you describe this experience? 



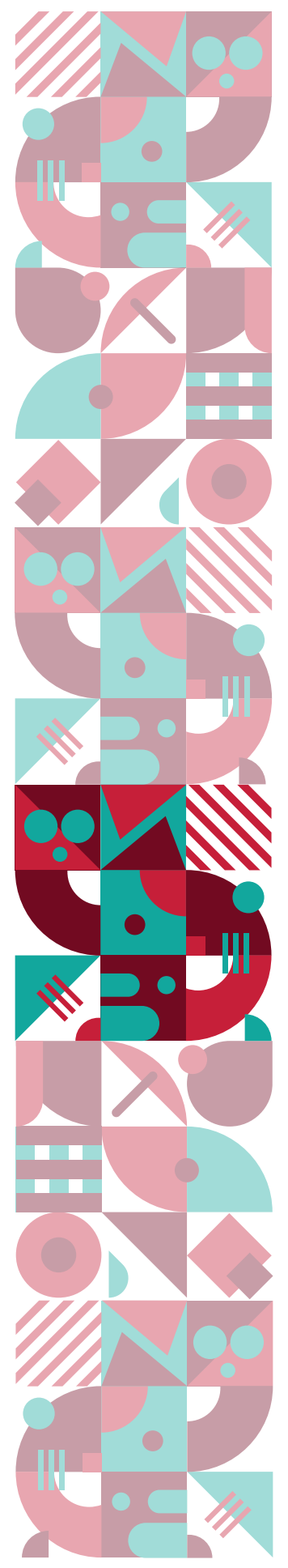

\section{CHAPTER 04}

From aggregation to interpretation: How assessors judge complex data in a competency-based portfolio

Andrea Oudkerk Pool, MSC

Marjan J. B. Govaerts, MD, PhD

A. D. (Debbie) C. Jaarsma, DVM, PhD

Erik W. Driessen, PhD

Published in Advances in Health Sciences Education, 23(2), 275-287. 


\section{ABSTRACT}

While portfolios are increasingly used to assess competence, the validity of such portfolio-based assessments has hitherto remained unconfirmed. The purpose of the present research is therefore to further our understanding of how assessors form judgments when interpreting the complex data included in a competency-based portfolio. Eighteen assessors appraised one of three competency-based mock portfolios while thinking aloud, before taking part in semi-structured interviews. A thematic analysis of the think-aloud protocols and interviews revealed that assessors reached judgments through a 3-phase cyclical cognitive process of acquiring, organizing, and integrating evidence. Upon conclusion of the first cycle, assessors reviewed the remaining portfolio evidence to look for confirming or disconfirming evidence. Assessors were inclined to stick to their initial judgments even when confronted with seemingly disconfirming evidence. Although assessors reached similar final (pass-fail) judgments of students' professional competence, they differed in their information-processing approaches and the reasoning behind their judgments. Differences sprung from assessors' divergent assessment beliefs and performance theories. Assessment beliefs refer to assessors' opinions about what kind of evidence gives the most valuable and trustworthy information about the student's competence, whereas assessors' performance theories concern their conceptualizations of what constitutes professional competence and competent performance. Even when using the same pieces of information, assessors furthermore differed with respect to inferences about the student as a person as well as a (future) professional. Our findings support the notion that assessors' reasoning in judgment and decision-making varies and is guided by their mental models of performance assessment, potentially impacting feedback and the credibility of decisions. Our findings also lend further credence to the assertion that portfolios should be judged by multiple assessors who should, moreover, thoroughly substantiate their judgments. Finally, it is suggested that portfolios be designed in such a way that they facilitate the selection of and navigation through the portfolio evidence. 


\section{INTRODUCTION}

With the rise of competency-based assessment, portfolios are increasingly seen as the linchpin of assessment systems. Although their format and content may differ, generally they all contain reporting on work done, feedback received from peers and faculty, progress made, and goals and plans on how to further improve competence (Harden, 1999).

Worldwide, multiple medical schools have implemented competency-based assessment systems in which the portfolio is key to the assessment of students' achievements (Dornan, 2006; Dornan, Hadfield, Brown, Boshuizen, \& Scherpbier, 2005; Littlewood et al., 2005; Ryan \& Deci, 2000). In these portfolio-based assessment systems, decisions regarding the students' level of competence typically rely on expert judgment. It is assumed that expert judges are able to select, interpret, and integrate relevant evidence in the portfolio, and consequently make a valid decision about a student's competence.

Evidence to support assumptions about assessors' decision-making is rather limited. Although prior research has addressed the question of how assessors develop judgments, the latter concerned judgments based on direct observations (Kogan, Conforti, Bernabeo, Iobst, \& Holmboe, 2011) or single assessments, forgoing the opportunity to investigate how holistic judgments are formed on the basis of complex data collected in the student's portfolio.

Moreover, recent studies on in-training evaluations revealed a discrepancy between what faculty see as important qualities in a future clinician, and the roles defined within competency-based assessment (Ginsburg, Gold, Cavalcanti, Kurabi, \& McDonald-Blumer, 2011; Harden, 1999; Rosenbluth, O’Brien, Asher, \& Cho, 2014). When asked to assess students' level of clinical competence, faculty assigned varying degrees of importance to certain aspects depending on the resident: shortcomings of exceptional students could be discounted while strong attributes of weaker students were overlooked (Ginsburg, Mcllroy, Oulanova, Eva, \& Regehr, 2010). Besides, some constructs that were of importance in the considerations of assessors were not even competencies at all. For example, assessors attached great importance to how the student affected the supervisor (coined 'impact on staff'). Hence, there seems to be a mismatch between the content of competency frameworks and the aspects that clinicians consider important.

Previous research on portfolio assessment in, for instance, teacher education has furthermore demonstrated that even assessors who hold a shared vision of effective teaching and who cite much the same evidence can, nonetheless, develop significantly different 'stories' or interpretive summaries of performance (Swing, 2007).

These aforementioned research findings and increasing importance of portfolio-based assessments (Senko, Hulleman, \& Harackiewicz, 2011) call for an exploration of assessors' 
information processing when interpreting and valuing complex competence data in a portfolio. The purpose of the present study is therefore to explore assessors' judgment and decision-making processes when interpreting evidence from various sources and multiple performance data in a competency-based portfolio. Findings may improve portfolio-based assessment practices.

\section{METHODOLOGY}

\section{Setting}

The research was set in the Master's in Medicine (MiM) program of Maastricht University, the Netherlands. The MiM curriculum spans a 3-year period following the bachelor's in Medicine. It consists of clerkships, a research project, and electives. The curriculum has been designed according to the principles of competency-based education and assessment, using the CanMEDS framework as overarching assessment framework (Frank \& Danoff, 2007). Competency-based assessment is supported by a web-based portfolio system in which students collect and reflect on evidence of their learning and development in each of the competency domains (Littlewood et al., 2005). Every student is assigned a mentor who monitors the student's competency development by guiding the student in his or her self-assessments and reflections, and in setting learning goals. Mentor and student meet three to four times per year, during which the mentor discusses the competency development and portfolio with the student. At a specific point in time the mentor must also assess the student's competency development and send an advisory judgment to the portfolio assessment committee which makes a formal pass-fail decision.

\section{Participants}

We purposefully selected 18 mentor-assessors using maximum variation sampling (Charmaz, 2006). To maximize variation in assessors' medical backgrounds, we selected assessors from different medical specialties (Family Medicine and surgical as well as non-surgical specialties). All these participants had experience of the portfolio system and had received training which included instructions on how to use and assess the portfolio. Participants did not receive any additional training for this study. 


\section{Student portfolio}

For the purpose of this study, the research team (consisting of a psychologist, two educationalists and a veterinarian) developed three mock portfolios representing three different student profiles, each reflecting varying levels of competency achievement. In our student profiles we chose to make a distinction between de medical expert competency and other competencies because previous research has shown that assessors have difficulty assessing the non-medical expert competencies (Whitehead, Kuper, Hodges, \& Ellaway, 2015). Furthermore we included a student profile containing predominantly positive narratives and qualifications in all competency domains because this resembles the profile of a large portion of students. By manipulating the competency data, we created the following portfolios and ensuing student profiles: portfolio A) predominantly positive feedback in the medical expert domain, but both critical and positive feedback in the domains of manager and communicator; portfolio B) both critical and positive feedback in the domain of medical expert, but predominantly positive feedback on the other competencies; and portfolio C) predominantly positive feedback in all domains.

The portfolios contained evidence on a student's competencies collected during a single 18-week clinical rotation, including student's self-assessments, workplace-based assessments (mini-CEXs, DOPSs, field notes, multi-source feedback), progress test results, and a curriculum vitae. Each portfolio comprised narrative feedback, competency ratings and qualifications (i.e., insufficient, sufficient, and good) as well as test results pertaining to each of the individual CanMEDS competencies. Figure 1 provides a print screen of the online portfolio environment used for this study.

Two recent medical graduates provided feedback on the first portfolio drafts. We also invited three assessors to take part in a dry run prior to data collection, to ensure that the information and instructions were clear, and the portfolio versions were authentic, and fit for the study purpose. On the basis of these dry runs and student feedback, we made some adaptations to the portfolios and constructed the final portfolios.

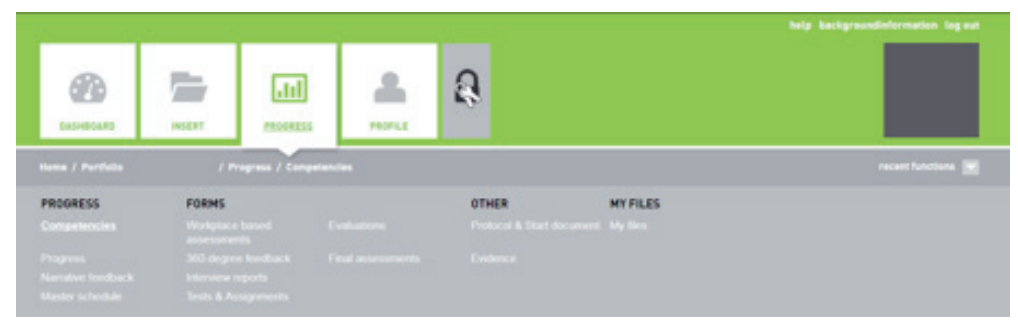

Figure 1. Print screen of the content and organization of the digital portfolio environment used in this study. The portfolio is organized according to the CanMEDS competencies. 


\section{Ethical approval}

We obtained ethical approval from the Ethical Review Board of the Netherlands Association for Medical Education (ERB-NVMO file number 474).

\section{Data collection and analysis}

Data were collected between October, 2015 and January, 2016.

We invited twenty-four mentor-assessors via e-mail to participate and obtained their consent prior to participation. Eighteen assessors responded to our invitation. Each assessor was presented one of the three portfolio versions, each portfolio versions was therefore assessed by six assessors. Assessors were instructed to carefully read it and provide a holistic judgment of the student's overall professional competence by rating it as 'insufficient,' 'sufficient,' or 'good.' Although assessors were allowed to comment on individual competencies, they did not need to rate each competency domain separately. We did not instruct assessors on how to evaluate the portfolio; they were free to read or skip any portfolio evidence as they deemed appropriate.

To capture assessors' cognitive processing during portfolio evaluation, we employed the think-aloud method (Van Someren, Barnard, \& Sandberg, 1994), which means that we instructed assessors to verbalize all their thoughts, ideas, and decisions while reading and evaluating the portfolio. If they fell silent for more than a few seconds, we reminded them to keep verbalizing their thoughts.

When the assessors indicated that they had finished reviewing the portfolio, we conducted a short, semi-structured interview. The first question was to provide a holistic judgment of the student's competence based on what assessors had found in the student's portfolio. Additional questions were aimed at encouraging the assessor to reflect on the portfolio assessment process (e.g., did the portfolio provide sufficient information to make a judgment? Did you notice anything unusual about the portfolio?).

All sessions were audiotaped and transcribed verbatim.

In the next phase, we performed a thematic analysis of the think-aloud and interview transcripts (Fereday \& Muir-Cochrane, 2006). The first author (A.O.P) read the first three transcripts and developed an initial coding manual, on the basis of which a research assistant (C.N.) then coded the same transcripts again. Subsequently, A.O.P. and C.N. compared their results and further refined the coding scheme. After the first seven transcripts were coded, research team members A.O.P., M.G., E.D., and D.J. identified initial patterns by clustering individual codes into broader themes. A.O.P. and C.N. applied the new coding manual to interviews 8 to 15 . The coding manual that ensued was consequently discussed with the entire research team (A.O.P., M.G., E.D., D.J., and C.N.). Theoretical saturation (Dornan et al., 2005) was reached after transcript 12 . To make sure that no relevant information had been missed, 
A.O.P. and C.N. reread all transcripts. Finally, an analysis and coding of transcripts 16,17 , and 18 confirmed the final themes, from where we moved to making a tentative interpretation of how assessors judge a student's professional competence based on aggregated data collated in a competency-based portfolio.

\section{RESULTS}

We observed that assessors went through a similar process of selecting and interpreting portfolio evidence, while we also noted variations in assessors' approaches to reaching a judgment. In the next sections we will first describe this shared process and then assessors' divergent approaches, followed by three explanations for this variance as inferred from the data.

\section{Assessors' information processing: a 3-phase cyclical process}

In processing information, all assessors followed a similar cyclical pattern of acquiring, organizing, and integrating information, respectively. During the first phase, assessors selected the information they considered the most important and credible pieces of evidence upon which to base their judgment. After reviewing this information, they defined if and how it contributed to an informed judgment about aspects of student's competence. Assessors subsequently weighed the various sources of evidence and decided on a (preliminary) judgment of the student's competence.

Upon conclusion of the first round, assessors reviewed the remaining portfolio evidence to look for additional confirming or disconfirming data thereby repeating the information acquisition phase which, in turn, influenced the organization and integration of information. This iterative process was repeated every time the assessor reviewed new portfolio evidence, until assessors felt they had obtained enough information to make a judgment about the student's competence. By comparing different pieces of evidence from multiple sources, assessors gradually came to recognize patterns in the student's competence.

A salient finding, moreover, was that assessors were inclined to stick to their initial judgments even when confronted with seemingly disconfirming evidence: Although their final judgments were, indeed, more elaborate and detailed compared to their preliminary judgments, they were not substantially different from their initial judgments. Differences between student profiles did not seem to affect the judgment process or assessors' overall judgment of the student's competence: Most assessors rated the students' competence as sufficient. 


\section{Assessors' idiosyncratic approaches to the student evaluation}

Analysis of the think-aloud protocols revealed that, from the onset of the judgment process, assessors relied on different kinds of portfolio evidence to inform their judgment. Likewise, the amount of portfolio evidence assessors took into account to arrive at decisions about student competence exhibited between-assessor differences: While some assessors read the entire portfolio before providing their final judgment, others mainly relied on either the student's selfevaluation or workplace-based assessment data to inform their judgment, largely ignoring additional portfolio evidence.

These divergent approaches were rooted in assessors' varying assessment beliefs, performance theories (i.e., conceptualizations of what constitutes performance effectiveness and professional competence), and inferences. As a result, assessors' reasoning behind their judgments and judgments of individual competencies were strongly governed by their unique personal profiles and differed accordingly. The following paragraphs will discuss each of these three inter-assessor differences in more detail.

\section{Differences in what assessors believed to be credible portfolio evidence}

First it should be noted that assessors mainly relied on narrative feedback to inform their judgment, because this provided meaningful and detailed information about the student's development, strengths and weaknesses, as well as specific suggestions for improvement as provided by others. Grades and qualifications were merely used to confirm impressions based on narratives. For example, if assessors suspected insufficient competence within the medical expert competence domain, they would purposefully select those workplace-based assessments for which the student had received an insufficient score because this would probably provide more insight into the reasons for their underperformance.

Despite this commonality, assessors had varying assessment beliefs about what kind of narrative evidence gave the most valuable and credible information about the student's competence.

Assessors, for instance, chose different pieces of narrative evidence to start their evaluation: Some selected narrative comments on workplace-based assessments, believing that these would generate the most authentic evidence of students' abilities; Other, however, started reading the student's self-evaluations and reflective writings as they assumed these would contain reference to salient feedback comments and assessment forms which they consequently read to check if the student's claims were justifiable.

The source also appeared to matter in deciding on the credibility of evidence: Some assessors mainly relied on feedback from physicians because they perceived them as content experts most 
likely to provide accurate and meaningful feedback on student competence; Others, in contrast, preferred feedback from fellow students and nurses who, they presumed, had worked more closely with students and therefore had more opportunities to directly observe them.

Between-assessor differences in source preferences also stemmed from assessors' frames of reference and the presumed impact of student-supervisor relationships. During the interviews, for instance, multiple assessors expressed their belief that student's progress could be established more reliably when the student had received feedback from the same person at different points in time, especially since they found it hard to interpret fragmented and divergent feedback:

"At least in my department we try as much as possible to match the interns with one staff member. And also strictly have this person assess presentations and CATs [Critical Appraisals of a Topic] and those sort of things. What you clearly see then, is a pattern and that actually became much less evident from those mini-CEX assessments." (Assessor 4)

At the same time, other assessors did value the input from multiple assessors, which they estimated to be more reliable and more informative compared to single-person feedback. In explaining their preferences, several assessors invoked perceptions of selection bias (i.e., students purposively selecting more lenient assessors to provide feedback) and feedback providers' reluctance to write down negative comments so as to avoid conflicts:

"As a student, in our department at least, you can be quite selective in who you ask [...]

So you yourself can choose to team up with your buddies and they give you positive feedback. But in the case of such a 360-degree assessment. That is very comprehensive. And anonymous. And that is, that does give you, I think, the most truthful answers." (Assessor 11)

Finally, the assessment data in the portfolio also induced different impressions about the quality of supervision. When a supervisor, for instance, failed to provide detailed written feedback, several assessors assumed that the supervisor had probably written down the essential comments and had provided more elaborate feedback verbally. Others, however, believed that the student had gone unobserved and therefore questioned the credibility of the supervisors' assessments.

\section{Differences in interpretations of what constitutes 'competence'}

We also observed inconsistencies between assessors' conceptualizations of 'competence'. As a result of these variable interpretations of what constitutes competence, assessors thought 
differently about what they needed to know about the student to be able to form a judgment. Interestingly, these so-called 'performance theories' tended to deviate from the formal assessment criteria. In the following we will outline the performance theories that prevailed.

One group of assessors defined students' competence in terms of the extent to which they actively engaged in their own learning process and effectively used feedback for competence improvement. More specifically, they considered active engagement in learning and assessment a key quality of a good student. Hence, to establish growth, they often read the portfolio evidence in chronological order to check if aspects that did not go well in the beginning of the clinical rotation had improved over time. In the same fashion, they screened the workplace-based assessments and feedback to verify whether the student had followed-up on all the aspects that needed to improve. In their perusal, they also included the student's self-assessment and learning goals as they felt that it was vital to know if students did follow up on learning goals and appointments. According to this group of assessors, the student's competence did not necessarily have to be up to standard as long as there was enough evidence that the student had sufficiently improved over time and actively tried to improve:

"What I expect the student to do is to make a strengths/weaknesses analysis of the competencies before the internship, a plan of action, like "how am I going to pay attention to that analysis, those strong points?". In the interim or final assessment an answer to those questions, "Did I accomplish that? Did I live up to that? And why not?" And "What is my assessment of myself when I look at myself, am I satisfied and have I mastered that competency to the level I aimed for?" (Assessor 14)

Other assessors measured students' level of competence by their ability to reflect on their own competencies. Consequently, they started by reviewing the student's self-reflections, considering it a no-no when a student was not aware of his or her competence in one or more areas:

"Because I think it is really very good if a person has self-knowledge about his own weaknesses. I appreciate that a lot, because that is where it all starts. When you yourself want to improve. When other people feel that you have weaknesses in a given competency and you yourself disagree, I think that is - that is a scary person." (Assessor 11)

A final distinction we found between assessors' interpretations of 'competence' was reflected in the way they weighted and valued the various CanMEDS competency domains in the portfolio. While most assessors, regardless of portfolio version, specifically targeted 'medical expert', 'manager', and 'communicator' competencies and scanned the remaining competencies, others sought to bring into focus the full range of competencies. This latter tactic allowed them to differentiate between students, as collecting valuable feedback on the less well defined competencies 
(e.g., health advocate or scholar) is quite a challenge for students. Hence, students who were able to do so and reflected on this evidence were considered to be above average and eager to learn:

"[....] in the domain of health advocate, for example, if someone already understands that there is more to being a health advocate than just, well, repeating to someone that he should quit smoking. Who also identifies where those problems - those difficult situations are in the workplace. Well, that's where I see an above-average person [...] Well, of all students, I think, the above-average ones know what to fill out under 'scholar,' 'professional,' and 'health advocate,' under those less obvious [competencies] that is." (Assessor 7)

\section{Differences in how assessors construed the portfolio evidence}

Throughout the entire judgment process assessors lent their own meanings to the evidence included in the portfolio, leading to different inferences about the student's competence and attitude. More specifically, based on the same pieces of information assessors drew different conclusions, for instance about students' responsibility for their competence and achievement: An insufficient rating on a workplace-based assessment of a specific student, was construed by one assessor as the result of a lack of knowledge, while another attributed it to insecurity. Conversely, sufficient ratings over a prolonged period of time were construed as underperformance by some, since they had learned from experience as an assessor and supervisor that written assessments were generally on the positive side be as supervisors eschew failing a student:

"And then I realize how hard it is to deliver that emphatic 'insufficient.' You are inclined to soften the blow for that person and then it is very difficult to give a one' or a two, so you give a three. And that is why I am cautious when someone only scores threes. Really, because those threes could also be taken to mean a score of one to three, instead of a three." (Assessor 12)

Yet other assessors felt they could not make an accurate interpretation of the assessment feedback in the portfolio without having some background information about the student. These assessors were also interested in the student's extracurricular activities, interests, and hobbies. In an effort to know more about the student's background, some assessors actually commenced their portfolio review by reading the student's curriculum vitae:

"Anyway, the reason why I do that from time to time is that you look, what kind of side jobs did this person have? Is he a member of an association? Is it someone who looks around him? I'd rather have people who travel, play music and sports, look around them, speak foreign languages, read three newspapers, and pass by the narrowest margin. Than someone who receives outstanding grades but does not leave his room, you see? Then it is 
not about what I want, but it is about, I just want to have the full picture of such a person." (Assessor 9)

The above-named different interpretations of performance data led to varying inferences about a student's performance and to equally dissimilar judgments about specific components in the competency framework. Although we described each of the three inter-assessor differences separately, they actually acted in concert to mediate assessor's decision-making process. When reading portfolio $\mathrm{A}$, for instance, assessor 1 attached great importance to the 'medical expert' role and therefore specifically looked for all portfolio evidence about this competency. Consequently, this assessor believed that the most reliable information about this competence came from doctors and could be found in the workplace-based assessments. In the end, the assessor inferred that the student's competence was problematic since the student lacked competence in the medical expert domain. Assessor 2, however, who read the same portfolio, was more interested in determining the student's progress. This assessor believed that by reading the comments in the multisource feedback he would be able to do so, because this feedback contained opinions of multiple people about the student's competence over a longer period of time. Although acknowledging that the student should pay attention to the medical expert competency, the assessor was not concerned because the student had improved considerably during the clinical rotation.

\section{DISCUSSION}

The present study has sought to enhance our understanding of how assessors form judgments of students' professional competence based on the evidence collated in a competency-based portfolio.

Our findings suggest that assessors' information processing is characterized by iterative phases of acquiring, organizing and integrating information. Previous research on rater cognition has found similar phases (Fernandez et al., 2012). Although all assessors had their unique approaches, as evidenced by differences in their credibility judgments, performance theories, and inferences, they eventually reached the same overall judgments. This finding is consistent with research by Gingerich, van der Vleuten, Eva, and Regehr (2014) who investigated what proportion of variance in physicians' mini-CEX ratings could be attributed to physicians' development of one of a few distinct social impressions about the resident: While raters provided different causal explanations for their judgment, subgroups of raters were making similar judgments.

We also found that assessors' selection of evidence and the extent to which they let this evidence influence their judgment were strongly governed by their beliefs about the credibility of the portfolio evidence. This judgment of credibility is not exclusive to assessors, as it resulted from a study by Lang, Mooney, O’Connor, Bordley, and Lurie (2009) who asked students to reflect on 
experiences that had influenced their learning. When confronted with feedback, students judged the credibility of this feedback in order to decide which information they would use to inform their development. As with the assessors, the source of feedback played an important role in their credibility judgment. When students, for example, respected the individual for his or her clinical competence, they would more readily accept the feedback. Despite some research suggesting that people eschew providing non-anonymous feedback on a student's underperformance for fear that it will affect their working relationship (O’Brien, Cooke, \& Irby, 2007; Teo, Harleman, O’Sullivan, \& Maa, 2011), both research by Lang et al. (2009) and the present research demonstrate that it is vital to know the feedback source in order to be able to assess the information's credibility.

Our findings also revealed that assessors held different performance theories which guided their beliefs about what they needed to know about a student to be able to make a well-informed decision. Confirming previous research where decision-making was based on direct observations (Ginsburg et al., 2010), the assessors in our study also based their judgments on aspects (such as student progress and self-reflections) that were external to the competency framework providing the portfolio structure.

Judgments based on direct observations inherently involve automatic decision-making processes. It has been demonstrated that automatic decision-making processes involving the categorization of people could lead to conversion errors and assessors' inability to differentiate between competencies (Moonen-van Loon, Overeem, Donkers, Van der Vleuten, \& Driessen, 2013; ten Cate, Kusurkar, \& Williams, 2011). Furthermore, automatic decision-making involves the use of heuristic techniques used to speed up the process of finding a satisfactory, though possibly not optimal, solution. If similar decision-making problems have often been faced earlier, decision makers tend to use readily available strategies to arrive at a decision more easily (Kane, 1992). In our study, various automatic processes including use of heuristics seemed to play a role in assessors' decision-making as well. Assessors, for example, automatically favored particular feedback sources. Furthermore, their inferences were shaped by previous experiences: Assessors automatically assigned causal explanations to portfolio evidence based on earlier experiences with similar students. Although these automatic decision-making processes influenced the judgment process and caused differences in assessors' reasoning behind their evaluations, assessors experienced no difficulty assessing the students' competence. What's more, their final overall assessments were in harmony, despite the differences caused by automatic decision-making processes.

In a previous study, Littlewood et al. (2005) tested the separate and composite reliability of three workplace-based assessment tools (mini-CEX, DOPS, and MSF) included in a resident portfolio. They demonstrated that, from a psychometric perspective, combining several workplace-based assessment tools in a portfolio can be a feasible and reliable method for high-stakes judgments. In addition to confirming these findings, our study suggests that, next to various types of workplace-based assessments and performance evaluations, including self-assessments and 
reflective writing in the portfolio adds information that is meaningful and important to assessors. Apparently, self-assessments and reflective writings provide assessors with information that cannot be inferred from workplace-based assessments. Another important contribution of our study is the observation that assessors feel need to contextualize the assessment by obtaining and interpreting more general information about the student's background.

\section{Limitations}

Several limitations are worthy of mention. First, we conducted this research at Maastricht University where a specific portfolio is used. Since portfolios differ substantially in content and format, it is advised that this study be replicated in other settings where different portfolio types are used.

Next, the think-aloud procedure inherently harbors a limitation in that various thought processes cannot be verbalized because they are either automatic or happen so quickly that there is no time to verbalize them (Dijksterhuis, Schuwirth, Braat, Teunissen, \& Scheele, 2013). Although the participants' verbalizations seem coherent and complete, it should be taken into account that we might have not captured all thought processes. Furthermore, using think-aloud procedures has the risk of participants creating explanations to satisfy the researcher rather than reporting their actual thought processes. However, in addition to the think-aloud procedure, we also conducted semi-structured interviews in which participants were asked about the reasons why they made particular decisions. Also, theoretical saturation was reached after 12 participants indicating that important common aspects of participants' decision-making are captured.

Third, the assessors in our study were not used to evaluating the student's competence based on portfolio evidence alone: Usually, they also knew the student personally and had regular face-toface meetings with the student. Although assessors did mention they missed this personal contact, they indicated to feel able to provide a judgment based solely on the portfolio evidence. This practice of providing judgments based exclusively on portfolio evidence, moreover, ties in with the idea that reviewers who take care of the summative portfolio assessment should not be the same as those providing the formative assessment. In this way the confidentiality of personal reflections is not compromised by the rigor and judgments necessary for making promotion decisions (Lang et al., 2009). Findings from our research thus suggest that it is feasible to separate both roles.

\section{Practical implications}

This study reiterates the importance of assessors explaining their judgments about students' competence. Differences between assessors' explanations suggest that decisions should not be made individually, but should result from group discussions. Although multiple assessors may 
reach the same general judgment about a student's competence, they do differ in their judgments of individual competencies and the reasoning behind their overall judgments.

Also, discussing judgment policies of other assessors will make assessors aware of the fact that their method of assessment is not universally shared. It will help them to become acquainted with other views of competence and portfolio interpretation. This enables assessors to incorporate assessment practices of other assessors into their own assessment process, and to build 'shared mental models' for competence assessment.

Our findings suggest implications for assessor training. Assessor training should focus on raising assessors' awareness of their own beliefs, performance theories, and inferences. If they gain more insight into their own decision-making process and get acquainted with those of other assessors their decision-making may improve. Furthermore, training should focus on the effect of group member composition and group processes on the decision-making processes as described by Macrae and Bodenhausen (2000).

Furthermore, since assessors have different approaches to the selection and use of portfolio evidence, it is important that portfolios be designed in such a way that they facilitate the selection of and navigation through the portfolio evidence. Captions are important as well, for they summarize the context in which the competency feedback was provided to the student (Driessen, 2017), helping assessors interpret the evidence and decide if and how they want to use it for their judgment.

\section{Conclusion}

The present study described the process whereby assessors reach judgments, when reviewing the evidence collated in a competency-based portfolio. Assessors were able to form a judgment based on the portfolio evidence alone. Although they reached the same overall judgments, they differed in the way they processed the evidence and in the reasoning behind their judgments. Differences sprung from assessors' divergent assessment beliefs, performance theories, and inferences acting in concert. These findings support the notion that portfolios should be judged by multiple assessors who should, moreover, thoroughly substantiate their judgments. Also, assessors should receive training that provides insight into factors influencing their own decision-making process and group decisions. Finally, it was proposed that portfolios be designed in such a way that they facilitate the selection of and navigation through the portfolio evidence.

\section{Notes}

1 On a mini-CEX form, performance in each competency area is scored on a scale from one (failure) to five (excellent). 


\section{REFERENCES}

Bowen, G. A. (2008). Naturalistic inquiry and the saturation concept: A research note. Qualitative Research, 8(1), 137-152.

Castanelli, D., \& Kitto, S. (2011). Perceptions, attitudes, and beliefs of staff anaesthetists related to multisource feedback used for their performance appraisal. British Journal of Anaesthesia, 107(3), 372-377. doi:

Charters, E. (2003). The use of think-aloud methods in qualitative research an introduction to think-aloud methods. Brock Education Journal, 12(2), 68-82.

Dannefer, E. F., \& Henson, L. C. (2007). The portfolio approach to competency-based assessment at the Cleveland Clinic Lerner College of Medicine. Academic Medicine, 82(5), 493-502.

Davis, M., Ben-David, M. F., Harden, R., Howie, P., Ker, J., McGhee, C., et al. (2001). Portfolio assessment in medical students' final examinations. Medical Teacher, 23(4), 357-366.

Driessen, E. (2016). Do portfolios have a future? Advances in Health Sciences Education, 22(1), 221-228. doi: 10.1007/s10459-016-9679-4.

Driessen, E., Van Tartwijk, J., Van Der Vleuten, C., \& Wass, V. (2007). Portfolios in medical education: Why do they meet with mixed success? A systematic review. Medical Education, 41(12), 1224-1233.

Fereday, J., \& Muir-Cochrane, E. (2006). Demonstrating rigor using thematic analysis: A hybrid approach of inductive and deductive coding and theme development. International Journal of Qualitative Methods, 5(1), 80-92.

Frank, J. R., \& Danoff, D. (2007). The CanMEDS initiative: Implementing an outcomes-based framework of physician competencies. Medical Teacher, 29(7), 642-647. doi: 10.1080/01421590701746983.

Gauthier, G., St-Onge, C., \& Tavares, W. (2016). Rater cognition: Review and integration of research findings. Medical Education, 50(5), 511-522.

Gingerich, A., van der Vleuten, C. P. M., Eva, K. W., \& Regehr, G. (2014). More consensus than idiosyncrasy: Categorizing social judgments to examine variability in Mini-CEX ratings. Academic Medicine, 89(11), $1510-1519$.

Ginsburg, S., Gold, W., Cavalcanti, R. B., Kurabi, B., \& McDonald-Blumer, H. (2011). Competencies "plus": The nature of written comments on internal medicine residents' evaluation forms. Academic Medicine, 86(10), S30-S34.

Ginsburg, S., McIlroy, J., Oulanova, O., Eva, K., \& Regehr, G. (2010). Toward authentic clinical evaluation: Pitfalls in the pursuit of competency. Academic Medicine, 85(5), 780-786.

Hauer, K. E., Cate, O. T., Boscardin, C. K., Iobst, W., Holmboe, E. S., Chesluk, B., et al. (2016). Ensuring resident competence: A narrative review of the literature on group decision making to inform the work of clinical competency committees. Journal of Graduate Medical Education, 8(2), $156-164$.

Ingram, J. R., Anderson, E. J., \& Pugsley, L. (2013). Difficulty giving feedback on underperformance undermines the educational value of multi-source feedback. Medical Teacher, 35(10), 838-846.

Kogan, J. R., Conforti, L., Bernabeo, E., Iobst, W., \& Holmboe, E. (2011). Opening the black box of clinical skills assessment via observation: A conceptual model. Medical Education, 45(10), 1048-1060.

Kolars, J. C., Mcdonald, F. S., Subhiyah, R. G., \& Edson, R. S. (2003). Knowledge base evaluation of medicine residents on the gastroenterology service: Implications for competency assessments by faculty. Clinical Gastroenterology and Hepatology, 1(1), 64-68.

Macrae, C. N., \& Bodenhausen, G. V. (2000). Social cognition: Thinking categorically about others. Annual Review of Psychology, 51(1), 93-120. 
Moonen-van Loon, J., Overeem, K., Donkers, H., Van der Vleuten, C., \& Driessen, E. (2013). Composite reliability of a workplace-based assessment toolbox for postgraduate medical education. Advances in Health Sciences Education, 18(5), 1087-1102.

Patton, M. Q. (1990). Qualitative evaluation and research methods. Thousand Oaks: SAGE Publications Inc.

Renting, N., Dornan, T., Gans, R. O., Borleffs, J. C., Cohen-Schotanus, J., \& Jaarsma, A. D. C. (2016). What supervisors say in their feedback: Construction of CanMEDS roles in workplace settings. Advances in Health Sciences Education, 21(2), 375-387.

Rosenbluth, G., O’Brien, B., Asher, E. M., \& Cho, C. S. (2014). The “Zing Factor”-How do faculty describe the best pediatrics residents? Journal of Graduate Medical Education, 6(1), 106-111. doi: 10.4300/JGME-D-13-00146.1

Schutz, A., \& Moss, P. (2004). Reasonable decisions in portfolio assessment. Educational Policy Analysis Archives, 12(33), n33.

Smith, S. R., Dollase, R. H., \& Boss, J. A. (2003). Assessing students' performances in a competency-based curriculum. Academic Medicine, 78(1), 97-107.

Tversky, A., \& Kahneman, D. (1975). Judgment under uncertainty: Heuristics and biases. In D. Wendt \& C. Vlek (Eds.), Utility, probability, and human decision making. Theory and decision library (An International series in the philosophy and methodology of the social and behavioral sciences) (Vol. 11). Dordrecht: Springer.

Van Someren, M. W., Barnard, Y. F., \& Sandberg, J. A. C. (1994). The think aloud method: A practical guide to modelling cognitive processes (Vol. 2). London: Academic Press.

Van Tartwijk, J., \& Driessen, E. W. (2009). Portfolios for assessment and learning: AMEE Guide no. 45. Medical Teacher, 31(9), 790-801.

Watling, C., Driessen, E., van der Vleuten, C. P., \& Lingard, L. (2012). Learning from clinical work: The roles of learning cues and credibility judgements. Medical Education, 46(2), 192-200.

Whitehead, C. R., Kuper, A., Hodges, B., \& Ellaway, R. (2015). Conceptual and practical challenges in the assessment of physician competencies. Medical Teacher, 37(3), 245-251. doi: 10.3109/0142159X.2014.993599. 



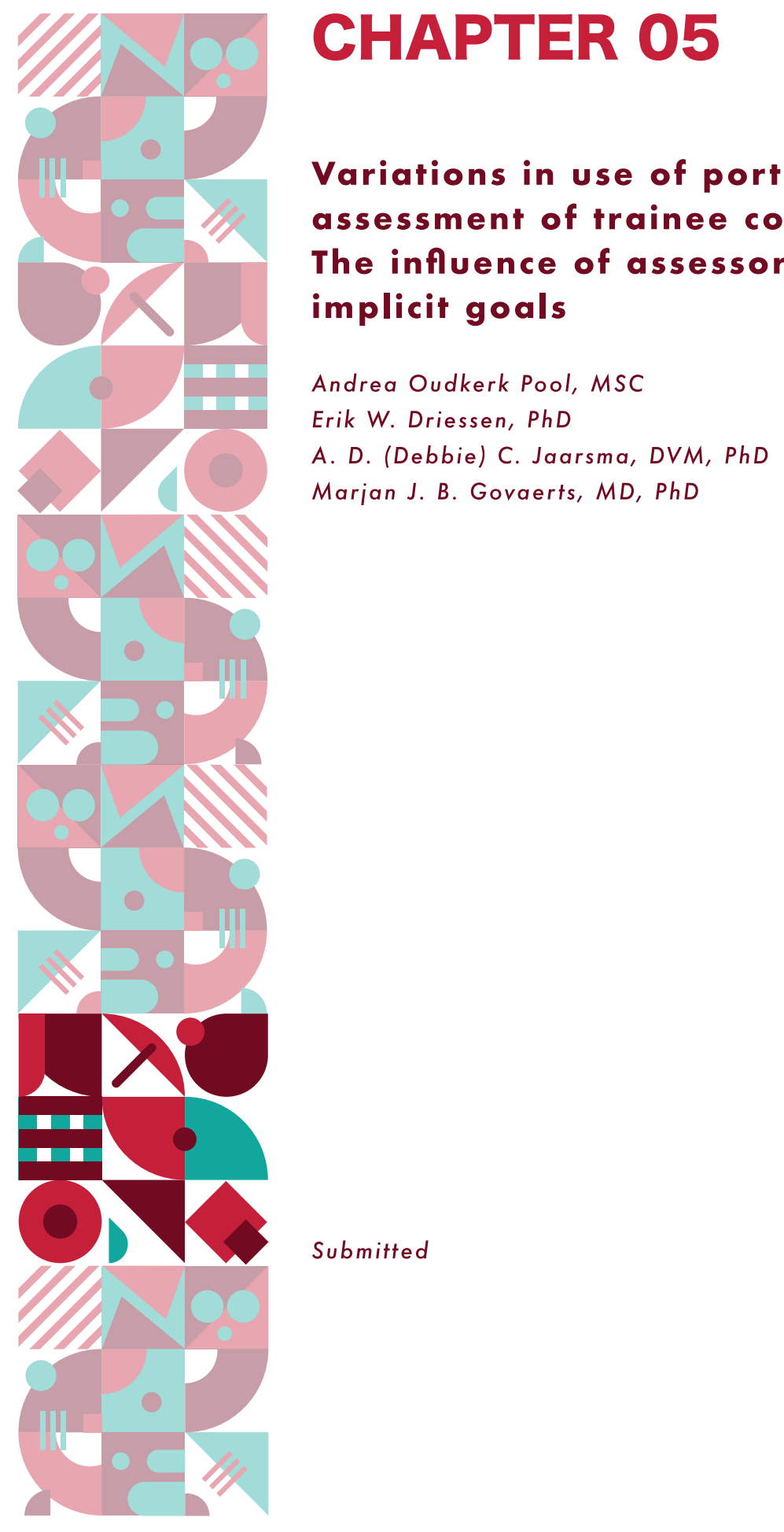




\section{ABSTRACT}

With the rise of competency-based medical education, assessment of students' learning and competence development is increasingly portfolio-based.

The purpose of the present study is to explore how daily supervisors in clinical settings and decision makers (i.e. independent portfolio assessors or members of Clinical Competency Committees) develop a judgment on student performance and how they use the portfolio in judgment and decision-making. Daily supervisors of ten students assessed their performance during an 18-week scheduled clinical rotation. At the end of the rotation, supervisors were asked to provide a narrative describing the student's performance. Subsequently, independent portfolio assessors were asked to review the evidence in the student's portfolio and develop a narrative on student performance. Both daily supervisors and independent assessors were interviewed to explain their reasoning in judgment and decision-making. Supervisors' and assessors' assessments and assessment approaches were compared using both within-case and cross-case analysis. Although supervisors and assessors developed the same overall judgment of students' performance (e.g. poor, average, exceptional), their approaches to judgment and decision making did differ. Differing implicit assessment goals caused them to use different performance information to judge and make decisions about a student's competence. Supervisors aimed to establish students' fitness to provide health care whereas portfolio assessors wanted to determine student's progress in relevant competency domains and self-directed learning. Assessors' roles thus influenced their use of portfolio evidence as well as the story they built of student's performance. Efforts should be made to improve the assessment processes of both supervisors and assessors. However, both should be involved in the assessment of learners as their assessments are complementary and valuable to inform student's learning. 


\section{INTRODUCTION}

The introduction of competency-based medical education (CBME) has changed the way in which students' performance is assessed. The assessment of students' learning and competence development has become increasingly portfolio-based. In order to enable trustworthy decisionmaking about the students' achievements, the evidence uploaded to the portfolio (e.g. performance evaluations) must represent a valid picture of the students' competence across all competency domains.

To this end, student's performance in workplace settings is regularly evaluated and documented to monitor progression towards performance standards and to support student learning (Carraccio et al., 2016; Holmboe et al., 2011). In general, these performance assessments are captured in various workplace-based assessments (WBAs), such as global ratings of student performance, multiple source feedback, and mini-CEXs, and preferably based on input from multiple sources and across multiple tasks and contexts (Holmboe, 2015). With the rise of CBME, and of related programmatic assessment approaches in particular, judgments on students' performance and competence development are increasingly made by independent assessors, for example members of clinical competency committees (CCCs) (Bok et al., 2013; Driessen, Van Tartwijk, Govaerts, Teunissen, \& van der Vleuten, 2012). Typically, these examiners do not know the students, and therefore they have to rely on the evidence collected in the students' portfolio (Driessen et al., 2012; Lang, Mooney, O’Connor, Bordley, \& Lurie, 2009). Research findings, however, suggest that collecting meaningful assessment data in a portfolio is difficult, especially in workplace settings. Due to time constraints faculty struggle to document feedback, potentially decreasing portfolio quality (Madan, Conn, Dubo, Voore, \& Wiesenfeld, 2012; Watling, LaDonna, Lingard, Voyer, \& Hatala, 2016). Moreover, faculty are reluctant to document negative narrative feedback (Hatala \& Norman, 1999). As a consequence, questions can be raised about the validity (i.e. defensibility) of portfolio-based high-stakes assessments and high-stakes decisions in particular.

Although the roles of daily supervisors and CCC members are different, as assessors they are both expected to use the portfolio when interpreting and valuing performance data in order to assess a student's competence level over a certain period of time. We do not know if and how differences in role enactment influence supervisors' and CCC members' judgment and decisionmaking process, and use of portfolio in particular. Gaining more insight into how different assessor groups (e.g. daily supervisors and independent portfolio assessors) execute and interpret their assessment task can enhance our understanding of assessment in the CBME context as well as improve the utility of portfolio within CBME.

The purpose of this study was therefore to explore how the different assessor groups develop a judgment on student performance and how they use the portfolio in judgment and decision-making. 


\section{METHODS}

\section{Setting}

Our study was set in the Master in Medicine (MiM) program of Maastricht University, the Netherlands. This three-year curriculum has been designed according to the principles of competency-based education and assessment, using the CanMEDS framework as overarching assessment framework (Frank \& Danoff, 2007).

The competency-based assessment program is supported by a web-based portfolio system in which students collect and reflect on evidence of their learning and development in each of the competency domains. High stakes decisions about students' progress and achievements are made by a committee of independent examiners (independent portfolio assessors). For this study we used authentic portfolios containing evidence on students' competency development collected during a single 18 -week clinical rotation. The portfolios consisted of students' self-assessments, workplace-based assessments (mini-CEXs, DOPSs, field notes, multi-source feedback), progress test results and reports of progress meetings. Each portfolio included narrative feedback, competency ratings and qualifications (i.e. insufficient, sufficient, and good). Each student was assigned a daily supervisor, who regularly discussed the student's progress with the student during formal and informal meetings throughout the clerkship. Moreover, the supervisor was required to give a final assessment about the student's performance at the end of the clinical clerkship. To inform the assessment, the daily supervisor could use his own experience with the student, feedback from colleagues and evidence collected in the portfolio. To enable trustworthy and defensible decision-making by independent portfolio assessors, however, one would expect all relevant performance information to be present in the portfolio.

\section{Participants}

We approached students who were enrolled in the 18-week clerkship at the time of the study to ask if they consented to the researchers discussing their portfolio and performance with their daily supervisor and an independent portfolio assessor. The principal researcher (AOP) visited the students during several mandatory educational moments at Maastricht University to inform them about the research and ask for their consent. After the students gave their consent, their supervisor and an independent portfolio assessor were contacted by email and were asked to participate.

Ten daily supervisors agreed to participate in this research. They were medical specialists in the surgical or non-surgical specialties. All supervisors had supervised one student during the 18 -week clerkship as described above. Five experienced independent portfolio assessors participated. They did not know the student they had to assess. All inddependent assessors and 
supervisors were familiar with the portfolio system and had received training, which included instructions about how to assess a student's competence using a portfolio.

\section{Procedure}

This research was conducted according to a stepwise procedure, which was identical for each student.

\section{Step 1}

After a student finished his/her rotation, his/her daily supervisor was asked to judge and discuss the student's performance during an interview of 45 to 60 minutes with the principal researcher. The goal of the interview was to gain a better understanding of how the supervisors developed their judgement. For each student, his or her daily supervisor was asked to provide a narrative assessment on the student's performance during the past rotation. Supervisors were then prompted to elaborate on the information they used to arrive at their assessment and how valuable they perceived this information to be for their assessment. After this, the supervisors were provided the opportunity to re-assess the student's portfolio.

\section{Step 2}

Subsequently, an independent portfolio assessor was asked to judge and discuss the student's performance during an interview of 45 to 60 minutes, with the principal researcher. The assessor was asked to review the portfolio evidence and to subsequently provide a narrative assessment on the student's performance during the past rotation. Next, the researcher asked which information the assessor used to arrive at the judgment and decision, and how valuable they regarded this information to be for the assessment.

Each student was assessed by one supervisor and one independent portfolio assessor. All interviews were audiotaped and transcribed verbatim. Data were collected between March and August 2018.

\section{Ethical approval}

Ethical approval was granted by the Ethical Review Board of the Dutch Association for Medical Education (NVMO-ERB reference number 700). 


\section{Data analysis}

All transcripts were analyzed according to a two-step procedure. A within-case analysis was performed to get a detailed understanding of how independent portfolio assessors and daily supervisors arrived at their assessment about a student's performance. Subsequently, a cross-case analysis was performed in order to develop a pattern of explanation and identify similarities and differences in supervisors' and assessors' assessment process (Miles \& Huberman, 1994).

For each student included in the study, a thematic analysis of the supervisors' and assessors' interview transcripts was performed. The first author (AOP) read the supervisor and assessor transcripts concerning three students and developed an initial coding framework using open coding with concepts from previous research on portfolio-based assessment as sensitizing concepts. After the transcripts of seven students transcripts were coded, initial patterns were identified by clustering individual codes into broader themes and specifying relationships between themes. The coding framework that ensued was consequently discussed within the entire research team. Key elements and processes in assessors' judgment and decision-making processes were identified. Based on the thematic analysis, for each student a case report summarizing assessment processes was made for each supervisor and each independent assessor respectively. The summaries of the supervisors' and assessors' assessment processes were enriched with illustrative quotes from the interviews (thick descriptions)(Geertz, 2008).

Following the within-case analysis, the cross-case analysis started with cross-referencing the supervisor and assessor summaries, comparing and contrasting the supervisors' and the independent assessors' assessment approaches (Ayres, Kavanaugh, \& Knafl, 2003). This resulted in the identification of three different key elements in the daily supervisors' and portfolio assessors' assessment processes. The robustness of our claims was strengthened by resolving disagreements and achieving consensus about the interpretation of results within the team (AOP, ED, MG and DJ).

The data analysis was facilitated by means of ATLAS.ti software v1.0.17 for Mac (Scientific Software Development GmbH, Berlin, Germany).

Concerning the influence of the researchers on the construction of the results, we wish to clarify that AOP was not involved in the medical training nor in the assessment. She only had contact with the participants during this study. E.D and M.G. and D.J. contributed expertise in medical education development and research. They have been regularly involved in the implementation of CBME in undergraduate and postgraduate education. None of the authors were involved in the assessment of the students. 


\section{RESULTS}

Comparison of daily supervisors' and independent assessors' narratives showed that, although their overall judgments of each student's performance (e.g. poor, average, exceptional) were similar, their narratives of the student performance did differ. Differences were related to content and scope of the assessments. Moreover, the assessments were based on dissimilar performance information. This was caused by the fact that daily supervisors and portfolio assessors had different implicit goals for assessing students' performance.

Daily supervisors' narratives of the student's performance tended to be less detailed and shorter than assessors' narratives. Especially when they had not worked closely together with the student on a regular basis, supervisors indicated only to have a general impression of the student's performance. Their narrative evaluations mainly contained global descriptions of a student's medical expertise, communication and organization skills and work ethic as important indicators underpinning their performance assessment.

"Such a guy who then - who performs better than average, in particular in his behavior, and I cannot judge the medical knowledge very well because in that respect I did not have enough experience with him, but he gets along very well with everybody. That's very important for us here. And he has the right commitment, he is always present, he is proactive, in short, the general impression is good." (DS_l)

Supervisors mostly referred to feedback from colleagues to substantiate their evaluations. They hardly mentioned the student's perspective (e.g. learning goals or reflections) or references to portfolio evidence.

Similar to the daily supervisors, portfolio assessors also emphasized the student's medical expertise, communication and organizational skills. However, contrary to the daily supervisors, they tried to provide an assessment of the student's performance on all the competency domains included in the CanMEDS framework. Moreover, their narratives were more detailed because they underpinned their assessment with performance evaluations captured in the portfolio. For example, assessors referred to several WBAs to support their judgement about how a student had developed on a specific skill. Portfolio assessors predominantly relied on the narrative evaluations documented in the student's portfolio. As a consequence, their narratives were generally a synthesis of the feedback the student had received and of the student's personal reflections.

"As point of improvement I see in his own notes as well as in those of the daily supervisor, I see that his modesty is mentioned several times. And if you look what they mean by that, then he can, as he himself writes, maybe I have to stand up for myself more in certain moments."(PA_1) 


\section{Performance information seeking behavior}

Daily supervisors' and assessors' assessments differed because both groups relied on different kinds of performance information to inform their assessments.

Supervisors did not use the performance evaluations captured in the student's portfolio to inform their assessment. However, they acknowledged that there were aspects of the students' performance that were captured in the portfolio, but were unknown to the daily supervisor. This mostly related to evidence regarding students' performance on the competencies of Scholar, Professional and Health Advocate. Supervisors predominantly relied on personal experiences with the student and informal feedback from colleagues (i.e. staff members and residents). However, they mentioned that they had to trust feedback from their colleagues because their own high workload prevented them from working together with their students on a regular basis. Therefore, colleagues were expected to observe and assess the students and share their judgments. Supervisors however rarely asked their colleagues supplementary questions concerning specific aspects of the student's performance because they believed that if there was something worth knowing, they would be told without asking:

"My staff members are competent enough, if there is a specific aspect that they don't like, they will tell me [...]" (DS_7)

Additionally, supervisors acknowledged that there were particular colleagues who had a more accurate impression of the student's performance because they had worked together more closely. As a consequence, supervisors attached great importance to that particular source of feedback, as this helped them to interpret the value of feedback in general.

"Apparently there were people who have seen him perform, supervised him in a better way, and deliberately thought about his performance. As a result their judgment is slightly more positive compared to mine." [DS_7]

On the other hand, supervisors mentioned that, in their opinion, feedback documented in the portfolio was not always trustworthy because they knew that faculty found it difficult to document critical feedback.

"Because if you really have problems with somebody, then - and you want to formulate that in the right way, then the writing will take ten minutes. We just don't have time for that and we don't like doing it. [...] then they just write down anything and that always takes away the sharp edges." (DS_3) 
Similar to daily supervisors, independent portfolio assessors highly valued feedback provided by the supervisor's colleagues and their performance assessments always included these colleagues' narrative feedback. However, assessors also attached great value to the student's reflections and formulations of their learning goals. Assessors' typically checked if there was coherence between the documented feedback and assessments on the one hand, and the students' reflections on the other. If assessors noticed discrepancies between the supervisors' narratives and the students' reflections, they found it difficult to determine if and how the students actually needed to improve their performance.

"The student regularly discusses time-management difficulties in her portfolio, but the supervisor does not mention this at all. Maybe I'm making too big a deal out of it, but I would have expected something about that in the supervisor's evaluation" (PA_5)

If the portfolio hardly contained any points for improvement, assessors raised concerns about the student's competence development, and were hesitant to provide a judgement. Assessors then started searching for specific performance evaluations that could illustrate and backup the general assessments presented in the portfolio, as it was difficult for them to arrive at a judgement based on broad and holistic statements about competence development in the portfolio.

"I think, this is a very general assessment, which is characterized really by saying: I haven't heard anything bad. Well, then you are missing a lot, of course." (PA_2)

Some portfolio assessors doubted if the supervisors had enough opportunities to observe or talk to the student. This was mostly due to the fact that, according to the assessors, the narratives of the daily supervisors were very broad in general and never mentioned the student's perspective. According to the assessors, this made the supervisors' narratives less valuable for their performance assessments.

"that student himself really indicates there are some aspects I'll have to work on. That has not been indicated at all from the perspective of the supervisor" (PA_8)

\section{Assessment beliefs and implicit goals}

Discrepancies between daily supervisors' and assessors' information seeking behavior could be partly explained by discrepancies in their implicit goals for assessing students' performance.

Supervisors mentioned to use WBAs and portfolio assessment in order to signal 'outliers'. In view of patient safety it was considered extremely important to signal students with a problematic performance early on in the process. According to supervisors this should be the main purpose 
of the portfolio: "to be able to identify students very early in their education, there is something here that isn't working and if necessary we will end his medical education."(DS_1). Also, supervisors were motivated to identify exceptional students because they could possibly be hired as residents at their department.

"What could for example be a question that summarizes a lot of things is if you were to ask for example, would you take this guy as a resident? After finishing his rotation" (DS_4)

As long as the informal and formal performance assessments suggested that a student's performance was 'according to expectations', supervisors did not feel the need to search for more details on the student's performance.

Similar to the supervisors, portfolio assessors recognized the importance of performance assessment for identifying outstanding or problematic performance. However, unlike the supervisors, the assessors indicated to also assess student's performance in order to support their learning process. In their opinion, the goal of assessment was not solely to have a general impression of each student's current performance, but also to establish if a student's development over time was satisfactory. Assessors searched for evidence on how the student was engaged in continuous performance improvement, or "lifelong learning". They mentioned that their performance assessments provided feedback that could stimulate students' self-directed learning and contribute to their performance development.

\section{DISCUSSION}

The purpose of this study was to explore how different assessor groups (i.e. daily supervisors and independent portfolio assessors) arrive at a judgment on student performance and how they use the portfolio for judgment and decision-making.

The results suggest that both the daily supervisors' and independent portfolio assessors' assessment processes were strongly influenced by their implicit goals (i.e. patient safety and evaluating student's self-directed learning) for assessing students' performance. Supervisors were predominantly concerned with determining if the student's overall performance was up to standard, reflecting a summative approach to assessment. On the other hand, portfolio assessors also valued the portfolio as an instrument to monitor the student's learning and prompt their self-directed learning. This is in line with a more formative assessment for learning approach. Research findings suggest that stakeholders' goal orientation is an important determinant of their assessment preference (Senko, Hulleman, \& Harackiewicz, 2011). In general, summative assessments which use pre-defined standards are preferred by performance orientated people (Dijksterhuis, Schuwirth, Braat, Teunissen, \& Scheele, 2013). This is in line with the supervisors' 
preferences and assessment beliefs in our study. It could be that these performance-orientated supervisors are less inclined to use assessment as a tool for fostering student learning. This could be a threat to CBME, as the use of assessments to maximize development is an important characteristic of CBME (King, 2004).

CBME has changed the way in which students are trained and assessed (Frank et al., 2010). Supervisors and assessors are expected to use multiple assessment methods and tools in collaboration with the trainee in order to assess student performance and stimulate their learning processes (King, 2004). In our study, supervisors and independent portfolio assessors held different assessment beliefs, and as a result they looked for different information and provided different kinds of performance feedback. This is in line with research findings that show that, in general, assessors' goals may differ, depending on their role, relationship with the student and the assessment context (Govaerts, Van der Vleuten, Schuwirth, \& Muijtjens, 2007). Our findings seem to suggest that supervisors keep relying on personal experiences, general impressions and infrequent informal feedback. They are reluctant to incorporate portfolio evidence in their assessment. This might be problematic for the assessment process, as potentially valuable information can be missed. This finding, however, also illustrates the difficulties that accompany the necessary change in assessment culture in competency-based approaches to education.

It is very likely that not all the information that supervisors use is captured in the student portfolio. As a consequence, independent portfolio assessors inevitably cannot base their assessments on the same information that supervisors use to inform their assessment. Supervisor training on how to document relevant performance information, as well as training in using assessment data to foster a student's development could help to improve assessment processes in CBME. Earlier research demonstrated positive changes in supervisor feedback quality after training (Renting et al., 2016). On the other hand, it would be advisable for portfolio assessors to not only use the portfolio evidence for high-stakes decisions but to also include conversations with supervisors and students based on the documented evidence. Finally, daily supervisors and assessors should be encouraged to explicate and discuss their performance assessments and performance standards with students and colleagues.

Findings from our study suggest that the supervisors and independent portfolio assessors had different conceptualizations of a competent student. Supervisors were mostly concerned about patient safety as well as about whether a student would fit into the health care team, whereas portfolio assessors found it important to know how a student was performing on each individual competency domain and if the student was invested in the learning process. These findings are in line with previous studies on assessors' perspectives on the portfolio as an assessment instrument (Oudkerk Pool et al., 2018). One could argue that this difference of opinion about competence poses a problem for both CBME and portfolio assessment because 
students are likely to be assessed on different criteria and against different standards, depending on the assessment context. Clear performance standards are thus essential as they not only promote the use and acceptance of feedback among students (Dijksterhuis et al., 2013), they also ensure fair and defensible assessment. However, our results also show the added value of involving both daily supervisors and independent assessors when making highstakes decisions about a student's performance. Supervisors' concern with patient safety, and assessors' goal to stimulate student's self-directed learning result in unique and complementary views on students' performance. Therefore, our results argue in favor of including supervisors and students in high-stakes decision-making by CCC members, in order to enhance robustness of decisions about students' competence development and performance.

\section{Strengths and limitations}

We used authentic student portfolios for this study, which adds to the authenticity of the supervisors' and portfolio assessors' assessment processes. Moreover, by comparing the supervisors' and the assessors' perspectives, we gained a better understanding of the utility of the portfolio as an assessment instrument in CBME.

Students had to give their consent to the use of their portfolio and to the evaluation of their performance. This may have resulted in selection bias, as we were not able to include students whose performance was not up to standard because they did not consent to participate. It is possible that including portfolios of students who were not doing well could have resulted in the supervisors and assessors looking for other kinds of information. However, during the interviews it was also discussed what kind of information supervisors and assessors looked for when they thought a student was performing either above or below average. They indicated that their assessment process would not be different if this was the case.

\section{Conclusion}

When assessing student performance, daily supervisors and independent portfolio assessors develop diverging assessments. Moreover, their assessments are based on different performance information caused by the fact that daily supervisors and portfolio assessors have distinct implicit goals for assessing students' performance. Efforts should be made to improve the assessment process of both supervisors and assessors. However, independent portfolio assessors (CCCs) should invest in conversations with workplace supervisors when making high-stakes decisions, as supervisors' assessments are complementary (not everything is written down in the portfolio), providing valuable input to inform decisions about the student's learning process. 


\section{REFERENCES}

Ayres, L., Kavanaugh, K., \& Knafl, K. A. (2003). Within-case and across-case approaches to qualitative data analysis. Qualitative health research, 13(6), 871-883.

Bok, H. G. J., Teunissen, P. W., Favier, R. P., Rietbroek, N. J., Theyse, L. F. H., Brommer, H., .. J Jaarsma, A. D. C. (2013). Programmatic assessment of competency-based workplace learning: when theory meets practice. BMC Medical Education, 13(1), 123.

Carraccio, C., Englander, R., Van Melle, E., Ten Cate, O., Lockyer, J., Chan, M., ... Snell, L. S. (2016). Advancing competency-based medical education: a charter for clinician-educators. Academic Medicine, 91(5), 645-649.

Dijksterhuis, M. G. K., Schuwirth, L. W. T., Braat, D. D. M., Teunissen, P. W., \& Scheele, F. (2013). A qualitative study on trainees' and supervisors' perceptions of assessment for learning in postgraduate medical education. Medical Teacher, 35(8), e1396-e1402.

Driessen, E. W., Van Tartwijk, J., Govaerts, M., Teunissen, P., \& van der Vleuten, C. P M. (2012). The use of programmatic assessment in the clinical workplace: a Maastricht case report. Medical Teacher, 34(3), 226-231.

Frank, J. R., \& Danoff, D. (2007). The CanMEDS initiative: implementing an outcomes-based framework of physician competencies. Medical Teacher, 29(7), 642-647. doi: 10.1080/01421590701746983

Frank, J. R., Snell, L. S., ten Cate, O., Holmboe, E. S., Carraccio, C., Swing, S. R., . . Dath, D. (2010). Competency-based medical education: theory to practice. Medical Teacher, 32(8), 638-645.

Geertz, C. (2008). Thick description: Toward an interpretive theory of culture The cultural geography reader (pp. 41-51): Routledge.

Govaerts, M. J. B., Van der Vleuten, C. P. M., Schuwirth, L. W. T., \& Muijtjens, A. M. M. (2007). Broadening perspectives on clinical performance assessment: rethinking the nature of in-training assessment. Advances in health sciences education, 12(2), 239-260.

Hatala, R., \& Norman, G. R. (1999). In-training evaluation during an internal medicine clerkship. Academic Medicine, 74(10), S118-120.

Holmboe, E. S. (2015). Realizing the promise of competency-based medical education. Academic Medicine, 90(4), 411-413.

Holmboe, E. S., Ward, D. S., Reznick, R. K., Katsufrakis, P. J., Leslie, K. M., Patel, V. L., . . Nelson, Elizabeth A. (2011). Faculty development in assessment: the missing link in competency-based medical education. Academic Medicine, 86(4), 460-467.

King, N. (2004). Using templates in the thematic analysis of text. Essential guide to qualitative methods in organizational research, 2, 256-270.

Lang, V. J., Mooney, C. J., O’Connor, A. B., Bordley, D. R., \& Lurie, S. J. (2009). Association between hand-off patients and subject exam performance in medicine clerkship students. Journal of general internal medicine, 24(9), 1018-1022.

Madan, R., Conn, D., Dubo, E., Voore, P., \& Wiesenfeld, L. (2012). The enablers and barriers to the use of direct observation of trainee clinical skills by supervising faculty in a psychiatry residency program. The Canadian Journal of Psychiatry, 57(4), 269-272.

Miles, M. B., \& Huberman, M. (1994). Qualitative data analysis: an expanded sourcebook (2 ed.). Thousand Oaks, CA Sage.

Oudkerk Pool, A., Govaerts, M. J. B., Jaarsma, A. D. C., \& Driessen, E. W. (2018). From aggregation to interpretation: how assessors judge complex data in a competency-based portfolio. Advances in health sciences education, 23(2), 275-287. 
Renting, N., Gans, R. O. B., Borleffs, J. C. C., Van Der Wal, M. A., Jaarsma, A. D. C., \& Cohen-Schotanus, J. (2016). A feedback system in residency to evaluate CanMEDS roles and provide high-quality feedback: Exploring its application. Medical teacher, 38(7), 738-745.

Senko, C., Hulleman, C. S., \& Harackiewicz, J. M. (2011). Achievement goal theory at the crossroads: Old controversies, current challenges, and new directions. Educational psychologist, 46(1), 26-47.

Watling, C., LaDonna, K. A., Lingard, L., Voyer, S., \& Hatala, R. (2016). 'Sometimes the work just needs to be done': socio-cultural influences on direct observation in medical training. Medical Education, 50(10), 1054-1064. 


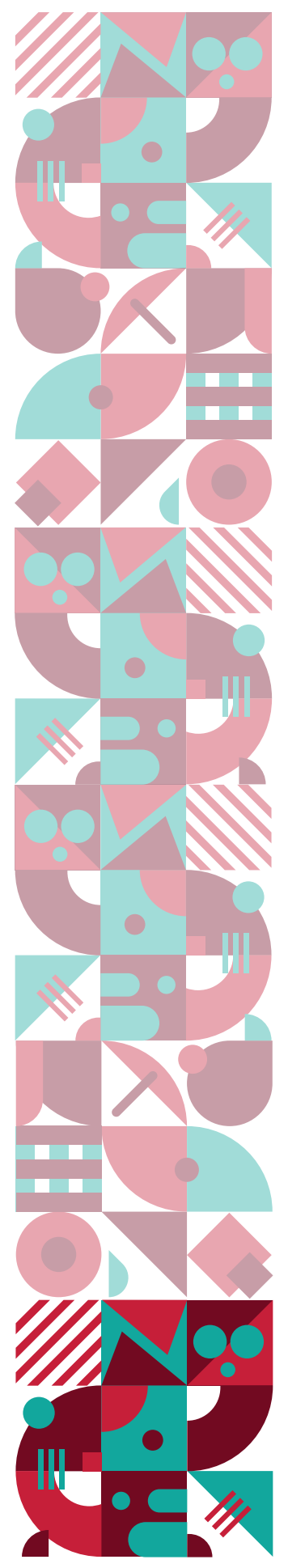

\title{
CHAPTER 06
}

\author{
General Discussion
}


We set out this research aiming to critically evaluate the quality of a competency-based portfolio as an instrument to assess students' competence and competence development. As explained in chapter 1 , this resulted in multiple studies investigating assumptions underlying the implementation of competency-based portfolio assessment. The following assumptions were critically evaluated:

- First, that students fill their portfolio with evidence that is of high relevance and quality, accurately reflecting their progress in competency development;

- Second, that portfolio evidence provides students with meaningful and relevant information to make decisions about their own competence development, so that they gain confidence in their own capabilities and competence development;

- Third, that portfolio assessors (decision-makers) are able to reliably assess students' competence development, to reliably distinguish and evaluate the different competencies, and consequently make fair and defensible decisions;

- And fourth, that the portfolio supports and reflects performance evaluations from daily supervisors (i.e. assessors who have been working with the student) and independent portfolio assessors in similar ways.

This chapter will start by considering how the studies described in this thesis have contributed to a critical evaluation of these assumptions and how these findings can be linked to other work. Furthermore practical implications for assessment practices within medical education will be discussed as well as the strengths and limitations of this thesis.

\section{Students fill their portfolio with evidence that reflects their competence development}

Chapter 2 focused on how students select and document performance data in their portfolio and how they perceive these data to be representative for their competence development. Students did indicate that in general the portfolio content matched their experienced competence development, strengthening the assumption that the portfolios provide a solid basis for competence assessment. This finding is significant, as earlier research suggested that there exists an ill fit between students' competence and performance in the workplace on the one hand and performance data in the student's portfolio on the other. For example it is argued that what is written down in portfolio does not necessarily reflect students' true reasoning, knowledge and attitudes (Rees $\&$ Knight, 2007). Findings from our study show that students attach great value to performance evaluations that reflect their actual learning and development over time. However, students perceived the performance data uploaded to the portfolio being snapshots of their competence development rather than providing a coherent narrative. Moreover, students seemed to predominantly focus on the 'medical expert' competency and struggled to document 
progress on the less well-defined competencies such as 'health advocate'. Students' beliefs, the learning environment and the portfolio assessment system influenced how, why and when they uploaded evidence of their performance and development to their portfolio. Reasons for not including relevant information in the portfolio were sometimes related to factors such as work pressure and scheduling difficulties, or reluctance to document failures. These findings are in line with previous research findings, in the medical domain as well as in (higher) education in general (Crommelinck \& Anseel, 2013; Madan, Conn, Dubo, Voore, \& Wiesenfeld, 2012; Watling, LaDonna, Lingard, Voyer, \& Hatala, 2016). Our findings showed that particularly students' personal beliefs about the goal of portfolio documentation had a large impact on their portfolio content. Students who considered the main goal was to demonstrate performance (doing well) tended to exclude mistakes or critical feedback, suggesting that these students considered single assessments to be summative (high-stakes) rather than formative (low-stakes). From that perspective, our study confirms research findings on programmatic assessment, for example, which show that combining formative (low-stakes) and summative (high-stakes) assessment within an assessment program is not an easy task (e.g. (Bok et al., 2013; Heeneman, Oudkerk Pool, Schuwirth, van der Vleuten, \& Driessen, 2015; Schut, Driessen, van Tartwijk, van der Vleuten, \& Heeneman, 2018)). Especially in a culture in which teachers and students embrace performance rather than learning, important feedback - to guide learning as well as support decision-making- may thus be missing from the portfolio. Creating a learning environment in which all students feel safe to acknowledge their weaknesses and to upload constructive feedback to their portfolio can thus be considered key to successful implementation of portfolio-based competence assessment.

Findings from our research thus suggest that, although students generally felt that the information in their portfolio enables decision-making about their achievement, relevant information reflecting their actual learning and development may be missing or is not systematically documented in students' portfolios. Optimizing use of portfolios in competencybased assessment systems may thus require not only clear communication about assessment goals and procedures as well as intensive training and coaching of all stakeholders in the assessment process; it first and foremost requires a fundamental change towards an assessment culture in which documentation of performance feedback is truly for learning, without compromising students' trust in assessors' use of assessment data for high-stakes decision-making.

\section{Students' interactions with the learning environment determine students' developing sense of competence}

Using audio-diary data as student records of feedback and reflections on performance, chapter 3 of this thesis explored how students gain confidence in their own capabilities and competence development during undergraduate clinical practice. Students' experienced confidence and self- 
efficacy is the result of students constantly interacting with their learning environment. Students' need to feel related (be part of a team) and their desire to autonomously participate in authentic tasks were prerequisites for developing a sense of control over their performance and gaining confidence in their capabilities (feeling competent). Students derive information about their competence from the extent to which they are allowed to participate and perform autonomously. Students who were not entrusted to perform tasks independently expressed that this negatively influenced their feeling of being competent. Moreover, our results showed that students' confidence was influenced by their comparison behavior, i.e. comparison of their own performance and performance feedback with other students' performance. The social comparison behavior students displayed in our study resonates with earlier research showing that students' social comparison with peers and faculty can greatly influence their motivation and level of distress (Raat, Schönrock-Adema, van Hell, Kuks, \& Cohen-Schotanus, 2015; Raat, Kuks, \& Cohen-Schotanus, 2010). The large influence of perceived autonomy on students' motivation and sense of competence corresponds with earlier findings demonstrating that students who are provided with limited autonomy experience fewer opportunities for active learning and therefore feel frustrated (Biondi et al., 2015).

Students recognized that being pro-active from the start of their internship was essential in order to create the conditions for a learning environment that supported their need for competence. Those students who displayed confidence and were proactive were also offered more opportunities to practice their skills, enabling them to boost their confidence even more. These findings are in line with current sociocultural learning theories, which state that students learning is highly influenced by the learning environment, while acknowledging that students at the same time co-create the setting in which they learn and work (Hager, 2011; Bleakley, 2006).

\section{Portfolio assessors can assess students' competence and can develop a final evaluation based on the competency-based portfolio}

The fourth chapter of this thesis described the process whereby portfolio assessors reach judgments when reviewing the evidence documented in a competency-based portfolio. Overall, assessors indicated to feel comfortable making assessments based on the portfolio evidence alone. However, although they reached the same overall judgments, assessors differed in the way they processed the evidence and in the reasoning behind their judgments. From the start of the assessment process, assessors relied on different kinds of portfolio evidence to inform their assessment. Likewise, assessors differed with regard to the amount of portfolio evidence they took into account to arrive at decisions about student competence. While some assessors read the entire portfolio before providing their final judgment, others mainly relied on either the student's self-evaluation or WBA data to inform their judgment, largely ignoring 
additional portfolio evidence. These divergent approaches result from assessors' varying assessment beliefs, performance theories (i.e., conceptualizations of what constitutes performance effectiveness and professional competence), and inferences. As a result, assessors' reasoning and motivation for their judgments and the judgments of individual competencies were strongly influenced by their unique personal profiles and differed accordingly. Confirming findings from previous studies in which decision-making was based on direct observations (Ginsburg, McIlroy, Oulanova, Eva, \& Regehr, 2010), the assessors in our study also based their judgments on aspects that were external to the competency framework underlying the portfolio structure, such as student progress and self-reflections. It could thus be argued that the use of pre-structured competency frameworks in order to capture students' competence does not always correspond with how assessors conceptualize competence. This reflects earlier raised concerns regarding the implementation of CBME signaling that competency-based frameworks do not adequately capture the knowledge, skills and abilities requisite of contemporary physicians (Hawkins et al., 2015).

Interpretation of aggregated performance data in a student's portfolio is inherently subjective. Standardizing assessors' reasoning and decision-making in order to achieve 'objectivity' prove to be difficult as this process inherently involves automatic decision-making processes. Rather than paying attention to all available information, automatic decisionmaking is driven by global, holistic impressions. Similar to the results in our study automatic decision-making processes involving the categorization of people has caused conversion errors and assessors' inability to differentiate between competencies (Wright, Boyd, \& Ginsburg, 2019).

The fact that assessors were able to construct an assessment about the student's competence solely based on the evidence collected in the portfolio strengthens the validity of the assessment process. However, the discrepancies between assessors' assessment process and their reasoning possibly impair the validity. Therefore, portfolios should be judged by multiple assessors who have to thoroughly substantiate their judgments.

\section{Daily supervisors and independent portfolio assessors adopt different approaches to portfolio-based assessment of competence.}

The fifth chapter explored how daily supervisors and portfolio assessors arrive at an assessment on student performance and how they use the portfolio for judgment and decision-making. Both groups tend to use different performance information when constructing an assessment. This was caused by the fact that assessors and supervisors had distinct implicit goals for assessing students' performance. Because supervisors and assessors held different beliefs, they looked for different information in the student's portfolio. This resulted in both groups developing divergent assessments about the same student. Our findings reflect earlier research suggesting that 
stakeholders' goal orientation is an important determinant of their assessment preference (Senko, Hulleman, \& Harackiewicz, 2011).

Independent portfolio assessors regarded the portfolio as an instrument to monitor the student's learning and to prompt their self-directed learning. This is in line with a more formative assessment for learning approach. Supervisors were more performance-orientated and predominantly concerned with determining if the student's overall performance was up to standard, reflecting a more summative approach to assessment. The supervisors were less inclined to use assessment as a tool for fostering student learning. This could be a threat to CBME, as assessments are expected to be used in order to maximize students' development.

Our findings furthermore show that, although systems and structures urge (daily) supervisors to use the portfolio when evaluating a student's competence development, they prefer to rely on personal experiences, general impressions and infrequent informal feedback from colleagues. Supervisors seem reluctant to incorporate portfolio evidence in their assessment. Therefore, it could be postulated that portfolios are currently not offering supervisors with satisfactory information to inform their assessment. Other research points out that also in the postgraduate setting supervisors do not include performance evidence in their assessment process. During group meetings where residents performance was discussed supervisors focused on emotions rather than performance data (Duitsman et al., 2019). This poses a problem for the portfolio assessment process because the portfolio is expected to be an important source of performance evidence informing supervisors' decision-making.

Findings from our study suggest that assessors' goals appear to differ, depending on their role, relationship with the student and assessment context. Both supervisors and assessors should be involved in the assessment of learners, as their assessments are valuable and complementary to inform a student's learning process and decisions about professional competence.

As described in this research, the portfolio assessment process is highly complex because multiple stakeholder groups (e.g. students, portfolio assessors and daily supervisors) are involved in the execution of the assessment process. Stakeholders' assessment behavior is shaped by their own beliefs and attitudes as well as their assumptions about the attitudes, beliefs and expectations of members of the other stakeholder groups. As a consequence, each stakeholder's behavior continuously influences the behavior and opportunities of other stakeholders involved in the assessment process. This makes the portfolio assessment process variable and difficult to regulate.

\section{Strengths and limitations}

An important strength of our research is that we have included the perspective of multiple key stakeholders (i.e., students, portfolio assessors and daily supervisors) on the portfolio assessment process. Furthermore we aimed to describe the beliefs and expectations that drive their assessment 
behaviors and to consequently explore how their behaviors affect the assessment process. Another strength of this research is that the results described in each individual study resulted from a triangulation of data derived from multiple qualitative methods. The use of multiple data collection methods allowed us to triangulate the data and added to the scientific rigor of this research.

Apart from the limitations already explained for each individual study as presented in separate chapters, it is important to mention the limitations related to our overall research approach and design. First, all the studies were performed within the Master's in Medicine (MiM) program of Maastricht University. Therefore the transferability of results to other contexts can be questioned. However, there are arguments to state that our results are relevant to a broader context as the design of the curriculum and portfolio assessment process is grounded in relevant educational and assessment theories and our research results can be linked to relevant work conducted in other settings. Furthermore, due to feasibility concerns data were collected over the course of a single clinical rotation. It could be argued that this has impacted the results because portfolio assessments generally involve data collection and assessment across multiple rotations. Although we do acknowledge this concern we must note that the participants in each study indicate that this limitation did not affect their approaches to competence assessment behavior or expressed assessment beliefs.

\section{Practical implications for assessment practice}

\section{Portfolio design}

Throughout our research students as well as portfolio assessors and supervisors expressed their desire to make changes in the design of the MiM's portfolio. Students wanted to have more freedom to express their self-assessments and personal views and to add comments clarifying characteristics of the learning context in which they were assessed. They felt that this additional information would help assessors to develop a better understanding of their competence development. This is in accordance with earlier findings claiming that students value experiencing some freedom to adjust the content of their portfolio to their personal preferences (Van Tartwijk $\&$ Driessen, 2009). Assessors echoed this need, as it would enable them to develop a better understanding of the student's competence. More specifically, it would help portfolio assessors to select those assessments that are most meaningful and informative for developing judgements, based on contextual features of specific assessments. Multiple options could be considered in order to create more freedom in the process of documenting portfolio evidence. First, captions could be used for this purpose (Van Tartwijk \& Driessen, 2009). Captions are textboxes attached to each piece of portfolio evidence describing what the evidence is, why this is valuable, and how it can be used to support judgement and decision-making (Collins, 1991). Moreover, providing an alternative to feedback in writing could result in documentation of more valuable performance 
evidence. Using an audio diary to capture learning experiences was easier for some students compared to having to write it down. The need for a more flexible portfolio resonates with the remark of Smith (1995) that students should be provided with clear guidance on how to develop their portfolio, but should also be given room for describing their unique experiences and composing an authentic product.

Our studies showed that portfolio assessors and daily supervisors all have different approaches to the selection and use of portfolio evidence. User friendliness of the electronic portfolio was an often-voiced concern throughout the course of this research. Students as well as portfolio assessors and supervisors sometimes struggled to find the information they were looking for or were unaware of the various data options the portfolio offered. It thus seems important that portfolios be designed in such a way that they facilitate the selection of and navigation through the portfolio evidence.

\section{Workplace-based Assessments}

Some adaptations in the process of collecting WBAs could support the documentation of valuable feedback. For example, incorporating dedicated time for observation and feedback into the daily clinical program seems essential for promoting the exchange and documentation of feedback (Rees \& Knight, 2007). Moreover, videotaping consultations enables supervisors to provide feedback when it fits their schedule (Lefroy, Watling, Teunissen, \& Brand, 2015).

Students indicated that the high number of required WBAs to be collected in a busy workplace caused them to ask for feedback when it was easy, instead of valuable for their development. Less mandatory WBAs could result in more meaningful and higher quality WBA feedback, yet might impact credibility and defensibility of decisions. However, Moonen-van Loon, Overeem, Donkers, Van der Vleuten, and Driessen (2013) demonstrated that combining different WBA tools in a portfolio can lead to a more feasible amount of required WBAs while still achieving acceptable reliability in residents' performance assessment. On the other hand, requiring less WBAs may have adverse effects as this may emphasize the summative aspects of the assessment as well as result in an even more fragmented portfolio and picture of an individual student's dynamic and unique competence development (Govaerts, Van Der Vleuten, Schuwirth, $\&$ Muijtjens, 2005). Careful balancing quantity (for reasons of reliability, for example) and quality of assessment data is therefore critical.

\section{Daily workplace supervisors}

Our results show the added value of involving both daily supervisors and independent assessors when making high-stakes decisions about students' performance. Supervisors' concern with patient safety, and assessors' goal to stimulate students' self-directed learning result in unique and complementary views on students' performance. Therefore, our results argue in favor of including supervisors when assessing students' performance and competence development in order to improve robustness of decision-making about learners' competence development within 
CBME. However, supervisor training on how to assess and foster students' development is needed to ensure high quality feedback and assessment. Earlier research demonstrated positive changes in supervisor feedback quality after training (Renting et al., 2016). In addition, assessment systems should facilitate and encourage daily supervisors' use of evidence collected in the portfolio to inform their assessments as well as documentation of relevant performance evidence to support fair and defensible competence assessments and decision-making by others.

\section{Clinical competency committees}

Our research sheds further light on the role of clinical competency committees (CCCs) in judgement and decision-making about the competence of a student. Differences between CCCmembers' approaches to competence assessment suggest that decisions should not be made individually, but should result from group discussions. Although multiple assessors may reach the same general judgment about a student's competence, they do differ in their judgments of individual competencies and the reasoning behind their overall judgments. Therefore, committee members should be encouraged to explain (substantiate) their judgements and decisions. Discussing judgment policies could make committee members aware of the fact that their approach to interpretation of performance data and competence assessment is not universally shared. It will help them to become acquainted with other conceptualizations of competence and approaches to interpretation and valuing of performance data in learners' portfolio evidence. This enables committee members to incorporate assessment practices of other assessors into their own assessment process, and to build 'shared mental models' for competence assessment.

Assessment training focusing on development of shared mental models could thus improve the CCCs decision-making process. As described above, this training should focus on raising CCC members' awareness of their own beliefs, performance theories, and inferences. Furthermore, training should focus on the effect of group member composition and group processes on the decision-making processes as described by Macrae and Bodenhausen (2000). Moreover, results from research presented in this thesis suggest that it would be advisable for CCCs to not only use the portfolio evidence for high-stakes decisions but also have conversations with supervisors and students based on the documented evidence.

\section{CONCLUSION}

In order to examine the competency-based portfolio as an instrument to make high-stakes decisions about students' competence development and achievement, this thesis sought to critically evaluate several assumptions about how the key actors in the portfolio assessment process (e.g. students, portfolio assessors and daily supervisors) perceive and execute their tasks within the portfolio assessment process. This thesis has described how the behavior of everyone involved in the assessment process is shaped through their beliefs and expectations about the goal 
of portfolio assessment, what it means to be a competent student and how a student's performance should be documented in the portfolio in order to inform a competence assessment. It also showed that many different beliefs and expectations exist between groups of students, assessors and supervisors, but also within these groups. These differences affect student's performance documentation and confidence in their performance and competence development, and influence if and how portfolio assessors and supervisors develop informed assessments about students' competence, based on the evidence collected in the portfolio. In other words, the outcome of the student's competence assessment based on the competency-based portfolio highly depends on the interplay between the students', assessors' and supervisors' beliefs and expectations. Our findings suggest that this is probably unproblematic as far as assessments concern overall, holistic judgments about a student's overall competence level (i.e. competent or incompetent; pass-fail decisions). However, portfolio-based competence assessment requires a comprehensive evaluation of a student's performance on various competency domains. A valid, fair and defensible assessment of students' performance on all competencies is possible only when the beliefs and expectations of everyone involved are clearly articulated and deliberated. Within the current assessment practice these beliefs and expectations are often unknown to others, impairing the quality of the competency-based assessment process. In addition, and perhaps as important, varying approaches to and beliefs about portfolio-based assessment may influence quality and uptake of relevant feedback for learning and competence development. 


\section{REFERENCES}

Biondi, E. A., Varade, W. S., Garfunkel, L. C., Lynn, J. F., Craig, M. S., Cellini, M. M., . . Baldwin, C. D. (2015). Discordance between resident and faculty perceptions of resident autonomy: can selfdetermination theory help interpret differences and guide strategies for bridging the divide? Academic Medicine, 90(4), 462-471.

Bleakley, A. (2006). Broadening conceptions of learning in medical education: the message from teamworking. Medical education, 40(2), 150-157.

Bok, H. G. J., Teunissen, P. W., Favier, R. P., Rietbroek, N. J., Theyse, L. F. H., Brommer, H., .. J Jaarsma, A. D. C. (2013). Programmatic assessment of competency-based workplace learning: when theory meets practice. BMC Medical Education, 13(1), 123.

Collins, A. (1991). Portfolios for biology teacher assessment. Journal of Personnel Evaluation in Education, 5(2), 147-168.

Crommelinck, M., \& Anseel, F. (2013). Understanding and encouraging feedback-seeking behaviour: a literature review. Medical Education, 47(3), 232-241.

Duitsman, M. E., Slootweg, I. A., van der Marel, I. C., Kate-Booij, M. T., de Graaf, J., Fluit, C., \& Jaarsma, D. (2019). Group Assessment of Resident Performance: Valuable for Program Director Judgment?. Journal of graduate medical education, 11(4s), 118-124..

Ginsburg, S., McIlroy, J., Oulanova, O., Eva, K., \& Regehr, Glenn. (2010). Toward authentic clinical evaluation: pitfalls in the pursuit of competency. Academic Medicine, 85(5), 780-786.

Govaerts, M. J. B., Van Der Vleuten, C. P. M., Schuwirth, L. W. T., \& Muijtjens, A. M. M. (2005). The use of observational diaries in in-training evaluation: student perceptions. Advances in health sciences education, 10(3), 171-188.

Hager P. Theories of Workplace Learning. In: Malloch M, Cairns L, Evans K, O'Connor BN, editors. The SAGE handbook of Workplace Learning. Los Angeles, United States.: Sage Publications 2011;17-32.

Hawkins, R. E., Welcher, C. M., Holmboe, E. S., Kirk, L. M, Norcini, J. J., Simons, K. B., \& Skochelak, S. E. (2015). Implementation of competency-based medical education: are we addressing the concerns and challenges? Medical Education, 49(11), 1086-1102.

Heeneman, S., Oudkerk Pool, A., Schuwirth, Lambert W. T., van der Vleuten, C. P. M., \& Driessen, E. W. (2015). The impact of programmatic assessment on student learning: theory versus practice. Medical Education, 49(5), 487-498.

Lefroy, J., Watling, C., Teunissen, P. W., \& Brand, P. (2015). Guidelines: the do's, don'ts and don't knows of feedback for clinical education. Perspectives on medical education, 4(6), 284-299.

Macrae, C. N., \& Bodenhausen, G. V. (2000). Social cognition: Thinking categorically about others. Annual review of psychology, 51(1), 93-120.

Madan, R., Conn, D., Dubo, Elyse, Voore, P., \& Wiesenfeld, L. (2012). The enablers and barriers to the use of direct observation of trainee clinical skills by supervising faculty in a psychiatry residency program. The Canadian Journal of Psychiatry, 57(4), 269-272.

Moonen-van Loon, J. M. W., Overeem, K., Donkers, H. H. L. M., Van der Vleuten, C. P. M., \& Driessen, E. W.. (2013). Composite reliability of a workplace-based assessment toolbox for postgraduate medical education. Advances in health sciences education, 18(5), 1087-1102.

Raat, A. N. J., Schönrock-Adema, J., van Hell, E. A., Kuks, J. B. M., \& Cohen-Schotanus, J. (2015). Student distress in clinical workplace learning: differences in social comparison behaviours. Advances in health sciences education, 20(1), 101-111. 
Raat, A. N. J., Kuks, J., \& Cohen-Schotanus, J. (2010). Learning in clinical practice: Stimulating and discouraging response to social comparison. Medical Teacher, 32(11), 899-904.

Rees, C. E., \& Knight, L. V. (2007). The trouble with assessing students' professionalism: theoretical insights from sociocognitive psychology. Academic Medicine, 82(1), 46-50.

Renting, N., Dornan, T., Gans, R. O. B., Borleffs, J. C. C., Cohen-Schotanus, J., \& Jaarsma, A. D. C. (2016). What supervisors say in their feedback: construction of CanMEDS roles in workplace settings. Advances in health sciences education, 21(2), 375-387.

Schut, S., Driessen, E., van Tartwijk, J., van der Vleuten, C., \& Heeneman, S. (2018). Stakes in the eye of the beholder: an international study of learners' perceptions within programmatic assessment. Medical Education, 52(6), 654-663.

Senko, C., Hulleman, C. S,, \& Harackiewicz, J. M. (2011). Achievement goal theory at the crossroads: Old controversies, current challenges, and new directions. Educational psychologist, 46(1), 26-47.

Smith, J. A. (1995). Semi-structured interviewing and qualitative analysis. Rethinking methods in psychology, 9-26.

van Tartwijk, J., \& Driessen, E. W. (2009). Portfolios for assessment and learning: AMEE Guide no. 45. Medical Teacher, 31(9), 790-801.

Watling, C., LaDonna, K. A., Lingard, L., Voyer, S., \& Hatala, R. (2016). 'Sometimes the work just needs to be done': socio-cultural influences on direct observation in medical training. Medical Education, 50(10), 1054-1064.

Wright, S. R., Boyd, V. A., \& Ginsburg, S. (2019). The Hidden Curriculum of Compassionate Care: Can Assessment Drive Compassion? Academic Medicine, 94(8), 1164-1169. 


\section{SUMMARY}

In medical education portfolios are more and more used as an instrument to assess students' competence and to make high-stakes pass-fail decisions. Numerous assumptions about the portfolio assessment process and portfolio construction guide the use of portfolio as an assessment instrument. Evidence supporting the use of competency-based portfolios for highstakes decision-making is advancing but still limited. This raises questions about the degree to which portfolio-based decision-making is defensible and robust. More evidence to support the interpretations and use of portfolio-based performance data for high-stakes decisionmaking about a student's competence and competence development is needed. CHAPTER 1 introduces the aim of this thesis to focus on a number of assumptions and inferences that are made when using portfolio as instrument to assess competence. More specifically, it will be explored how various key stakeholders (students, portfolio assessors and daily supervisors) perceive and use the portfolio for purposes of decision-making, and how this might affect the quality of the information in the portfolio, and potential consequences for interpretation and use of the performance data collected in the student portfolio. Chapter 1 first introduces competency-based medical education (CBME) and describes the role of portfolios within $\mathrm{CBME}$, as well as describes key findings from the literature thus far. Furthermore, student, portfolio assessor, and daily supervisor difficulties when using the portfolio as an assessment instrument are presented. Finally, this chapter introduces the research questions as well as an outline of this thesis.

The research described in CHAPTER 2 confirms the importance of taking students' perspectives into account when implementing a competency-based portfolio. When using the portfolio as an instrument to assess students' competence development it is assumed that their development is adequately reflected in portfolio documentation. Therefore, the study presented in chapter 2 explored to what extent performance data included in a competency-based portfolio correspond with what students consider meaningful feedback and experiences reflecting their development. Students uploaded performance data to their competency-based portfolio as part of their regular educational activities. Additionally, twelve students recorded an audio diary during one clerkship period. In this audio diary they reflected on experiences and feedback they considered to be illustrative of their competence development. Afterwards, these students were interviewed to explore the extent to which the performance documentation in the portfolio corresponded with what they considered illustrative of their development. Students regard their portfolio to provide an accurate, but fragmented picture of their development. Portfolio documentation was sometimes hindered by tensions between learning and assessment, students' beliefs about the goal of portfolios, students' performance evaluation strategies, the learning environment and portfolio structure. Coaching on how to select meaningful performance data for their portfolio could help students with developing a more 
representative portfolio. Also, more flexibility in portfolio structure and requirements could establish a better fit between students' experienced competence development and portfolio content.

In CHAPTER 3 the students' perspective is further examined. This study describes how students' need for competence results from a continuous interaction with their learning environment. As already explained in chapter 1 students have a great influence on what evidence is documented in their portfolio. The portfolio process requires students to experience ownership and feel motivated to collect and document evidence in their portfolio. Therefore, chapter 3 focuses on the question how students gain confidence in their own capabilities and develop control over their own performance during undergraduate clinical training. Twelve students were invited to record an audio diary during their clerkship. In their audio diaries, the students answered questions that were designed to stimulate them to reflect on the feedback and experiences they perceived to be important for their competence development and that added to their sense of confidence in their capabilities. In order to develop control over their performance and gain confidence in their capabilities students had to feel related to their team members. Also, team members were more inclined to support students' need for competence if students showed pro-active behavior. During their clerkship students constantly compared their performance with the performance of their peers as a strategy to develop their sense of confidence in being or becoming competent. Faculty should be aware how students can gain confidence in their capabilities and should strive for reciprocal relationships in which students can communicate their preferences. Raising awareness about aspects that influence students' need for competence and stimulating conversations about these issues between students and faculty can ultimately promote students' intrinsic motivation to engage in meaningful assessment activities.

CHAPTER 4 moves away from the students' perspective and focuses on unraveling how assessors judge students' competence when interpreting evidence from various sources and multiple performance data in a competency-based portfolio. Eighteen assessors appraised one of three competency-based mock portfolios while thinking aloud, before taking part in semi-structured interviews. Assessors reached judgments through a 3-phase cyclical cognitive process of acquiring, organizing, and integrating evidence. After completing the first cycle, assessors reviewed the remaining portfolio evidence to look for confirming or disconfirming evidence. Assessors tended to stick to their initial judgments even when confronted with seemingly disconfirming evidence. Although assessors reached similar final (pass-fail) judgments of students' professional competence, they displayed different information-processing approaches and the reasoning behind their judgments also varied. These differences stem from assessors' divergent assessment beliefs and performance theories (i.e., their conceptualizations of what constitutes professional competence and competent performance). Assessors furthermore 
differed with respect to inferences about the student as a person as well as a (future) professional. Similar to what we saw in students' portfolio-assessment behavior, assessors' reasoning in judgment and decision-making varies and is guided by their mental models of performance assessment. This could impact their performance feedback and the credibility of their decisions. Therefore, portfolios should be judged by multiple assessors who thoroughly substantiate their judgments and develop a joint assessment.

CHAPTER 5 combines the perspective of the student's daily supervisor and the portfolio assessor. It is assumed that the portfolio supports and reflects performance evaluations of daily supervisors and independent portfolio assessors in similar ways (e.g. to ensure transparency in decision-making). This chapter focused on finding an answer to the question how daily supervisors and portfolio assessors interpret and enact their assessment task and how they use the portfolio to develop a judgment on student performance. Daily supervisors of ten students assessed the students' performance during a scheduled clinical rotation. At the end of the rotation, supervisors were asked to provide a narrative describing the student's performance. Subsequently, independent portfolio assessors reviewed the evidence in the student's portfolio and develop a narrative on student performance. Both daily supervisors and independent assessors were interviewed to explain their reasoning in judgment and decision-making. The research described in this chapter shows that assessors' roles influence their use of portfolio evidence as well as the story they build of student's performance. Similar to the results we found in chapter 4, supervisors and assessors developed the same overall judgment of students' performance (e.g. poor, average, exceptional). However, their assessments did differ. Portfolio assessors' and daily supervisors' implicit assessment goals differed. This caused them to use divergent performance information to establish their assessment. Supervisors wanted to establish students' fitness to provide health care whereas portfolio assessors' goal was determine student's progress and self-directed learning. Because daily supervisors' and assessors assessments are complementary and valuable to inform student's learning they should both be involved in the portfolio assessment process.

The last chapter, CHAPTER 6, is the general discussion of this thesis. The chapter first provides a summary of the main findings of all chapters and then describes the answers to the research questions introduced in chapter 1 . Our study confirms that, overall, the portfolio provides a fairly representative overview of the students' competence development. The portfolio furthermore enables portfolio assessors to arrive a general (pass-fail decisions). However, in order for the portfolio to accurately represent the students' development and provide portfolio assessors and daily supervisors with adequate performance information that is useful and of interest, changes have to be made to the process of portfolio construction and assessment. Suggestions on how to improve the portfolio construction and assessment process are 
provided. The chapter concludes by highlighting that the beliefs and expectations of all stakeholders about the goal of portfolio assessment, what it means to be a competent student and how a student's performance should be documented in the portfolio in order to inform a competence assessment should be taken into account when attempting to improve the portfolio assessment process. These beliefs and expectations affect student's performance documentation and confidence and control over their performance, and influence if and how portfolio assessors and supervisors are supported to develop informed assessments about students' competence, based on the evidence collected in the portfolio. The outcome of the student's competence assessment based on the competency-based portfolio thus highly depends on the interplay between the students', assessors' and supervisors' beliefs and expectations. A valuable assessment of students' performance on all competencies is possible when the beliefs and expectations of everyone involved are clearly articulated. Within the current assessment practice these beliefs and expectations are often unknown to others, impairing the quality of the competency-based assessment process. 


\section{SAMENVATTING}

Binnen medisch onderwijs worden portfolio's in toenemende mate gebruikt als instrument voor het beoordelen van de competentie van studenten en het nemen van zak-slaag beslissingen. Aannames over het beoordelingsproces en de inhoud van het portfolio vormen de basis voor het gebruik van het portfolio als beoordelingsinstrument. Onderzoek naar het inzetten van competentiegerichte portfolio's voor summatieve (high-stakes) beslissingen is nog beperkt. Dit roept de vraag op in hoeverre op portfolio gebaseerde beslissingen als robuust en verdedigbaar kunnen worden beschouwd. Het is daarom noodzakelijk meer bewijs te leveren ter ondersteuning van het gebruik van competentiegerichte portfolio's om de ontwikkeling van studenten te monitoren en de competentie van studenten te beoordelen. In HOOFDSTUK 1 wordt het doel van dit proefschrift geïntroduceerd en worden een aantal aannames en gevolgtrekkingen die worden gemaakt bij het gebruik van portfolio als beoordelingsinstrument benoemd. Er wordt besproken hoe verschillende gebruikers (studenten, portfoliobeoordelaars en dagelijkse begeleiders) het portfolio kunnen inzetten ten behoeve van de besluitvorming. Ook wordt omschreven hoe de houding en het gedrag van de gebruikers van invloed kan zijn op de kwaliteit van het bewijsmateriaal dat in het portfolio wordt opgenomen en hoe de inhoud van het portfolio het besluitvormingsproces kan beïnvloeden. In dit eerste hoofdstuk wordt het competentiegericht medisch onderwijs geïntroduceerd om vervolgens de rol van portfolio's binnen competentiegericht onderwijs te beschrijven. De belangrijkste bevindingen uit de literatuur tot nu toe worden samengevat. Vervolgens wordt ingegaan op de uitdagingen waar studenten, portfoliobeoordelaars en dagelijkse begeleiders voor kunnen staan bij het gebruik van het portfolio als beoordelingsinstrument en middel om voortgang te monitoren. Tot slot worden de onderzoeksvragen gepresenteerd en volgt een indeling van het proefschrift.

Het in HOOFDSTUK 2 beschreven onderzoek bevestigt het belang van rekening houden met het perspectief van de student bij de implementatie van een competentiegericht portfolio. Bij het gebruik van het portfolio als instrument om de competentieontwikkeling van studenten te beoordelen wordt ervan uitgegaan dat hun ontwikkeling getrouw is vastgelegd in het hun portfolio. In dit hoofdstuk wordt onderzocht in hoeverre het bewijs dat in het portfolio is opgenomen overeenkomt met wat studenten beschouwen als betekenisvolle feedback en ervaringen die hun ontwikkeling correct weergeven. Voor deze studie hebben twaalf studenten bewijsmateriaal van hun competentieontwikkeling geüpload in hun portfolio, als onderdeel van de reguliere onderwijsactiviteiten. Daarnaast hebben deze studenten tijdens een coschap periode een audiodagboek opgenomen. In dit audiodagboek reflecteerden zij op ervaringen en feedback die ze als illustratief beschouwden voor hun competentieontwikkeling. Vervolgens werden de studenten geïnterviewd om na te gaan in hoeverre het in het portfolio gedocumenteerde bewijsmateriaal overeenkwam met wat zij zelf als illustratief beschouwden voor hun ontwikkeling. Volgens studenten geeft de inhoud van hun portfolio een redelijk accuraat, maar 
gefragmenteerd beeld van hun ontwikkeling. Documentatie van bewijslast in het portfolio werd soms belemmerd door ervaren frictie tussen willen leren en de angst om beoordeeld te worden. De opvattingen van studenten over het doel van portfolio's en hun strategieën bij het vragen om feedback belemmerden soms ook de documentatie van waardevol bewijsmateriaal. Bovendien waren de leeromgeving en de portfoliostructuur van aanzienlijke invloed op welk bewijsmateriaal in het studentenportfolio werd gedocumenteerd. Coaching van studenten bij het selecteren van zinvol bewijsmateriaal zou hun kunnen helpen bij het samenstellen van een meer representatief portfolio. Ook kan meer flexibiliteit in de portfoliostructuur en de eisen die aan het portfolio worden gesteld resulteren in een betere aansluiting tussen de ervaren competentieontwikkeling van studenten en de inhoud van het portfolio.

In HOOFDSTUK 3 wordt het perspectief van de studenten verder onderzocht. Dit onderzoek beschrijft hoe het streven van studenten naar competentie het resultaat is van een continue interactie met hun leeromgeving. Zoals in hoofdstuk 2 reeds is beschreven, hebben studenten een grote invloed op welk bewijs in hun portfolio wordt gedocumenteerd. Het documentatieproces vereist dat studenten eigenaarschap ervaren over hun portfolio en gemotiveerd zijn om bewijsmateriaal te verzamelen en vast te leggen. Daarom richt hoofdstuk 3 zich op de vraag hoe studenten tijdens de coschappen vertrouwen krijgen in hun eigen capaciteiten en controle ontwikkelen over hun leren en handelen. Twaalf studenten werden uitgenodigd om een audiodagboek bij te houden tijdens hun coschap. In hun audiodagboeken beantwoordden de studenten vragen die hen stimuleerden om te reflecteren op die feedback en ervaringen die naar hun mening belangrijk waren voor hun competentieontwikkeling en bijdroegen aan het zelfvertrouwen in hun capaciteiten. Het bleek dat alleen wanneer de studenten zich opgenomen voelden in het team zij erin slaagden om meer controle over hun leren en handelen te krijgen. Op die manier groeide ook het vertrouwen in hun eigen capaciteiten. Studenten bemerkten dat collega's binnen het zorgteam meer bereid waren hen te ondersteunen in het ontwikkelen van hun competenties wanneer de zij zich proactief opstelden. Tijdens hun coschap vergeleken studenten hun eigen prestaties voortdurend met de prestaties van medestudenten als strategie om hun eigen competentie-ontwikkeling te monitoren en bij te sturen. Door zich meer bewust te zijn van hoe studenten vertrouwen opbouwen in hun eigen capaciteiten en door samenwerkingsrelaties met studenten op te bouwen waarin studenten zich veilig voelen hun leerwensen te delen, kunnen supervisors tijdens een coschap bijdragen aan de ontwikkeling van het geloof in eigen kunnen. Door op deze manier het gevoel van (toenemende) competentie bij studenten te stimuleren, zal de intrinsieke motivatie van studenten worden bevorderd.

HOOFDSTUK 4 richt zich op het doorgronden van de manier waarop portfolio-beoordelaars de competentie van studenten beoordelen wanneer zij een grote variatie aan bewijsmateriaal verzameld in een competentiegericht portfolio moeten interpreteren. Achttien assessoren beoordeelden elk één van de drie voor dit onderzoek ontwikkelde competentiegerichte portfolio's. Tijdens dit proces 
werden zij geacht hun gedachtes en beslissingen hardop te verwoorden. Vervolgens namen zij deel aan een semigestructureerd interview. Het bleek dat assessoren tot een oordeel kwamen door het doorlopen van een cyclisch cognitief proces bestaande ui drie fases, waarbij zij portfolio bewijs selecteerden, organiseerden en vervolgens integreerden in een eerste oordeel. Na het voltooien van deze eerste cyclus, gingen de assessoren in de resterende documentatie in het portfolio documentatie op zoek naar bewijs dat hun initiële oordeel kon bevestigen of weerleggen. Beoordelaars hadden hierbij de neiging om vast te houden aan hun eerste oordeel, zelfs wanneer ze geconfronteerd werden met schijnbaar tegensprekend bewijs. Hoewel alle beoordelaars tot een vergelijkbaar algemeen eindoordeel over de competentie van de studenten kwamen, hanteerden zij verschillende benaderingen om de informatie in het portfolio te verwerken. Ook verschilden de beoordelaars wat betreft de door hun gegeven motivaties voor hun eindoordeel. Deze verschillen kwamen voort uit de uiteenlopende opvattingen van beoordelaars over waarom en hoe studenten getoetst moeten worden en aan welke criteria een competente professional dient te voldoen. De assessoren verschilden bovendien met betrekking tot hun aannames over de student als persoon en als (toekomstige) professional. Net zo verschillend als studenten zijn in hoe ze het portfolio ervaren en gebruiken, zo verschillend zijn ook assessoren in hoe ze hun beoordelingstaak ervaren en uitvoeren. Dit wordt veroorzaakt door de uiteenlopende mentale modellen die de beoordelaars hebben over wat een competente student is en hoe deze beoordeeld moet worden. Deze overtuigingen hebben invloed op de feedback van beoordelaars op de prestaties van de student en de validiteit van hun beslissingen. Daarom moeten portfolio's worden beoordeeld door meerdere beoordelaars die hun oordeel zorgvuldig onderbouwen en in deliberatie tot consensus en een gezamenlijk een oordeel komen.

In HOOFDSTUK 5 wordt het perspectief van de dagelijkse begeleider van de student en de onafhankelijk portfoliobeoordelaar gecombineerd. Bij het gebruik van een competentiegericht portfolio als beoordelingsinstrument wordt aangenomen dat het portfolio de oordelen van dagelijkse begeleiders enerzijds en van onafhankelijke portfoliobeoordelaars anderzijds op eenzelfde manier ondersteunt en op deze manier de transparantie in en verdedigbaarheid van de besluitvorming waarborgt. Uit het in dit hoofdstuk beschreven onderzoek blijkt dat de rollen van beide assessoren van invloed zijn op hoe ze zich een indruk vormen over de competentie(ontwikkeling) van de student en hoe ze het portfoliobewijs gebruiken om tot een oordeel te komen. Dit hoofdstuk richt zich op het vinden van een antwoord op de vraag hoe dagelijkse begeleiders en portfoliobeoordelaars hun beoordelingstaak interpreteren en uitvoeren en hoe zij vervolgens het portfolio gebruiken om tot een oordeel te komen over de competentie van een student. Dagelijkse begeleiders van tien studenten beoordeelden de competentie-ontwikkeling van hun studenten tijdens een semiarts stage. Aan het einde van de stage werd aan de begeleiders gevraagd om een (mondeling) verslag te geven van hoe de student tijdens de stage had gepresteerd. Vervolgens beoordeelden onafhankelijke portfoliobeoordelaars het bewijsmateriaal in het portfolio van de student en brachten zij ook een mondeling verslag uit over de competentie-ontwikkeling van de student tijdens deze stage. Zowel de dagelijkse begeleiders als de onafhankelijke beoordelaars werden geïnterviewd om hun redeneringen en besluitvormingsproces 
toe te lichten. Vergelijkbaar met de resultaten die we in hoofdstuk 4 presenteren, ontwikkelden de begeleiders en assessoren hetzelfde algemene oordeel over de competentie van de studenten (d.w.z. beneden verwachting, naar verwachting of boven verwachting). Beide groepen beoordelaars verschilden echter wel wat betreft hun beoordelingsproces en hun verslaglegging over de competentieontwikkeling van de student. De impliciete beoordelingsdoelen van de onafhankelijke portfoliobeoordelaars en de dagelijkse begeleiders lagen uit elkaar. Dit zorgde ervoor dat zij verschillend bewijsmateriaal gebruikten om hun beoordeling te vormen. Begeleiders wilden voornamelijk de geschiktheid van studenten als toekomstig professional en collega vaststellen terwijl het belangrijkste doel van de onafhankelijke beoordelaars was om de ontwikkeling en het zelfsturend vermogen van de studenten te bepalen. Aangezien de beoordelingen van de dagelijkse begeleiders en portfoliobeoordelaars complementair zijn aan elkaar en waardevol zijn voor het sturen van het leerproces van de student moeten ze beide worden meegenomen in de beoordeling van het portfolio.

Het laatste hoofdstuk, HOOFDSTUK 6, is de algemene discussie van dit proefschrift. Eerst wordt een samenvatting gegeven van de belangrijkste bevindingen van de in het proefschrift opgenomen studies en vervolgens worden de antwoorden op de in hoofdstuk 1 geïntroduceerde onderzoeksvragen beschreven. Ons onderzoek bevestigt dat het portfolio over het algemeen een redelijk representatief overzicht geeft van de competentieontwikkeling van studenten. Het portfolio maakt het bovendien mogelijk om tot een betrouwbaar algemeen oordeel over de competentieontwikkeling, en daarmee een zak-slaag beslissing te komen. Om de ontwikkeling van de studenten getrouw weer te geven én om de portfoliobeoordelaars en de dagelijkse begeleiders te voorzien van accurate en bruikbare informatie moet het proces van portfolio opbouw en beoordeling echter worden aangepast. In dit hoofdstuk worden suggesties gedaan om het proces van portfolio opbouw te verbeteren. Tot slot wordt benadrukt dat de overtuigingen en verwachtingen van alle gebruikers over het doel van portfolio gebaseerde toetsing, wat het betekent om een competente student te zijn en hoe de prestaties van een student in het portfolio moeten worden gedocumenteerd, meegenomen dienen te worden bij implementatie en verbetering van portfolio gebaseerde toetsing. Deze overtuigingen en verwachtingen beïnvloeden wat studenten in het portfolio vastleggen en in welke mate zij vertrouwen in en controle over hun eigen competentie ontwikkelen. Bovendien bepalen deze overtuigingen of en op welke manier portfoliobeoordelaars en begeleiders het portfolio en het daarin opgenomen bewijsmateriaal gebruiken bij de totstandkoming van hun oordelen over de competentie van de student. Het proces en de uitkomst van de competentiebeoordeling van de student op basis van het competentiegericht portfolio is dus sterk afhankelijk van het samenspel tussen de opvattingen en verwachtingen van de studenten, beoordelaars en begeleiders. Een betrouwbaar en verdedigbaar oordeel over de prestaties van studenten in alle relevante competentiedomeinen is alleen mogelijk wanneer deze overtuigingen en verwachtingen duidelijk zijn geformuleerd en met elkaar worden gedeeld. Echter, binnen de huidige toetspraktijk blijven deze vaak impliciet, waardoor de kwaliteit van het beoordelingsproces wordt aangetast. 


\section{VALORIZATION}

The previous chapters of this thesis covered the research focus, how this research was carried out and the discussion of the results. In this chapter on valorization the societal relevance and practical implications of the research captured in this dissertation are described.

\section{Societal implications}

An important goal of medical education is to train medical professionals of the future. This is no easy task as no one can say with certainty what this future will look like. For example, the impact of technological developments on healthcare is expected to increase. However, we do not yet know what this technology will look like and how this will impact the work of medical professionals, making it difficult to determine what we should teach our medical students right now. This uncertain future requires that we educate professionals who are agile, can guide their own learning, and have a lifelong learning attitude in which they continuously look for opportunities that promote their own development. In order to be able to do this we need to give these future professionals the tools that will empower them to develop a good understanding of their own progress and competence level. The competency-based portfolio as described in this thesis can be a suitable tool to support the students in this lifelong learning process. Furthermore, the research presented in this thesis provides input on how to improve the portfolio as an instrument to assess learning and foster development.

\section{Practical implications}

The results presented in this thesis are relevant for a number of stakeholders. Most of these stakeholders were involved in the research described in this thesis. The described results and practical implications could have a positive influence on the way these stakeholders use the portfolio as an assessment instrument.

Clinical competency committees are expected to develop high-stakes decisions based on performance information captured in the student's portfolio. The research included in this thesis provides evidence for the assumption that it is possible for assessors to develop high-stakes decisions solely based on the evidence included in the student's portfolio. The research also highlights the importance of a thoroughly structured decision-making process when developing a final assessment. It is advised that all CCC members first individually develop a motivated assessment before they gather in a group to formulate a final assessment. In this way the richness of various information included in the portfolio is also captured in the student assessment. Additional practical suggestions for the CCCs are described in chapter 4 of this thesis. 
As for daily supervisors, they sometimes struggle to be up-to-date on the activities and development of the students they are guiding. The students' portfolio can and should be a resource to inform their assessment of the students' and to help them guide students' learning. As described in chapter 5, daily supervisors seem to be less inclined to use the information captured in the portfolio. It could be assumed that portfolios are currently not providing supervisors with satisfying information to inform their assessment. Based on these results chapter 5 includes specific recommendations on how to facilitate daily supervisors use of portfolio assessment instrument. Included in these recommendations is training on how to capture relevant information in the portfolio and how to use the performance information included in the portfolio to foster students' learning.

Student training should be focused on fostering awareness of what kind of evidence is valuable to capture in their portfolio and how to capture this information. Chapters two and three include various aspects that have an impact on how students develop competence and how this is captured in their portfolio. Crucial influences on how students gain ownership and feel motivated to collect and document evidence in their portfolios are described. For example, social comparison and relatedness to their team greatly influenced this process. In order for students to fully profit from the opportunities of competency-based portfolios, these insights should be implemented in student training.

Current digital competency-based portfolios already capture a great amount of valuable performance information. The challenge for portfolio developers is to provide the opportunity for portfolio users to adapt their portfolio to their personal preferences. Students, assessors, and supervisors have clear ideas of what they want to include in their portfolio or use from the portfolio in order to establish students' competence. Current portfolio systems do not always allow for these requirements. Moreover, future portfolios should facilitate the documentation of evidence other than text and numerical data. Video, audio and other sources are highly valuable to inform student development and assess student performance, but are currently often not part of the students' portfolio.

In addition, the results of this thesis are not only applicable to medical education but are also helpful when developing and implementing portfolio-based assessment in other educational settings. 


\section{ACTIVITIES AND PRODUCTS}

The research included in this thesis has resulted in multiple projects and output relevant to society as well as research. First, studies described in this thesis were published in peer reviewed medical education journals. Moreover, the findings of this $\mathrm{PhD}$ project were presented at multiple national as well as international conferences. The results from this research were also used as input for multiple workshops and presentations aimed at educating professionals involved in portfolio-based assessment. Over the past year insights gained during this $\mathrm{PhD}$ research were also used to develop and implement portfolio assessment at the Fontys University of Applied Sciences. 


\section{ABOUT THE AUTHOR}

Andrea Oudkerk Pool was born on the 8th of April 1991 in Maastricht, the Netherlands.

She has received a Bachelor's degree in Psychology at Maastricht University in 2012. After obtaining her Bachelor's degree, she enrolled in the Health and Social Psychology Master which she successfully completed in 2013. During her Bachelor and Master studies she regularly worked as a research assistant at the Faculty of Psychology and Neuroscience (FPN) and the Faculty of Health, Medicine and Life Sciences (FHML) of Maastricht University.

After obtaining het Master's degree she started her PhD-project at the School of Health Professions Education (SHE). The topic of her PhD research was the quality of the competencybased portfolio as an instrument to assess students' competence and monitor students' progress. During her $\mathrm{PhD}$ she represented the SHE PhD community in the departmental management team and the Faculty $\mathrm{PhD}$ community (FPC). In addition to working on her PhD project, she also assumed various teaching roles, such as tutoring in Health Sciences courses.

Andrea is currently working as an educational consultant at Fontys International Business Studies in Venlo. In this capacity she is involved in the implementation of programmatic assessment and the Basic Qualification Examination training of staff. 


\section{ACADEMIC WORK}

\section{This thesis}

Oudkerk Pool, A., Govaerts, M. J., Jaarsma, D. A., \& Driessen, E. W. (2018). From aggregation to interpretation: how assessors judge complex data in a competency-based portfolio. Advances in Health Sciences Education, 23(2), 275-287.

Oudkerk Pool, A., Jaarsma, A. D. C., Driessen, E. W., \& Govaerts, M. J. (2020). Student perspectives on competency-based portfolios: Does a portfolio reflect their competence development?. Perspectives on Medical Education, 9(3), 166.

\section{Other publications}

Heeneman, S., Oudkerk Pool, A., Schuwirth, L. W., van der Vleuten, C. P., \& Driessen, E. W. (2015). The impact of programmatic assessment on student learning: theory versus practice. Medical education, 49(5), 487-498.

Stammen, L. A., Stalmeijer, R. E., Paternotte, E., Oudkerk Pool, A., Driessen, E. W., Scheele, F., \& Stassen, L. P. (2015). Training physicians to provide high-value, cost-conscious care: a systematic review. Jama, 314(22), 2384-2400.

Waterval, D. G., Frambach, J. M., Oudkerk Pool, A., Driessen, E. W., \& Scherpbier, A. J. (2016). An exploration of crossborder medical curriculum partnerships: balancing curriculum equivalence and local adaptation. Medical teacher, 38(3), 255-262. 


\section{DANKWOORD}

Mijn naam staat op de kaft van dit proefschrift, maar dit boekje was er nooit gekomen zonder de hulp en steun van velen. Daarom neem ik op deze plek graag de ruimte om enkele mensen te bedanken die belangrijk voor mij zijn geweest in dit proces.

Allereerst veel dank aan mijn promotieteam. Jullie input, betrokkenheid en geduld waren essentieel voor dit lange traject. Erik, als jouw student assistent begon ik met het uittypen van interviews vastgelegd op een toren van cassettebandjes en nu ligt er zowaar een boek waar we samen aan hebben gewerkt. Jouw optimisme en talent voor het vinden van creatieve oplossingen kwamen vaak van pas tijdens dit promotietraject. Regelmatig wandelde je onze $\mathrm{PhD}$ kamer binnen voor een snelle check hoe het met iedereen ging. Het was dan niet ongebruikelijk dat je ook even bleef hangen voor de laatste nieuwtjes. Bedankt voor je geduld en dat je in jouw drukke leven altijd tijd wist vrij te maken voor raad en steun. Debbie, de afstand tussen Maastricht en Groningen is groot, maar ik heb dit in onze samenwerking nooit ervaren. Jouw tomeloze energie gaf elke keer weer een stimulans aan mijn onderzoek. Ook wist je mij door jouw uitgebreide netwerk te koppelen aan mensen die mij verder konden helpen. Juist omdat jij niet dagelijks betrokken was bij de vorderingen van het onderzoek wist je vaak een perspectief in te brengen waar wij nog niet aan hadden gedacht. Marjan, bedankt voor jouw begeleiding en ondersteuning de afgelopen jaren. Ik heb bewondering voor jouw kennis en kundigheid en vermogen tot kritisch denken. Vraagstukken waar ik lang mee stoeide wist jij in enkele rake zinnen te ontrafelen en hiermee triggerde je mijn denkproces. Daarnaast toonde jij belangstelling voor mij persoonlijk en wist je ook hier de juiste vragen te stellen. Bedankt voor de fijne samenwerking.

Je kunt nog zo'n interessante studies bedenken en opzetten, maar zonder de bereidheid van mensen om hieraan deel te nemen blijft het slechts bij plannen. Daarom wil ik heel graag alle studenten, mentoren en werkplekbegeleiders bedanken die hun medewerking hebben verleend aan de studies beschreven in dit proefschrift. Jullie openheid en kritische blik heeft geresulteerd in inzichten waarvan jullie in de toekomst hopelijk ook kunnen profiteren.

Celine, veel dank voor jouw ondersteuning en harde werk. Immer vrolijk en vol energie heb je mij geholpen bij het doorploegen van al die data.

Een promotietraject is met periodes een solo reis. Je spendeert dagen achter elkaar verzonken in je eigen analyses of schrijfproces. Ik heb het dan ook als een groot geluk ervaren dat ik mijn promotiejaren heb mogen doorbrengen in een hechte PhD community. Dank aan mijn medePhDs: Derk, Serge, Jolien, Samantha, Juliette, Stephanie, Felicitas, Lianne, Emmaline, Dominique, HQ, Cindy en Guy. Jullie waren een warme omgeving waar ik terecht kon met vragen, ideeën of voor wat afleiding. Bedankt voor de gezellige PhD platform bijeenkomsten, 
vrijdagmiddag borrels en ongeëvenaarde PhD uitjes. Suzanne, sparringspartner en soto-maatje. Een bijzonder woord van dank voor jou. Racend over de Limburgse wegen of genietend van een biertje in jouw achtertuin bespreken wij de belangrijke en minder belangrijke zaken in het leven. Jouw kritische vragen houden mij scherp en zetten mij aan het denken. Ik kan niet wachten tot de poppodia weer open gaan en we samen naar bandjes kunnen kijken.

De originele cast van mijn Phd kamer: Ellen, Jorrick, Lorette en Koos. Ellen, hoewel sarcasme jou soms ontging is jouw scherpte op onderzoeksgebied ongeëvenaard. Ook toen je verhuisde naar de postdoc kamer was er altijd tijd voor wat 'moederlijk' advies, waar ik gretig gebruik van heb gemaakt. Jorrick, een grote 'Chapeau' voor jouw bijdrage aan de kamer spirit. Elk probleem of irritatie wist jij op een humoristische manier te relativeren . Gouverneur avondjes met jou zijn de beste. Lorette, de Disney prinses onder de PhDs. Als ik aan jou denk hoor ik Whitney héél zacht op de achtergrond. De bitterballen kunnen in het vet, want ons after PhD life is begonnen. Koos, wil je feedback? We begonnen tegelijkertijd aan onze promotiereis en bereiken nu ook samen de eindbestemming. Tijd om dit snel te vieren met een candlelight dinner. Aan de originele Phd cast werd een damestrio toegevoegd. Sanne S. en Sanne R., Op rijstwafels met chocopasta zijn jullie door je PhD geracete. Bedankt voor de fijne gesprekken en feedback de afgelopen jaren. Carolin, we zijn begonnen als collega's maar ik ben blij dat ik je nu ook een vriendin kan noemen. Onze groene loper wandelingen geven mij altijd waardevolle input en nieuwe energie. Ik kan enorm lachen om de manier waarop jij als keurige Duitse dame soms onverwacht uit de hoek kan komen. Het is een fijn gevoel om jou als paranimf aan mijn zijde te hebben. Joy and Luotong, although we've only spend a short time together I want to thank you for your warmth, amazing plant skills and cozy dinners.

Lilian, Nicky, Rianne en Audrey zonder jullie ondersteuning wordt ons werk heel moeilijk, dan wel onmogelijk. Met allerlei soorten vragen kon ik bij jullie terecht. Bedankt voor de mailtjes, telefoontjes, sleutels, de koekjes en het snoep en jullie vermogen om in onmogelijke agenda's altijd ruimte te vinden voor een afspraak.

Al mijn O\&O collega's, hartelijk dank voor de prettige samenwerking, praatjes bij de koffieautomaat en onovertroffen uitjes. Met zo'n gezellige groep was borrels organiseren altijd een koud kunstje.

Julia, bedankt voor de mooie omslag van dit proefschrift. Ik ben er heel erg blij mij. Leuk dat onze paden elkaar na zoveel jaren weer kruisen.

Lieve Wycker vrinden, met nacho's en speciaalbier krijgt de werkweek een gouden randje. Bedankt voor de gezellige borrelmomenten en stapavonden. Helaas hebben we de 'alla' nooit bereikt. 
Allerliefste Bunga's, wij blijven altijd bij elkaar, al worden we meer dan honderd jaar. Onze vriendschap is gevormd door jarenlang flightcases sjouwen en drijfnat regenen tijdens Pinkpop vrijwilligerswerk. Passies en carrières hebben ons wat over de aardbol verspreid, maar als we elkaar treffen, dan is het alsof we elkaar gisteren nog hebben gezien. Ik koester jullie vriendschap.

Nénée, Laura, Kim, Joyce en Dyonne. Na onze middelbare school jaren hebben we allemaal ons eigen pad gekozen, maar door onze vaste tradities zijn we altijd onderdeel gebleven van elkaars leven. Ik kijk uit naar nog vele jaren met high-tea's, Sinterklaas vieringen en spelletjesavonden.

Lieve Voramus meiden en Fyrfad Fossielen, Marijn, Carla, Marloes, Anouk, Rian, Sara en Boukje. Tijdens de studie vonden we elkaar door onze passie voor volleybal, wijn en eten (hier in willekeurig volgorde opgeschreven). Dit zijn nu nog steeds de thema's van onze weekendjes weg. Niks zo fijn als midden in een werkweek bij een van jullie aanschuiven om bij te praten en van jullie kookkunsten te genieten. Jullie zijn stuk voor stuk ondernemende en drukbezette meiden, maar hebben altijd tijd voor een goed gesprek. Bedankt voor jullie luisterend oor, belangstelling en benodigde afleiding.

Allerliefste Timo. Spelend op het veldje, met uitgaan in de stad en tijdens het verdedigen van mijn proefschrift, jij staat altijd (letterlijk) achter mij. Je bent de liefste en meest zorgzame broer die ik mij kan wensen. Ik heb bewondering voor de manier waarop jij jouw eigen onderneming hebt opgezet en vind het prachtig om te zien hoe jij geniet van jouw gezin. Lieve Mayella, een schoonzus erbij in de familie is natuurlijk altijd spannend, maar ik heb het enorm met jou getroffen. Eindelijk nog iemand om de Harry Potter passie mee te delen en van wie ik fashion en styling tips kan krijgen. Liefste Zoë, wat geniet ik enorm veel van jou. Met jouw grote lach en ondeugende ogen weet je nu al heel goed wat je wilt. Een kwaliteit die jou ongetwijfeld nog ver gaat brengen in jouw leven.

Lieve Henny en Victor, het laatste woord is natuurlijk voor jullie. Jullie hebben even moeten wachten, maar hier is het proefschrift dan toch echt. Zonder jullie vroegere hulp met spreekbeurten en werkstukken en latere feedback op congres presentaties was een academische prestatie ongetwijfeld moeilijker geworden. Echter zonder jullie onvoorwaardelijke steun en betrokkenheid was het onmogelijk geweest. Jullie kennen mij soms beter dan ik zelf en dat kan confronterend zijn, maar het komt altijd uit een goed hart. Ik heb het enorm met jullie getroffen. 


\section{SHE DISSERTATIONS SERIES}

The SHE Dissertation Series publishes dissertations of $\mathrm{PhD}$ candidates from the School of Health Professions Education (SHE) who defended their PhD theses at Maastricht University. The most recent ones are listed below.

For more information go to: https://she.mumc.maastrichtuniversity.nl

Giuliani, M. (19-05-2020) A Critical Review of Global Curriculum Development, Content and Implementation in Oncology

Schreurs, S. (20-03-2020) Selection for medical school; the quest for validity

Schumacher, D. (19-03-2020) Resident Sensitive Quality Measures: Defining the Future of PatientFocused Assessment

Sehlbach, C. (21-02-2020) To be continued.... Supporting physicians' lifelong learning

Kikukawa, M. (17-12-2019) The situated nature of validity: Exploring the cultural dependency of evaluating clinical teachers in Japan

Kelly, M. (10-12-2019) Body of knowledge. An interpretive inquiry into touch in medical education

Klein, D. (06.11.2019) The performance of medical record review as an instrument for measuring and improving patient safety

Bollen, J. (01.11.2019) Organ donation after euthanasia: medical, legal and ethical considerations

Wagner-Menghin, M. (25-09-2019) Self-regulated learning of history-taking: looking for predictive cues

Wilby, K. (02-07-2019) When numbers become words: Assessors' processing of performance data within OSCEs

Szulewski, A. (20-06-2019) Through the eyes of the physician: Expertise development in resuscitation medicine

McGill, D. (29-05-2019) Supervisor competence as an assessor of medical trainees; Evaluating the validity and quality of supervisor assessments

Van Rossum, T. (28-02-2019) Walking the tightrope of training and clinical service; The implementation of time variable medical training 